



\section{DURCH SCHLANGEN./}

MONOGRAPHISCH BEARBEITET

VON

\section{DR. M. BRENNING,

MIT EINEM VORWORT VON PROF. DR. L. LEWIN.

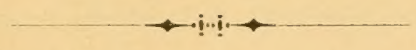

STUTTGART.

VERLAG VON FERDINAND ENKE.

1895 . 
Duuck der Union Deutsche Verlagsgesellschaft in Stuttgart. 


\section{Vorwort.}

Die Fragen, die sich wissenschaftlich und praktisch an die Vergiftungen durch Schlangengift knüpfen, sind ausserordentlich zahlreich. Eine schier unendliche Fülle von rein phantastischen und abergläubischen, von märchenumwobenen wahren und rein wahren Mittheilungen liefert die Geschichte des Menschengeschlechtes über die Giftschlangen. Mögen aber die betreffenden Schilderungen aus dem Alterthum und Mittelalter noch so sehr das Gepräge von rein Erdichtetem tragen - in allen von ihnen spiegelt sich, von Aristoteles an bis auf Gessner, das hohe Interesse wieder, das die Menschen gerade an diesem Thiere nahmen, das sie aus der Bibel als das von Gott verfluchte kannten, und das sie wegen seiner Tücke und der Gefährlichkeit der von ihm geschlagenen Wunden fürchteten. Mythen bestehen nicht mehr über Giftschlangen. Ihr Körperbau ist gekannt, ihr Gift untersucht - aber die Furcht vor ihnen nahm nicht ab. Zugenommen hat das rein wissenschaftliche Interesse an diesem Gegenstande. Handelt es sich doch hier, wie man seit lange weiss, um Eiweissgifte, durch welche ganz bestimmte Gruppen von Krankheitssymptomen erzeugt werden. Und war es doch für jeden Denkenden zwingend, Parallelen zwischen diesem 
Gift und im menschlichen Körper erzeugten Eiweissgiften zu ziehen, und die Parallelisirung auch auf eine etwaige Immunisirung für solche Stoffe auszudehnen!

$\mathrm{Zu}$ einer Zeit, wo an eine Immunisirung gegen Eiweissgifte noch nicht gedacht wurde, habe ich bereits in meinen Vorlesungen auf die Thatsachen hingewiesen, die über die Impfung von Menschen mit Schlangengift, schwer zugänglich, hier und da in Reisewerken zerstreut, mitgetheilt wurden. Nunmehr ist das, was bisher nur deductiv vorgetragen werden konnte, experimentell begründet worden. Man hat Thiere durch Impfung gegen Schlangengift gefeit. Noch ist nicht Alles, was auf diesem Gebiete gefunden werden kann und muss, klargestellt. Die direct hierher gehörigen und damit in fernerem Zusammenhange stehenden Thatsachen älterer und neuerer Zeit bergen in sich viele Weiser für neue Wege der Forschung.

Es war ein Bedürfniss, einmal eine vollständige Darstellung der Schlangenfrage zu geben, und ich bin überzeugt, dass das, was hier mein Schüler, Herr Dr. Brenning, als ersten Abschnitt historisch-toxikologischer Studien aus meinem Laboratorium, zur Ausführung gebracht hat, eine Förderung der Forschungen auf diesem Gebiete wird veranlassen können.

\section{Lewin.}




\section{Vorbemerkungen des Verfassers.}

Die vorliegende Arbeit ist in der Absicht geschrieben worden, eine zusammenfassende Darstellung alles dessen zu geben, was von den ältesten Zeiten an bis auf die Gegenwart über die Giftschlangen selbst, namentlich über ihren Giftapparat, über die Natur und die Wirkungsweise ihres Giftes, sowie ganz besonders ïber die zahllosen gegen dasselbe angewandten Gegenmittel geschrieben wurde. Eigene Messungen des Verhältnisses der Giftzahnlïnge zu der Körperlänge sollen die in dieser Beziehung noch vorhandene Luicke ausfüllen helfen. Wie gross die Literatur über Giftschlangen und Schlangengift ist, kann man daraus ersehen, dass die von Weir Mitchell in seinem umfangreichen Werke iiber die Klapperschlange aufgestellte Bibliographie bis zum Jahre 1860 etwa 250 Titel aufweist, und seitdem sind noch gregen 300 Werke und Aufsätze hinzugekommen, welche ich, soweit möglich, in den Originalen für meine Arbeit benutzt habe. Der grösste Theil von diesen beschäftigt sich freilich nur mit der Anführung einzelner Fälle von Schlangenbiss und mit Berichten über die günstige Wirkung von diesem oder jenem Heilmittel, indessen haben doch auch manche Schriften, wie die von Fontana, Russell, Weir Mitchell und namentlich 
Fayrer's berühmte Thanatophidia of India eine epochemachende Bedeutung erlangt.

Ich habe den Stoff in der Weise angeordnet, disss ich in jedem Abschnitte zunïchst die älteren Anschauungen einer kurzen Besprechung unterzog und sodam die Ansichten der Gegenwart ïber den betreffenden Gegenstand darlegte, um zu zeigen, wie gerwaltig auch auf liesem Gebiete der Fortschritt der Neuzeit gegeniil)er der tief in aberglïubischen Vorstellungen wurzelnden alten Zeit ist.

Ich habe die angenehme Pflicht zu erfüllen, an dieser Stelle vor Allem meinem hochverehrten Lehrer, Herrn Prof. Dr. L. Lewin, für die Anregung zu der Arbeit, sowie für scine gütige Unterstützung bei der Anfertigung derselben meinen aufrichtigsten Dank auszusprechen. Auch Herrn Dr. Tornier, Assistenten an der zoologischen Sammlung des Königl. Museums für Naturkunde zu Berlin, welcher mir bereitwillig die Giftschlangen jener Sammlung zur Untersuchung überliess, sage ich hiermit Dank.

Berlin, December 1894.

\section{Brenning.}




\section{Inhaltsangabe.}

Seite

Vorwort von Prof. L. Lewin . . . . . . . . . . . III

Vorbemerkungen des Verfassers . . . . . . . . . V

I. Statistisches über Schlangenbisse . . . . . . 1

II. Geschichte und Anatomie der Giftschlangen . . . 4

III. Systematik der wichtigsten Giftschlangen . . . . 13

IV. Die Natur des Schlangengiftes . . . . . . . 25

V. Die Wirkung des Schlangengiftes und die Symptomatologie der Vergiftung . . . . . . . . . 35

Oertliche Symptome nach dem Schlangenbiss . . . . 44

Resorptive Vergiftungssymptome . . . . . . . . 46

Nachwirkungen des Schlangengiftes . . . . . . . 49

VI. Ursachen und Mechanismus der Giftwirkungen und des Todes............. . . . 51

VII. Pathologisch-Anatomisches über die Vergiftung durch Schlangenbiss . . . . . . . . . 57

VIII. Therapie des Schlangenbisses . . . . . . . . . 60

1. Die Schlangenbeschwörer . . . . . . . . . 60

2. Operative und mechanische Mittel . . . . . 65

3. Thierische Mittel . . . . . . . . . . . 75

4. Chemische Mittel . . . . . . . . . . 80

5. Pflanzliche Mittel . . . . . . . . . 96

6. Impfung mit Schlangengift . . . . . . . . 165 



\section{I.}

\section{Statistisches über Schlangenbisse.}

Es ist selbstverstïndlich unmöglich eine den thatsächlichen Verhältnissen entsprechende Schätzung der Häufigkeit der durch Giftschlangen erzeugten Schädigungen zu erzielen. Kommen schon nicht alle Verwundungen durch diese Thiere in Deutschland in ärztliche Behandlung, und werden von den durch Aerzte behandelten mindestens die Hälfte nicht literarisch verewigt, so ist an eine ärztliche Behandlung oder gar literarische Mittheilung solcher Vergiftungen in tropischen Gebieten - manche Theile Ostindiens ausgenommen - gar nicht zu denken.

Nicht minder unbestimmbar ist die Schätzung der Mortalität. Wie bei anderen Vergiftungen spielen auch hier nicht nur die individuellen Verhältnisse der Verletzten, nicht nur die Stelle, von der aus das Gift in den Körper gedrungen ist, sondern - was besonders erschwerend für die Beurtheilung des endlichen A usganges der Vergiftung ist - auch die Schlangenart sowie deren zeitlicher Zustand eine hervorragende Rolle. Dies muss bei der Beurtheilung der nachstehenden Angaben in Berïcksichtigung gezogen werden.

Was die europäischen Giftschlangen betrifft, so ist der Biss der Krenzotter, entgegen der gewöhnlichen Meinung, selbst für Kinder selten tödtlich, und auch der Biss der südeuropäischen Viper in der Regel nicht lebensgefährlich. So sah Fontana ${ }^{1}$ ) unter 62 Fällen von Vipernhiss nur zwei

1) F ontana, Traité sur les venins de la vipère. Florence 1781. Brenning, Die Vergiftungen durch Schlangen. 
tödtlich verlaufen, und seit F ontana wurden ungefähr 100 Todesfälle durch Tipern in der Literatur veröffentlicht, von denen etwa die Hälfte auf Kinder fallen. In der Schweiz kamen in den Jahren 1877-86 7 Todesfälle durch Kreuzottern und Vipern vor, und in Deutschland wurden in einem Zeitraum von 10 Jahren 216 Personen von Kreuzottern gebissen; von den Verletzten starben 14, d. h. ca. $6,5 \%$. Nach Viaud Grand-Marais endeten von 316 in der Vendée und im Département Loire inférieure beobachteten Fïllen 44 tödtlich, d. h. $14 \%$; nach einer anderen Statistik beträgt dagegen die Mortalitiat an Schlangenbissen in Département Loiret nur $\left.1 \%{ }^{1}\right)$.

Im Durchschnitt wird man die Sterblichkeit an Bissen der europäischen Giftschlangen auf ungefähr 8,5\% annehmen köinnen. Eine ganz andere Bedeutung für die Mortalität haben jedoch die Giftschlangen tropischer Länder und besonders diejenigen Ostindiens. Hier erreicht die Zahl der jührlichen Todesfälle an Schlangenbiss infolge der grösseren Zahl der Schlangen, ihrer grösseren Giftigkeit und ihres leichten Eindringens in menschliche Wohnungen und in die Schlafstätten eine erstamliche Höhe. Nach den Berichten der englischen Regierung starben in Ostindien an Schlangenbiss :

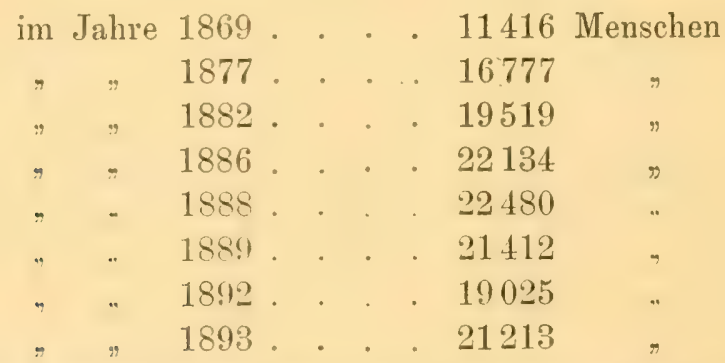

Trotzdem von der englischen Regierung im Jahre 1877 811 Pfund für 127295 getödtete Schlangen, 18821487 Pfund fïr 322421 Schlangen als Prümie gezahlt wurden, und ob-

1) Boullet, Etude sur la morsure de vipère. Paris 1867. 
gleich im Jahre 1888 sogar 578435 Giftschlangen vertilgt wurden, so hat sich doch in 20 Jahren die Zahl der durch sie ums Leben gekommenen Menschen verdoppelt. Man hat berechnet, dass von 100000 Einwohnern in Britisch-Indien jährlich mindestens 16 an Schlangenbiss sterben. Was das Verhältniss der tödtlichen Bisswunden zu den nicht tödtlicheı betrifft, so beobachtete Im lach unter 306 Fällen 63 letale; dies würde also einer Mortalität von 20,6\% entsprechen, während, wie wir gesehen haben, in Europa von den Gebissenen höchstens $8,5 \%$ zu Grunde gehen.

Viel schlimmer gestalten sich diese Verhältnisse noch auf manchen Inseln der ostasiatischen Meere, wo die Schlangenplage zur Verödung von ganzen Districten, ja auf manchen Inseln zum Verlassen derselben genöthigt hat. Reisenden in jener Gegend ist die Frage bekannt, welche von den Eingeborenen an den Weissen oft genug gestellt wird, ob er ein Schlangenmittel besitze. Selbst eine naturwissenschaftliche Durchforschung solcher Inseln ist mit Schwierigkeiten verknüpft, da Eingeborene schwer oder gar nicht als Führer zu haben sind. 
II.

\section{Geschichte und Anatomie der Giftschlangen.}

Die Kenntniss der Giftschlangen reicht bis in das früheste Alterthum zurück. Die Bibel spricht von ihnen ebenso wie die altgriechische Mythologie, und $\mathrm{Homer}{ }^{1}$ ) erzählt, dass Philoktetes, weil er von einer Hyder gebissen war, auf der Insel Lemnos von den Griechen zurückgelassen werden musste.

Herodot ${ }^{2}$ ) spricht ron kleinen mit zwei Hörnern versehenen Schlangen, die un Theben in Aegypten vorkommen und von den Aegyptern für heilig gehalten werden sollen. Merkwürdigerweise erklärt er dieselben für ungefährlich, obgleich man sonst im Alterthum im Gegentheil in der Regel alle Schlaugen, auch die wirklich unschädlichen, für giftig ansal, und obgleich die von ihm gemeinten Schlangen in der That eine giftige Art, mïmlich den anch sonst den Alten wohlhekinnten Cerastes aegyptiacus s, cornutus repräsentiren.

Ausser dieser Schlange erwähnt II e rod ot noch geflügelte Schlangen, Riesenschlangen, und solche mit einem Horne auf dem Kopfe ${ }^{3}$ ).

Im Alterthum unterschied man vorzüglich zwei Arten von Giftschlangen, nämlich die Viper (Echis, Echidna) und die Aspis; erstere entspricht der in den Mittelmeerländern gemeinen Vipera ammodytes, der Sandviper, und letztere der ägyptischen Naja haje, durch die sich Cleopatra tödten liess. Der erste, der uns Genaneres iiber Schlangen berichtet, ist

1) Homer, llias II. 723 .

$\left.{ }^{2}\right)$ Herodot, Histor. II. 74.

$\left.{ }^{3}\right)$ Herodot, Histor. II. 75, IV. 191-192. 
Aristoteles ${ }^{1}$ ). Nach ihm haben die Schlangen eine sehr lange Luftröhre und eine noch lïngere Speiseröhre. Der Anfang der ersteren liegt im Munde selbst, so dass die Zunge unter ihr zu liegen scheint. Letztere ist dünn, lang und schwarz, wird weit vorgestreckt und ist an der Spitze gespalten; die Spitzen sind so dünn wie Haare. Der Magen ist wie ein erweiterter Darm und dem des Hundes ähnlich. Der Darm ist lang, dünn und bis ans Ende einfach. Neben dem Schllundkopf liegt das kleine, lange und nierenförmige Herz; dam folgt die einfache, sehr lange, durch eine faserige Brücke gesonderte und rom Herzen weit entfernte Lunge. Auch die Leber ist lang und einfach, die Milz klein und drehrund. Die Gallenblase ist ähnlich wie bei den Fischen; die Wasserschlangen haben sie an der Leber, die übrigen Schlangen jedoch an den Gedärmen. Alle haben ein sägeförmiges Gebiss. Die Zahl der Rippen beträgt 30. Die ansgestochenen Augen und der abgehanene Schwanz sollen wieder wachsen. Die Wirbelsäule ist grätenartig. Die Schlangen legen Eier, nur die Echidna bringt lebendige Junge zur Welt, erzengt aber auch zuvor in sich Eier. Das Ei ist wie das der Fische einfarbig und weichschalig. Die jungen Vipern werden in Häutchen geboren, die am dritten Tage zerreissen; zuweilen fressen sich die Jungen aber auch von selbst durch und schlüpfen aus. Die Eier der übrigen Schlangen längen zusammen wie die Halsschnüre der Weiber; wenn sie die Eier in die Erde abgesetzt haben, brüten sie. Die Weibchen sind grösser als die Männchen.

Auch die Geschlechtsorgane beschreibt uns Aristoteles genauer; ebenso weiss er, dass sich die Schlangen häuten und einen Winterschlaf halten. Ausser der Viper und Aspis kennt er auch die schon von $\mathrm{H}$ e rod ot errähnte ägyptische Schlange mit einem hornartigen Auswuchs über dem Auge, den Cerastes aegyptiacus.

Von anderen Autoren des Alterthums, die uns mehr oder

1) Aristoteles, Hist. anim. II. 12, 10 u. a. O. 
weniger über Giftschlangen berichten, sind besonders zu erwähnen: Nikander, Dioscorides, Celsus, Plinius, A elianus, Galenus, deren Mittheilungen im weiteren Verlaufe dieser Abhandlung noch gewürdigt werden sollen. Wie wenig in jenen Zeiten eine unbefangene naturwissenschaftliche Beobachtung zum Ausdruck kam, davon zeugen vor Allem Plin i us und A elian, die abgeschmackte Volksmärchen, in denen zumeist auch nicht einmal ein Kern von Wahrheit steckt, verewigt haben.

So meint Plinius, dass aus dem Rückenmarke menschlicher Leichen Schlangen entständen. Die letzteren hätten weder Wärme noch Schweiss noch Blut; frässen sie vor dem Bisse etwas Giftiges, so würden sie dadurch geführlicher. Er kennt ausser Aspis und Hornschlangen auch Amphisbänen und Jacula; erstere sollen auch am Schwanze einen Kopf haben und vorwärts und rückwärts kriechen können, während die Jacula (auch Akontias genannt) sich wie Wurfspiesse fortschleudern sollen. In Indien soll es Riesenschlangen geben, die ganze Hirsche und Stiere verschlingen. Die schönste Schlange, die aber an Giftigkeit keiner anderen nachstehe, sei die im Wasser lebende Hyder. Plinius weiss, dass die Schlangen im Stande sind lange Zeit zu hungern, dass sie die Haut abstreifen und einen Winterschlaf halten; ferner spricht er ron dem Kampf der Schlange mit dem Wiesel und Ichneumon.

Noch märchenhafter als die Schilderungen des Plinius sind diejenigen des Aelian, der ja auch eigentlich nur das berichtet, was er von anderen Leichtgläubigen gehört hat, und nichts selbst beobachtet zu haben scheint. So soll es nach ihm in Indien eine Purpurschlange mit weissem Kopf, aber olme Zähne geben; sie beisst nicht, aber das Glied, das sie anspeit, fault ab. Die Schlangen sollen das Herz im Schlunde, die Galle in den Eingeweiden, die Hoden am Schwanze haben. Die Eier, die sie legen, sind lang und weich; das Gift ist in den Zühnen. Der Magen ist lang und dünn. Beim Fressen stellen sie sich aufrecht. 
Ausser den von Aristoteles und Plinius erwähnten Schlangen beschreibt A elian noch eine in Libyen und Arabien vorkommende "Dipsas", die einen brennenden Durst verursachen soll, ferner die Natter "Thermutis* in Aegypten, den "Hämorrhus", der theils feuerfarben theils tiefschwarz ist, und dessen Kopf mit starrenden Hörnern besetzt ist, die Schlange "Sepedon", die "Seps", welche die Farbe der Orte annimmt, auf denen sie sich aufhält, endlich auch Wasser- und Meerschlangen.

Es würde zu weit führen, wollte man hier alle mysteriösen Beschreibungen von gehörnten, hundertköpfigen, geflügelten Schlangen und Drachen berücksichtigen, wie man sie, vielfach von den wunderbarsten Abbildungen begleitet, in den Werken des Alterthums und besonders in denen des Mittelalters und Anfangs der Neuzeit findet.

Dagegen darf nicht unerwähnt gelassen werden, welche Vorstellungen die Alten von dem Bau des Giftapparates und von seiner Wirkungsweise hatten. Zwar wusste man schon im Alterthum, dass das Gift durch den Biss der Schlange in die Wunde gelangt, aber über den Ursprung des Giftes und über den Mechanismus beim Beissen war man doch noch sehr im Unklaren.

Nach Nikander ${ }^{1}$ ) ergiesst sich das Gift bei der Seps aus vier hohlen Zähnen, über die eine Haut gebreitet ist, welche die Höhlung bedeckt.

Plinius ${ }^{2}$, dessen Beschreibung des Giftapparates der Wirklichkeit schon sehr nahe kommt, lässt die Zähne der Aspis den Fischzähnen ähnlich sein; jedoch ständen im Oberkiefer noch jederseits zwei sehr lange Zähne, durch welche eine feine Röhre geht, aus der sie das Gift in die Wunde fliessen lassen. Diese gifttragenden Zähne sollen von einem dünnen Häutchen umgeben sein; wenn sie beisst, so wende sich letzteres um, und das Gift trete heraus; darauf zögen sich die Häute wieder zusammen.

') Nikander, Theriaka 145, $182 \mathrm{ff}$.

2) Plinius, Hist. nat. XI. 62. 
Einige behaupten, wie Plinius erzählt, die Schlangen hätten auf jeder Seite nur eineu Giftzahn, der krumm sei und sich mach dem Bisse zurücklehne; andere meinen, der Giftzahn breche leicht $a b$ und erneuere sich dann wieder. Die Zühne der Viper sollen sich im Zahnfleische verbergen; dieses, von Gift strotzend, lïsst durch den Druck der Zühne das Gift in die Wunde fliessen. Der Sitz des Giftes soll die Gallenblase sein, von wo es durch besondere Adern unter der Wirbelsänle hin zum Maule gelange. Manche Autoren des Alterthums, wie Galen, glaubten, dass das Gift in ganzen Körper der Schlange vertheilt sei. Neuere Autoren, wie Mercurialis ${ }^{1}$ ) und Redi ${ }^{2}$ ) meinten, dass das Gift im ganzen Kopfe entstehe und durch besondere Günge in die Zähne umhüllende Scheiden gelange.

Nach Gessner ${ }^{3}$ ) liegt es unterhalb der Zähne in einem kleinen Loche verborgen oder wird in einem kleinen Blättchen unter der Zunge gesammelt, ans welchem es nach dem Zerspringen desselben wie Speichel fliessen soll. Nach der Ansicht von Aldrovandus ${ }^{+}$) entleert es sich aus einem unter der Zunge liegenden Bläschen durch die Zahnhöhle.

Auch über die Zahl der Giftzïhne herrschten lange Zeit Meinungsverschiedenheiten. So sollen sich nach Nikander ${ }^{5}$ ) beim Bisse der Echis zwei, bei dem der Echidna dagegen noch mehr Spuren von Zähnen zeigen. Mercurialis meint, dass bei der Aspis und Viper die Münnchen zwei, die Weibchen aber vier Wunden machen.

Auch die Ansicht findet man vertreten, dass es nicht die Zähne, sondern die Zunge sei, welche das Gift führe. Lange Zeit wurde auch der Speichel der Schlangen für giftig gehalten, bis seine Unschädlichkeit von $\mathrm{Charas}^{6}$ ) nachgewiesen

$\left.{ }^{1}\right)$ Mercurialis, De venenis. 1548. lib. II. cap. 2.

2) Redi, Observationes de vipera. Opuscul. tom. II. p. 176 ff. 1729.

3) Gessner, De serpentibus. 1587.

$\left.{ }^{4}\right)$ Aldrovandus, Serpentum et draconum historia libri II. 1640.

4) Nikander, Theriaka $231 \mathrm{f}$.

6) Charas, Nouvelles expériences sur la vipère. Paris 1694. 
wurde, der auch die Speicheldrüsen bei den Schlangen entdeckte. Manche glaubten sogar, dass die Viper nicht durch Beissen gefährlich werde, sondern am Schwanze einen Stachel habe, mit dem sie steche.

Erst gegen Ende des vorigen Jahrhunderts gelangte man durch die Untersuchungen Fontana's, welchem das Verdienst gebührt zuerst eine richtige Beschreibung des Giftapparates, und zwar bei der Vipera aspis, geliefert zu haben, zu klareren Vorstellungen über diesen Gegenstand.

Die moderne Wissenschaft hat mit Scheere und Messer, mit Lupe und Mikroskop jeden Zweifel über die Anatomie der Gifteinrichtung völlig gelöst, so dass über diesen Punkt nunmehr vollständige Klarheit herrscht.

Das Thatsächliche über den Giftapparat der Schlangen ist folgendes:

Alle giftigen Schlangen, die man auch im Gegensatze zu den ungiftigen Schlangen Thanatophidii nennt, zeichnen sich dadurch aus, dass sie jederseits ausser der Speicheldrüse oberhalb des Mundwinkels eine besondere Giftdrüse besitzen, deren giftiges Secret mittelst eines Ausführungsganges jederseits zu der Basis eines meist gebogenen und sehr verschieden bis zu $3 \mathrm{~cm}$ langen Giftzahnes geleitet wird und von dort bei der Abtheilung der Proteroglyphen durch eine an der Vorderfläche des Giftrahnes befindliche Furche, bei den Solenoglyphen dagegen durch einen im Innern des Zahnes befindlichen Canal an die Spitze des Zahues und beim Beissen von dort in die Wunde hinein gelangt. Die Lage der Giftzähne ist verschieden; bei manchen Schlangen finden sie sich ziemlich vorn in Oberkiefer, bei anderen so weit nach hinten, dass man in das Maul den Zieigefinger legen kann, ohne dass der Zahn diesen zu verwunden vermag. Das Gift wird nur in den beiden Giftdrüsen gebildet und findet sich in keinem anderen Organe der Schlange; daher sind auch alle Theile derselben ausser den Giftdrüsen mit ihren Ausführungsgängen ungiftig. Der Form nach sind die Giftdrüsen theils knopfförmig, theils platt zusammengedrückt, theils cylindrisch oder röhrenförmig; ihrem 
Bau nach gehören sie zu den acinösen Drïsen. Bei der Mehrzahl der Giftschlangen liegen sie zwischen Oberkiefer und Quadratbein unter und hinter dem Auge; bei einigen reichen sie dagegen bis weit auf den Rücken, und bei Callophis (Elaps) intestinalis und C. bivirgatus liegen sie sogar innerhalb der Banchlöhle als langgestreckte, gelb gefärbte Körper dicht neben einander und sind $1 / 1$ bis $1 / 2$ so lang wie das ganze Thier. Drüsen und Ausführungsgänge sind von quergestreiften Muskeln umgeben, um das Gift herauszupressen. Die Giftzïhne sitzen anfang's frei beweglich im Oberkiefer, verwachsen aber später mit ihm; dicht hinter ihnen folgen zwei bis sechs Reservezähne, die zum Ersatz der ersten Giftzähne nach ilurer Abnutzung oder zufälligem Ausbrechen dienen.

In der Ruhe oder beim Fressen liegen die Giftzähne, mit ihrer Spitze nach hinten gerichtet, in einer Scheide oder einem Sack verborgen, der durch Erweiterung des Ausführungsganges an der Wurzel des Zahnes und durch eine Duplicatur des Zahnfleisches oder der Lippenschleimhaut gebildet wird. Wenn die Schlange zum Beissen den Rachen öffnet, so richten sich die Zühne durch Verschieben des Quadratbeines durch einen Muskel, der an der Schädelbasis entspringt und sich am hinteren Theile des Gaumenbogens ansetzt, derart auf, dass die obere Oeffnung des Giftzahnes auf die Mündung des Drüsenausführungsganges passt; darauf wird der Giftsack durch den Musculus pterygoideus externus in die Höhe gezogen und durch Contraction der Schlüfenmuskeln zusammengepresst, wodurch sich das Gift aus ihm entleert und in die Zähne gelangt.

Manche Schlangen, wie Naja tripudians und Bungarus fasciatus, haben keinen beweglichen Oberkiefer, weshalb die Giftzähne bei denselben nicht erectil sind ${ }^{1}$ ). Bei einzelnen Schlangen (Meerschlangen) finden sich hinter den Giftzähnen auch gewöhnliche solide Zähne im Oberkiefer.

Trotz der scheinbaren anatomischen Uebereinstimmung:

1) Fayrer, Edinb. Med. Journ. 14. May. p. 999. 1869. 
liegen für die toxikologische Betrachtung in dem bisher Mitgetheilten doch zahlreiche, recht bedeutungsvolle Verschiedenheiten, die erklärlich machen, weshalb die Giftwirkung verschiedener Schlangen, abgesehen von der Verschiedenartigkeit des Giftes selbst, sich oft verschieden darstellen kann.

Die Gefährlichkeit der Bisswunden hängt nämlich $a b$ :

1. Von der Grösse der Schlange resp. ihrer Giftdrüsen. Es giebt Trigonocephalus-Arten, bei denen die Giftdrüsen die Grösse einer menschlichen Parotis erreichen. Je grösser die Giftdrüse ist, desto grösser ist auch die darin enthaltene Giftmenge.

2. Von der Kraft der Expulsion; diese ist bei den Schlangen, welche ihre Drüsen im Leibe haben, wegen der Mitwirkung der Bauchmuskulatur grösser als bei denen, die ibre Giftdrüsen im Kopfe zu liegen haben und sie nur durch Contraction der Temporalmuskeln entleeren.

3. Von der Länge des Giftzahnes und der davon abhängenden Tiefe des Bisses. Der Giftzahn ist z. B. bei Vipera Berus 1/2", bei Trigonocephalus mutus etwa $1^{1 / 4} \mathrm{~cm}$ lang.

4. Von der Oertlichkeit des Bisses. Am gefährlichsten sind solche Wunden, welche direct Gefässe oder sehr gefüssreiche Körpertheile, besonders das Gesicht, sowie solche Bisse, welche Körpertheile mit kleinem Umfange treffen, da in diesem Falle die Giftzähne mehr senkrecht und dadurch tiefer eindringen.

5. Von dem Zustande, in dem sich die Schlange befindet. Eine in der Gefangenschaft lebende, die lange Zeit nicht gebissen hat, ist viel gefährlicher als eine frei lebende Schlange, ebenso ist eine Schlange gefährlicher, wenn sie gereizt ist, weil sie dann mit grösserer Energie beisst.

6. Von der Jahreszeit; an heissen Tagen sind die Bisswunden geführlicher als bei kühler Temperatur.

7. Von dem Zustande des Gebissenen; kräftige Personen sind im Allgemeinen weniger gefährdet als schwache. Ferner soll es günstig sein, wenn der Gebissene sich in einem Zu- 
stande der Erregung befindet, da das Schlangengift depressorisch auf die Nerven wirkt.

8. Von dem Alter der Schlangen. Die indianischen Aerzte behaupten nämlich, dass nur der Biss der jungen Klapperschlangen tödte, und dass die Intensitit der Wirkung ihres Giftes dem Altex proportional abnehme; am gefährlichsten sollen die drei- bis achtjährigen sein. Dasselbe glauben die brasilianischen Neger ${ }^{1}$ ).

Was die Menge des bei einem Biss entleerten Giftes betrifft, so liefert ein ausgewachsenes Exemplar von Vipera ammodytes durchschnittlich 0,06g Giftflüssigkeit; Kreuzottern geben $0,022 \mathrm{~g}$, Klapperschlangen $0,5 \mathrm{~g}^{2}$ ). Bei rasch wiederholtem Beissen erschöpft sich der Giftvorrath schnell, so dass oft schon der fünfte Biss ungiftig ist. Nach viermonatlichem Winterschlaf ist noch ein ganz actives Gift vorhanden. Alle Organe der Schlangen, ausser den Giftdrüsen und Ausführungsgüingen derselben sind ungiftig. Muscarin und Pilocarpin wirken auf die Giftproduction nicht ein, eben so wenig Atropin. Die stïrksten Schlïge des Magnetelektromotors, die man durch die Giftdrüsen eben getödteter Schlangen treten liess, bewirliten keine Giftabsonderung. Dagegen scheint Nahrungsenthaltung ein zeitweiliges Versiegen des Giftes resp. die Production eines mur wenig oder gar nicht wirkenden Drüsensaftes zu veranlassen. Die im Laboratorium geborenen Thiere geben schon am ersten Lebenstage ein ganz actives Gift.

$\left.{ }^{1}\right)$ N a phegyi, Philad. med. a. surg. Recorder. XVIII. 12. p. 249. March 1868.

$\left.{ }^{2}\right)$ Feoktistow, Experimentelle Untersuchungen über Schlangengift (Inaug.-Dissert. Dorpat 1888). 
III.

\section{Systematik der wichtigsten Giftschlangen.}

Bei der folgenden Besprechung der am häufigsten vorkommenden Giftschlangen habe ich, dem Zwecke dieser Arbeit entsprechend, weniger die zoologischen Eigentbümlichlieiten und Kennzeichen als vielmehr die Differenzen in der Giftwirkung und Gefährlichkeit der einzelnen Arten berücksichtigen zu müssen geglaubt.

Da ein Moment, worauf es bei der Beurtheilung dieser Frage, wie schon oben erwähnt, vorzüglich ankommt, nämlich die Länge der Giftzähne, bisher eine verhältnissmässig geringe Beachtung gefunden hat, so habe ich mich auf Veranlassung von Herrn Prof. Lew in der Mühe unterzogen, eine grosse Zahl der in der zoologischen Sammlung des Königlichen Museums für Naturkunde zu Berlin befindlichen Giftschlangen daraufhin zu untersuchen, und füge die gefundenen Resultate den betreffenden Species bei.

Man theilt die Giftschlangen in zwei Abtheilungen ein:

I. Viperina oder Solenoglypha; dieselben haben im Oberkiefer jederseits einen im Innern von einem Kanal durchbohrten Giftzahn und hinter ihm keine soliden Zühne.

II. Colubrina venenosa oder Proteroglypha; diese haben im Oberkiefer an ihrer vorderen Seite mit einer Längsfurche versehene Giftzähne; hinter denselben befinden sich entweder gar keine oder doch nur kleine solide Zähne.

\section{Solenoglypha.}

1. Crotalidae: Jederseits zwischen Auge und Nasenloch befindet sich eine tiefe Grube. Die wichtigste Gattung 
dieser Familie, deren Arten zu den gefährlichsten Giftschlangen gehören und sehr lange und starke Giftzähne haben, ist die Gattung Crotalus, die dadurch ausgezeichnet ist, dass alle Arten derselben an der Spitze des Schwanzes eine meist aus neun Hornringen bestelende Klapper besitzen.

Crotalus durissus Daud., die nordamerikanische Klapperschlange, ist die häufigste Giftschlange der Vereinigten Staten. Sie kommt bis zum 46. Grad n. Br. vor und wird selten über $1,5 \mathrm{~m}$ lang. Ein ron mir untersuchtes Exemplar hatte bei einer Gesamntlänge ron $110 \mathrm{~cm}$ sehr krïftige, stark gekrümmte Giftzähne von $10 \mathrm{~mm}$ Länge.

C. cerastes Hallow in Californien und Mexico.

C. a damanteus Pall. findet sich im südlichen Nordamerika und wird über $2 \mathrm{~m}$ lang.

C. miliarius L. hat ungefähr dasselbe Verbreitungsgebiet wie die vorige Art.

C. horridus Daud., die südamerikanische Klapperschlange, die Cascavela der Brasilianer, kommt in Südamerika und auf den Antillen vor. Zwei von mir gemessene Exemplare massen 93 resp. $160 \mathrm{~cm}$, ihre Giftzähne 10 resp. $13 \mathrm{~mm}$; dieselben sind ebenfalls stark und gekrümmt. Sie soll bei jedem Biss $1,5 \mathrm{~g}$ Gift entleeren und fast stets den Tod bringen, wenn die Giftzïhne tief eindrangen. Der Biss durchdringt das dickste Zeug und die stärksten Stiefel.

Zu den Crotaliden gehört ferner die Gattung Lachesis; statt der Klapper findet sich hier vor dem Schwanzende eine Anzahl dorniger Schuppenreihen.

Lachesis rhombeata Pr. Neuried (Lachesis muta Daud., Crotalus mutus L.), die Surucucú oder der „Buschmeister" der hollïndischen Colonisten von Surinam, bewohnt die heissen Trwälder der südamerikanischen Ostkïste, besonders von Guyana, wird ïber $3 \mathrm{~m}$ lang und ist die grösste Giftschlange. Länge des Giftzahnes $20 \mathrm{~mm}$ (bei $175 \mathrm{~cm}$ Gesammtlänge). Sie soll, wie mir von glaubwürdiger Seite in Brasilien versichert wurde, beim Nahen eines Menschen sich gegen denselben zum Beissen emporrichten. 
Die Gattung Trigonocephalus hat einen spitzen Schwanz ohne Klapper oder Dornen; der Kopf ist dreieckig: und besitzt ein grosses Scheitelschild.

Trigonocephalus contortrix Holbrook, die Mocassinschlange, lebt im östlichen Nordamerika und wird $1 \mathrm{~m}$ lang.

T. piscivorus Lacép., lebt ebenfalls in Nordanerika, besonders in Louisiana und Nordcarolina und wird 1,5 m lang. Sie wird mehr gefürchtet als die Klapperschlange, weil sie im Gegensatz zu letzterer, welche nur beisst, wenn sie gereizt ist, direct den Menschen angreifen soll. Giftzähne an einem Kopfskelet $7 \mathrm{~mm}$ lang.

T. halys Dum., im westlichen Asien, z. B. häufig an den Ufern des Kaspischen Meeres. Länge $65 \mathrm{~cm}$.

T. rhodostoma Reinw., auf Java und in Sian sehr gefürchtet, weil ihr Biss in weniger als einer Viertelstunde tödten soll, und weil sie vielfach in die Besitzungen eindringt. Giftzahn $12 \mathrm{~mm}$ lang.

T. Blom hoffii Boie, in Ostasien, besonders in Japan. Sie verursacht oft tödtliche Vergiftungen. Länge des Giftzahns $5-7 \mathrm{~mm}$ bei $55-69 \mathrm{~cm}$ Totallänge.

Die Gattung Bothrops ist ähnlich der vorigen, hat aber am Kopfe jederseits ein grosses Supraciliarschild.

Bothrops lanceolatus Wagl., die Lanzenschlange, kommt auf den Antillen, besonders auf Martinique sehr häufig vor und ist daselbst sehr gefürchtet. Sie verursacht unter den ca. 150000 Einwohnern der Insel jährlich ca. 50 Todesfälle. Der längste von $\mathrm{Rufz^{1 }}$ ) gemessene Giftzahn dieser Schlange war ca. $25 \mathrm{~mm}$ lang (bei einer Totallänge von $190 \mathrm{~cm}$ ). Im Pariser Museum soll sich sogar ein Exemplar mit einem 15 Linien (etwa $34 \mathrm{~mm}$ ) langen Giftzahn befinden. Eine von mir gemessene Schlange hatte bei einer Gesammtlänge von $150 \mathrm{~cm}$ einen $15 \mathrm{~mm}$ langen Giftzahn.

B. Jararacá Neuw., die Jararacá, ist die häufigste

$\left.{ }^{1}\right) \mathrm{Rufz}$, Enquête sur le serpent (Fer de lance) de la Martinique. Paris 1859. p. 67. 
Giftschlange Brasiliens. Sie wird $1,8 \mathrm{~m}$ lang und dem Menschen dadurch besonders geführlich, dass sie ihn, ohne irgendwie gereizt zu sein, zuweilen aus freien Stücken angreifen und sogar verfolgen soll. Uebrigens ist sie die einzige Schlange, ron welcher letzteres mit Sicherheit constatirt ist. Unter $100-200$ Einwohnern stirbt in manchen Gegenden jährlich einer durch den Biss dieser Schlange.

B. atrox Dum., die Labaria der Colonisten, Sororaima der Macusis, lebt in Brasilien und Guyana, und zwar besonders in den dichten Urwäldern. Sie ist ebenfalls sehr gefürchtet, ihr Biss tödtet oft schon in weniger als 24 Stunden. Bei drei Exemplaren des Berliner Museums betrug die Länge der Giftzïhne 4, 9, $12 \mathrm{~mm}$, die Totallünge der betreffenden Schlangen 38, 75, $85 \mathrm{~cm}$.

B. viridis Dum., in Ostasien. Giftzahn an einem Kopfskelet der Schlange $6 \mathrm{~mm}$ lang.

Weniger wichtige Arten der Gattung Bothrops sind noch:

B. formosus Schl, auf Sumatra.

B. nigromarginatus Dum. auf Ceylon.

B. Jararacussú in Brasilien.

B. Neuwiedi Wagl. und

B. Castelnaudi Dum., ebenfalls in Brasilien.

B. bilineatus Dum., in Brasilien und auf den Antillen.

B. pictus Tschudi in Peru.

B. Boussingaulti Dum, in Ecuador.

B. alternatus Dum. in Südamerika.

B. Lansbergi Schl, in Mittel- und Südamerika.

Trineresurus Riukiuauus Hilg., dieHabu-Schlange, ist auf den Liu-kiu-Inseln derartig gefürchtet, dass ganze Dörfer rerlassen werden, wo die Schlange sehr zunimmt; ihr Biss soll schon nach wenigen Stunden, spütestens in zwei Tagen den Tod nach sich ziehen. Die Schlange wird etwa $2 \mathrm{~m} \mathrm{lang.}$

T. erythrinus Cant. in Ostasien. Giftzahn $8 \mathrm{~mm}$, Totallänge $80 \mathrm{~cm}$.

T'. gramineus Shaw. in Indien wird weniger gefürchtet, da ihr Biss nur Localerscheinungen verursachen soll. 
Tropidolaemus sumatranus Rafft, auf den Sundainseln und in Ostindien. Giftzahn $11 \mathrm{~mm}$, Totallänge $75 \mathrm{~cm}$.

T. semiannulatus, Giftzahn $4 \mathrm{~mm}$ lang.

T. Hombroni Dum. auf den Philippinen.

Hypnale nepa Laur. auf Ceylon und in Ostindien.

Peltocolor macrolepis Bedd. in Indien.

Atropos acontia Gray auf Japan und Borneo.

A. undulatus in Mexico.

2. Viperidae. Diese Familie unterscheidet sich von den Crotalidae dadurch, dass sich zwischen Auge und Nasenloch keine Grube befindet.

Die Giftzähne sind zwar bei den meisten Viperiden bedeutend kleiner als bei den Crotaliden, erreichen jedoch bei einzelnen ebenfalls eine bedeutende Länge und Stärke.

Die Arten der Gattung Cerastes haben den Scheitel des Kopfes mit warzigen Schuppen bedeckt, welche sich über den Augen zu hornartigen Fortsätzen erheben.

Cerastes aegyptiacus Wagl. ist die von den Alten so oft erwähnte, und von Herodot für ungefährlich gehaltene Hornviper; sie lebt in Nordafrika, besonders in Aegypten und in der Wüste, und findet sich anch in Arabien. Giftzahn $6 \mathrm{~mm}$, Totallänge $51 \mathrm{~cm}$.

Cerastes lophophrys Dum., die Helmbuschviper, hat über jedem Auge ein Büschel kleiner Hornfäden; sie lebt am Cap der guten Hoffnung.

Cerastes caudalis Snith in Südafrika.

Cerastes persicus Dum. in Persien.

Bei der Gattung Vipera sind die Schuppen anf dem Scheitel des Kopfes glatt.

Vipera aspis Merr. (Vipera Redii Fitz), die Redi'sche Viper, wird $65-75 \mathrm{~cm}$ lang und findet sich im südwestlichen Europa, besonders in Südfrankreich, Italien, in der Schweiz, seltener in Südtirol, Kärnthen, Illyrien, Dalmatien; in Deutschland kommt sie nur bei Metz und in Baden vor. Sie ist kenntlich an der etwas aufgeworfenen Schnauze und an den vier Reihen schwarzer grosser Flecken auf dem Rücken, welche 
aber kein Zickzackband bilden. Die Mortalität der Verwundung durch diese Viper verhält sich wie 1:25. Bei jedem Biss werden 1,,15 g Gift entleert. Giftzahn $5 \mathrm{~mm}$ bei $50 \mathrm{~cm}$ Totallänge.

Vipera ammodytes Dum. und Bibr., die Sandviper, wird $65-95 \mathrm{~cm}$ lang; sie ist die von den meisten alten Autoren als Viper, von Dioscorides als Kenchros bezeichnete, gefährlichste aller europäischen Giftschlangen und ist in allen Mittelmeerlïndern, besonders in Dalmatien und Griechenland gemein, findet sich aber auch in Kärnthen, Steiermark, Südungarn, Tirol. Sie hat über der Schnauzenspitze eine weiche, hornartige Verlängerung. In Bezug auf die Mortalität verhält sie sich ungefähr wie die vorige. Giftzahn $5 \mathrm{~mm}$, Totallänge $51 \mathrm{~cm}$.

Vipera rhinozeros Schl., in Gabun, soll einen schnellen Tod verursachen. Giftzahn an einem Kopfskelet im Berliner Museum $30 \mathrm{~mm}$ lang, sehr stark und von bedeutender Krümmung.

Vipera nasicornis Shaw, in Guinea und an der Goldküste.

Vipera atropos Schl. in Südafrika, Giftzahn $7 \mathrm{~mm}$, Totallänge $42 \mathrm{~cm}$.

Vipera latastei Bosc. lebt in Spanien und Portugal.

Vipera lebetina L. auf der Insel Milo und in Afrika.

Die Gattung Pelias, die von Vielen auch zur Gattung Vipera gezählt wird, hat vorn auf dem Kopfe ein grösseres centrales Schild, das von kleineren Schilden umgeben ist.

Pelias berus Merr. (Vipera berus Daud.), die gemeine Kreuzotter, wird $50-70 \mathrm{~cm} \mathrm{lang}$, findet sich in ganz Europa ausser in den nördlichsten und südlichsten Theilen, sowie in Asien. Sie ist leicht kenntlich durch das auf dem Rücken befindliche schwarze Zickzackband. Auf ihre verhïltnissmässig geringe Giftigkeit ist bereits in der Einleitung hingewiesen worden. Bei jedem Biss entleert sich etwa $0,1 \mathrm{~g}$ Gift; ihre Giftzähne sind etwa $3-4 \mathrm{~mm}$ lang:

Variationen von Vipera berus sind die ron den Alten 
als Prester oder Dipsas beschriebene Vipera prester L., die sogen. Höllennatter, und die Kupferschlange, Vipera chersea $\mathrm{L}$.

Von aussereuropäischen Viperiden sind noch zu nennen:

Clotho arietans Gr., die Puffotter in Südafrika, deren Biss häufig schnell tödtet. Giftzähne von drei Exemplaren des Museums, deren Länge 27-3t $\mathrm{cm}$ betrug, $7-8 \mathrm{~mm}$ lang. Die Zähne an einem Kopfskelet waren sogar 12 (rep. 14) mm lang.

Daboia Russelii Gthr., die Katuka Rekula Poda oder Bora Siah Chunder der Eingeborenen in Ostindien. Sie verursacht nächst der Brillenschlange die meisten Todesfälle daselbst, ist aber noch weit mehr gefürchtet als diese, weil sie, wenn sie auch langsamer in ihren Bewegungen ist als die Brillenschlange und weniger häufig beisst, so doch desto sicherer den Tod verursacht. Länge dcs Giftzahnes $14 \mathrm{~mm}$, Totallänge $110 \mathrm{~cm}$.

Echis carinata Merr. ebenfalls in Indien (Horatta $\mathrm{Pam}$ ). Sie steht an Gefährlichkeit hinter den meisten anderen Giftschlangen Indiens zurück. Länge $60 \mathrm{~cm}$.

Echis chlorechis Schl, an der Goldküste.

\section{Proteroglypha.}

Die Giftzähne der Proteroglyphen sind bedeutend kleiner als die der Solenoglyphen.

1. Elapidae. Körper fast cylindrisch, Nasenlöcher seitlich gerichtet.

Bei der Gattung Elaps sind die Schuppen der Rückenmittellinie nicht besonders ausgezeichnet, die unteren Schwanzschilder zweireihig und der Kopf flachgedrückt.

Elaps corallinus Wied., Korallenschlange, $65-70 \mathrm{~cm}$ lang, in Südamerika. Giftzahn ca. $2 \mathrm{~mm}$ lang. Trotz der Kleinheit der Zähne ist das Gift dieser Schlange so wirksam, dass man schon eine Stunde nach dem Bisse den Tod eintreten sah.

E. lemniscatus Schl. in Südamerika. 
E. fulvius L. in Nordamerika.

E. frontalis Dum. in Südamerika. Länge $85-90 \mathrm{~cm}$, Giftzähne 2-4 mm.

E. bivirgatus Schl. auf Java. Giftzähne $3 \mathrm{~mm}$ lang.

Die Gattung Naja hat einen hohen, vierkantigen Kopf; die vorderen Rippen sind verlängert, und der Hals ist ausdehnbar.

Die wichtigste Schlange dieser Gattung ist Naja tripudians Merr., Cobra de Capello, die ostindische Brillenschlange. Sie wird $1 / 1 / 4-2 \mathrm{~m}$ lang und findet sich ausser in Ostindien auch auf Java und in Südchina. Sie ist diejenige Giftschlange, welche in Indien wegen ihres ausserordentlich häufigen Vorkonmens daselbst und ihrer leichten Reizbarkeit und davon abhängigen Geneigtheit zum Beissen die meisten Opfer fordert. Bei jedem Biss sollen ca. $2 \mathrm{~g}$ Gift entleert werden. Zwei von mir untersuchte Brillenschlangen besassen bei einer Totallänge von 105 resp. $118 \mathrm{~cm}$ Giftzähne von nur 4 resp. $5 \mathrm{~mm}$ Länge.

Naja haje Merr., die Aspis der Alten, die Schlange der Cleopatra oder ägyptische Brillenschlange, ist 1,6-2,25 m lang und lebt in West- und Nordafrika. Giftzahn $6 \mathrm{~mm}$ lang bei einer Totallänge von $174 \mathrm{~cm}$.

Naja angusticeps Smith. in Gabun. Giftzähne bei einem $3 \mathrm{~m}$ langen Exemplar $7 \mathrm{~mm}$, an einem Kopfskelet $8 \mathrm{~mm}$ lang.

Naja sputatrix Boie auf Banka. Giftz:̈hne $4 \mathrm{~mm}$ lang. Naja regalis Schl. an der Goldküste.

Naja nigricollis Reinh. in Guinea, Sierra Leone und an der Goldkïste.

Sepedon ha emachates Merr. in Südafrika ist fast ebenso giftig wie Naja tripudians und N. haje.

Bei der Gattung Pseudechis sind die unteren Schwanzschilder vorn einreihig, hinten zweireihig.

Pseudech is porphyricus Wagl., 2,5 m lang, Schwarze Schlange (black suake), in Australien. Sie verursacht oft schnellen Tod, Giftzahn 5 mm lang. 
Bei der Gattung Bungarus sind die Schuppen der Rückenmittellinie besonders ausgezeichnet, gross und sechsseitig; After- und untere Schwanzschilder sind nicht getheilt.

Bungarus coeruleus Daud., Krait oder Gedi Paraguda der Eingeborenen, ist $80 \mathrm{~cm}$ lang und gehört $\mathrm{zu}$ den gefährlichsten Schlangen Ostindiens und Javas. Giftzähne kleiner als bei Naja tripudians, nämlich $2 \mathrm{~mm}$ bei einer Totallänge von $106 \mathrm{~cm}$.

Bungarus annularis Daud. (B. fasciatus Schn.). Sankni oder Bungarum $\mathrm{Pamah}$ der Eingeborenen, 1,6 bis $2 \mathrm{~m}$ lang, auf Ceylon, in Ostindien und in China, ist weniger gefährlich.

Die Gattung Dinophis (Dendraspis) hat grosse dreieckige Schuppen auf der Rückenmittellinie und getheilte Afterund untere Schwanzschilder.

Dinophis Jamesonii Traill. lebt auf Bäumen in Westafrika, besonders an der Goldküste.

Atractaspis Bibroni Smith in Westafrika. Giftzähne $5 \mathrm{~mm}$, Totallänge $70 \mathrm{~cm}$.

Ophiophagus elaps Gth., 4-5 m lang, Sunkerchor der Indier, findet sich in Indien, auf den Andamanen, den Sunda-Inseln, Neu-Guinea. Sie ist nach Fayrer vielleicht die grösste und gefährlichste Giftschlange Ostindiens und vermag einen Elephanten in 3 Stunden zu tödten. Sie soll ebenfalls den Menschen angreifen.

Causus rhombeatus Wagl. in Süd- und Westafrika. Vier von mir gemessene Exemplare hatten Giftzïhne von $1^{1 / 2}$, 2, 3, 4 mm Länge bei einer Totallänge von 21, 39, 42, $57 \mathrm{~cm}$.

Callophis intestinalis Gth. in Indien ist dadurch ausgezeichnet, dass sich bei dieser Schlange die Giftdrüsen in der Bauchhöhle befinden. Sie ist relativ wenig gefährlich, ihr Giftzahn auch nur ca. ${ }^{3 / \pm} \mathrm{mm}$ lang bei einer Totallänge von $37 \mathrm{~cm}$.

Callophis japonicus gehört zu den wenigen in Japan vorkommenden Giftschlangen. 
Hoplocephalus curtus Schl, Tigerschlange, in Australien. Ihr Biss tödtet ziemlich häufig.

H. superbus Gthr., large scaled oder diamondsnake, in Australien, ist weniger giftig.

Acanthophis antarctica, death adder, Todesnatter, ist die gefährlichste aller australischen Schlangen. Giftzahn $3 \mathrm{~mm}$ bei $35 \mathrm{~cm}$ Totallänge, $6 \mathrm{~mm}$ an einem Koptskelet.

Diemansia superciliaris Fisch., brown snake, in Australien. Giftzïhne an einem Kopfskelet $2 \mathrm{~mm}$.

Im Allgemeinen sind von den australischen Giftschlangen, deren Zahl 208 beträgt, die meisten für den Menschen vollkommen ungefährlich.

2. Hydrophidae. Die Meer* oder Seeschlangen haben einen seitlich zusammengedrückten Körper und Schwanz; die Nasenlöcher sind nach oben gerichtet. Sie sind die am wenigsten gefährlichen Giftschlangen und haben anch die relativ kleinsten Giftzähne.

Platurus fasciatus Latr. im Chinesischen und Indischen Meere. Giftzahn $1 \mathrm{~mm}$ bei $75 \mathrm{~cm}$ Totallänge.

P. laticaudatus L. Giftzähne $2 \mathrm{~mm}$ bei $90 \mathrm{~cm}$ Totallänge.

Hydrophis cyanocincta Gthr. im Meere von Ceylon bis Japan. Giftzähne $2-3 \mathrm{~mm}$ bei $45-75 \mathrm{~cm}$ Totallänge.

Hydrophis pelamoides Schl. im Indischen Meere.

Pelamis bicolor Daud. ist die gemeinste Seeschlange und kommt von Madagaskar bis zum Golf von Panama vor. Giftzähne sehr fein, $1^{1} \mathrm{~mm}$ bei $50 \mathrm{~cm}$ Totallänge. Sie vermag unter Umständen einen Menschen in 4 Stunden zu tödten, doch gehören Todesfälle nach ihrem Bisse zu den Ausnahmefällen.

Manche Seeschlangen, wie z. B. Platurus fasciatus, sollen nicht einmal dann beissen, wenn man sie in die Hand nimmt.

Aus der vorstehenden Betrachtung der einzelnen Giftschlangen scheint hervorzugehen, dass die Lünge des Gift- 
zahnes eine wesentliche Rolle bei der Beurtheilung des Giftigkeitsgrades der einzelnen Arten spielt. Am gefährlichsten wären danach die Crotaliden, dann folgen die Viperiden und Elapiden, und am ungefährlichsten sind die Hydrophiden. Dieselbe Reihenfolge in der Gefährlichkeit hat übrigens auch Fayrer ${ }^{1}$ ) für die ostindischen Giftschlangen aufgestellt, und zwar ebenfalls mit Bezugnahme auf die Länge der Giftzähne.

Was nun die Abtheilung der Colubriformia (Aglyphodontia, Opistoglypha) betrifft, welche nicht mehr zu den eigentlichen Giftschlangen gezählt werden, so besitzen manche Gattungen derselben, nämlich Scytale, Dipsas, Dryophis, Langaha, Psammophis, Coelopeltis, Homalopsis, Tachymenis und zuweilen auch Calamaria und Geophis im Oberkiefer jederseits hinter einer Reihe von soliden Hakenzähnen einen Furchenzahn und werden deshalb als Serpentes suspecti bezeichnet. Nachdem aber bereits Duvernoy bei verschiedenen Opistoglyphen, und neuerdings auch Jourdain ${ }^{2}$ ) bei Coelopeltis insignitus eine kleine Giftdrüse entdeckt hat, deren Ausführungsgang mit den hinteren Furchenzähnen in Verbindung steht, so unterliegt es wohl keinem Zweifel, dass schliesslich bei allen diesen "verdïchtigen Schlangen" eine Giftdrüse nachgewiesen werden wird, und dass dieselben somit eigentlich zu den Giftschlangen gehören. Jourdain ist sogar der Meinung, dass alle Schlangen im Besitze von Giftapparaten, wenn auch von verkümmerten, sind. Wie weit sich diese Ansicht bestätigen wird, muss dahingestellt bleiben, jedenfalls ist $\mathrm{zu}$ hoffen, dass wenigstens die "Serpentes suspecti“ in absehbarer Zeit dieses unbestimmten Charakters entkleidet und als giftige oder ungiftige Schlangen erkannt werden. Diese Frage ist wahrscheinlich auch für den Menschen nicht ohne Bedeutung; zwar tödten die meisten dieser Schlangen ihre Opfer nicht durch Beissen, sondern

1) F a yrer, Edinb. Med. Journ. 14. May 1869. p. 997.

$\left.{ }^{2}\right)$ J o u rdain, Compt. rend. de l'Acad. des sciences. T. 118. 1894. p. 207. 


\section{$-\quad 24$}

durch Umschlingen, und wenn sie einmal wirklich beissen, so thun sie dies in der Regel nur mit den ungiftigen Vorderzähnen. Sperrt man aber z. B. einer Coelopeltis absichtlich die Kiefer weit aus einander und schiebt das Glied des zu beissenden Thieres ganz weit hinein, so dass dann auch die Giftzähne eindringen können, so sterben kleine Säugethiere und Vögel schon sehr kurze Zeit nach dem Biss. Es geht daraus hervor, dass auch diese Schlangen ein durchaus wirksames Gift zu produciren vermögen. Hierfür scheint auch der Umstand zu sprechen, dass die ebenfalls zu den "Verdüchtigen" gehörende Langaha-Schlange von den Eingeborenen von Madagaskar wegen ihrer Giftigkeit gefürchtet sein soll ${ }^{1}$ ).

1) Gmelin, Allgem. Geschichte der thierischen und mineralischen Gifte. 2. Aufl. Erfurt 1811. S. 78. 
IV.

\section{Die Natur des Schlangengiftes.}

Ueber die Natur des Schlangengiftes finden sich bei den Alten nur wenige Bemerkungen. Nach Aelian soll die indische Purpurschlange zwei Arten von Gift, eine schwarze und eine dem Bernstein gleichende, enthalten. Gessner sagt rom Schlangengift, es sei kalt und trocken und werde nur bei grosser Trockenheit erzengt, weswegen Einige meinten, die Galle sei das Gift der Schlangen. Auch Plinius erzählt, dass die besten Autoren die Galle für das Gift der Schlange hielten.

Mead ${ }^{1}$ ) fand im Viperngift äusserst zarte, spitze, sehr beständige Krystalle und erklärte dieselben für das wirksame Prinzip des Giftes.

Dass man lange Zeit den Speichel der Schlange als giftig ansah, habe ich bereits erwähnt.

Entsprechend der Bedeutung des Gegenstandes hat unsere Zeit ganz besonders eifrig an der Aufklärung des Schlangengiftes gearbeitet. Ist hier auch jetzt dem weiteren Forschen, wie die folgenden Zeilen es lehren werden, eine gewisse natürliche Schranke gezogen worden, so kann man doch den Zuwachs an Erkenntniss begrüssen und vor Allem sich freuen, dass ein Wust von falschen Angaben nummehr endgültig beseitigt ist.

Die ergebnissreichsten Untersuchungen stellten Mitchell und Reichert ${ }^{2}$ ) an. Sie benutzten zu ihren Versuchen be-

1) Mead, De vipera. Opera medica. Vol. II. 1749.

$\left.{ }^{2}\right)$ Weir Mitchell, Researches upon the renom of the Rattlesnake (Smithsonian contributions to knowledge. Philad. 1860. $4^{\circ}$ ). - Americ. 
sonders die Gifte folgender amerikanischer Schlangen: Crotalus adamanteus, Cr. durissus und Ancistrodon piscivorus (Mocassinschlange), sowie das getrocknete Gift der indischen Cobra.

Die physikalischen Eigenschaften der Schlangengifte sind bei allen Giften fast die gleichen.

Die Farbe variirt von blass Smaragdgrün bis Orangeund Strohgelb. Auch das Gift der Surucucú soll eine grünliche Färbung haben, das der Jararacá dagegen wasserklar sein und mit Kalilauge eine carminrothe Farbe annehmen ${ }^{1}$ ). Das spezifische Gewicht des Giftes schwankt zwischen 1030 und 1077. Durch langen Aufenthalt in der Drüse wird es concentrirter. Das eingetrocknete Gift bleibt ausserordentlich lange wirksam, da es z. B. in einem Falle nach 16 jührigem, in einem anderen sogar nach 22 jührigem Aufbewahren noch nichts von seiner Giftigkeit eingebüsst hatte. Ebenso hält sich Viperngift, wenn gut verschlossen, über 18 Monate lang ${ }^{2}$ ) und war sogar noch wirksam, nachdem es mehrere Jahre in der Höhlung des Giftzahnes gewesen war. Auch selbst längere Zeit in Spiritus aufbewahrte Giftschlangen können noch gefährlich werden, wie der Fall eines Assistenten am Petersburger Museum beweist, welcher sich durch unvorsichtige Manipulation mit einer solchen Schlange eine tödtliche Verletzung durch deren Giftzahn zuzog. In Glycerinlösung bleibt das Gift lange Zeit wirksam. Wässrige Lösungen des Schlangengiftes dagegen zersetzen sich schnell und werden bald unwirksam. Das Gift ist klebrig (bei der Viper wie Harz) und trocknet sehr langsam. In völlig trockenem Zustande gleicht es getrocknetem Eiweiss und bildet es dünne, gelbe, durchscheinende Lagen. Die Krystalle, welche Me a d im Viperngift gefunden haben wollte, sind nichts Anderes als zahllose Risse, welche diese Lagen durchkreuzen. Das frische Gift

med. chir. Rev. V. p. 269-311. March 1861. - Weir Mitchell and Reichert, Researches upon the venom of poisonous serpents (Smithsonian contrib. Wash. 1886).

1) v. 'T's chudi, Reisen durch Südamerika. III. 1867.

2) Mangili, Annales de Chimie et de Physique. Florence 1817. 
ist geruch- und geschmacklos. Einige Autoren wollen allerdings einen scharfen, ätzenden Geschmack daran wahrgenommen haben. Das Gift zersetzt sich, wenn lange feucht gehalten, unter Ammoniakentwickelung und riecht dann furchtbar, ist aber auch dann häufig noch giftig:

Unter dem Mikroskope zeigt sich im frischen Gifte häufig ausser einigen Epithelzellen und Speichelkörperchen eine granulirte Masse; davon erwiesen sich bei genauerer Untersuchung die grösseren Granula als Körper von albuminoider Natur, die kleineren als Mikrokokken. Die letzteren spielen aber sicher keine Rolle in der Wirksamkeit des Giftes trotz der gegentheiligen Ansicht Lacerda's, der im Gifte von Bothrops-Arten Bacterien entdeckt zu haben glaubte ${ }^{1}$ ). Neuere Untersuchungen ${ }^{2}$ ) ergaben, dass frisches Schlangengift überhauptkeine Organismen enthält, es sei denn, dass solche aus der Mundhöhle der Schlange stammen oder durch irgend einen Zufall hineingeriethen. Krystalle, die denen der phosphorsauren Ammoniak-Magnesia ähnlich sahen, wurden im Gifte von Crotalus confluentus gefunden; sie sind aber offenbar auch nur die Folge beginnender Zersetzung des Giftes. Im getrockneten Viperngifte fehlte jede Krystallisation; es stellt eine amorphe, in Wasser völlig lösliche Substanz dar. Auch etwaigen im Gifte befindlichen Krystallen darf also kein Einfluss auf die Wirksamkeit desselben zugeschrieben werden, wie man es früher zuweilen that.

Eine $20 \%$ ige wässerige Lösung des eingetrockneten Viperngiftes soll in der Wirkung auf Thiere ganz dem ursprünglichen Gifte entsprechen ${ }^{3}$ ).

Die Reaction des Schlangengiftes ist nach Angabe der meisten Untersucher sauer; das Cobra-Gift wird jedoch von neueren Autoren ${ }^{4}$ ) für neutral erklärt.

1) La cerda, Compt. rend. de l'Acad. des sc. Déc. 1878.

${ }^{2}$ ) Fredet, Uuion méd. 'T. XXV. 1878. - M. Ka ufmann, Du venin de la vipère. Paris 1889.

${ }^{3}$ ) Karlinski, Fortschritte der Medicin. VIII. 16. 1890.

$\left.{ }^{4}\right)$ Feoktistow, Experimentelle Untersuchungen über Schlangen- 
Kilapperschlangengift beginnt bei $41^{\circ} \mathrm{C}$. zu gerinnen und ist bei $53^{\circ} \mathrm{C}$. beinahe fest; es löst sich in kaltem Wasser ohne Rückstand auf. Das Viperngift ist in absolutem Alkohol, Alkalien und Oelen gar nicht, in kaltem Wasser schlecht, in verdünntem Alkohol besser, in kochendem Wasser gut löslich ${ }^{1}$ ). Es wird durch Mineralsäuren gefällt; die Niederschläge sind im Ueberschuss des Fällungsmittels löslich; auch Tannin fällt das Gift. Mit Eisenchlorid, Silbernitrat, Platinchlorid, Eisen- und Kupfersulfat giebt es ebenfalls Niederschlïge. Dasselbe Verhalten zu den Mineralsäuren zeigt auch Klapperschlangengift; mit Essigsïure liefert letzteres keinen, mit Tannin einen dichten weissen Niederschlag, der in Wasser und im Ueberschuss der Säure unlöslich, aber in Ammoniak löslich ist. Chlorwasser bringt einen dichten Niederschlag hervor, ebenso Jodlösung und Jodkali einen solchen, der im Ueberschuss des Reagens sich auflöst. Kali und Natron haben keinen sichtbaren Einfluss auf das Gift, ebenso Ammoniak und Kalkwasser. Mit Sublimat entsteht ein dicker weisser Niederschlag. Natrium sulfuricum und Magnesium sulfuricum bringen einen voluminösen weissen Niederschlag hervor, der sich im Ueberschuss von Wasser auflöst. Alkohol bewirkt einen schweren, flockigen Niederschlag, der auch nach dem Trocknen in Wasser löslich ist.

Die Frage, welchem Bestandtheiledas Schlangengift seine Wirkung verdankt, lasst sich jetzt mit Sicherheit beantworten. Es sind nicht Mikroorganismen, welche die Giftwirkung hervorrufen. Auch die Ansicht, dass es im Schlangengift enthaltene Cyanverbindungen sein könnten, hat sich nicht bestätigt; Mitchell konnte niemals im Klapperschlangengift Rhodankalium nachweisen, dem man auch bei Bissen anderer Thiere die Giftwirkung zuschrieb. Eben so

gift. Inaug.-Diss. Dorpat 1888. - Kanthak, Journ. of the Physiol. 1892. p. 272. - Calmette, Annales de l'institut Pasteur. 1892. IX. p. 168.

$\left.{ }^{1}\right)$ L e Gage, Journ. de Chim. méd. 5. sér. IV. Avril 1868. 
wenig bilden Alkaloide das wirksame Prinzip in Schlangengift. Die vermeintlichen Alkaloide Najin und Elaphin, die Gautier ${ }^{1}$ ) im Naja-Gifte entdeckt haben wollte, sind nichts anderes als Zersetzungsproducte.

Das Schlangengift ist eine Eiweisssubstanz. Im Klapperschlangengift sind wenigstens zwei eiweissartige Substanzen, eine, die sowohl durch Kochen als auch durch Alkohol gerinnt, und eine, die nur durch Alkohol coagulirt wird, neutral reagirt und das eigentlich wirksame Prinzip des Giftes bildet. Mitchell nannte diese letztere Substanz Crotalin. Schon früher hatte Prinz Lucien Bonaparte, der übrigens im Jahre 184:) überhaupt die erste chemische Untersuchung von grösserem Werte, die bis dahin über Schlangengift gemacht war, anstellte, aus dem Viperngift durch Alkoholbehandlung als wirksames Prinzip das Viperin oder Echidnin dargestellt.

Bei den späteren gemeinsam mit Reichert angestellten, den neuesten Anschaunngen nicht mehr ganz entsprechenden, aber doch erwähnenswerthen Versuchen Mitchell's zeigte es sich, dass die eiweissartigen Substanzen im Schlangengift den Charakter der Globuline und Peptone haben. Es gelang ihnen, drei Arten von giftigen Globulinen zu isoliren:

1. Ein Globulin, das durch starke Verdünuung des Giftes mit Wasser fällbar war und dem Myosin im Verhalten gegen Salzlösungen sehr ähnlich sah.

2. Ein Globulin, das im Filtrat des vorigen durch Kupfersulfat gefällt wurde.

3. Ein Globulin, das durch Dialyse abscheidbar war.

Das Filtrat von diesem letzten Globulinkörper coagulirte nicht mehr beim Kochen, gab aber noch alle Farbenreactionen der Eiweisskörper. Mitchell und Reichert nannten diesen Körper "Giftpepton". Das relative Verhältniss zwischen Globulin und Pepton ist je nach der Schlangenart verschieden. So enthält das getrocknete Gift der Klapperschlange ca. $24^{\circ} \mathrm{n}$

1) Gautier, Buil. de l'Acad. de méd. 2. sér. X. p. 950. 1881. 
Globulin und $75 \%$ Pepton, das der Mocassinschlange ca. $8 \%$ Globulin und $92 \%$ Pepton.

Ausser diesen Eiweisskörpern sind nach MitchellReichert's Untersuchungen im Schlangengift noch vorhanden: ein Farbstoff, Spuren von Fett und Salze, besonders Chloride und Phosphate.

Die chemische Zusammensetzung des Giftes bei den anderen Schlangenarten, namentlich bei den indischen und europäischen, ist im Wesentlichen eine ähnliche wie die bei dem Gifte der amerikanischen Schlangen.

Ueberall bilden Eiweisskörper, die sogenannten Toxalbumine, die wirksame giftige Substanz. Zwar behaupten einige Autoren, dass im Schlangengift, speziell in dem der Brillenschlange, P tomaine enthalten seien ${ }^{1}$ ), indessen fehlen im frischen Gifte Ptomaïne ebenso wie auch Alkaloide gänzlich. Die Wirkung des Giftes der Brillenschlange beruht auch nicht auf Cobrasiuure (die vermeintlichen Krystalle, denen der Name Cobrasäure gegeben wurde, bestehen ans Gyps), sondern auf der Gegenwart folgender Eiweisskörper $\left.{ }^{2}\right)$ :

1. Globulin. Es ist immer vorhanden und wirkt tödtlich durch Asphyxie.

2. Syntonin, das durch Magnesiumsulfat zusammen mit dem Globulin gefïllt wird. Es dialysirt in gewissem Grade durch Pergamentpapier. Die giftige Wirkung des sauren Dialysates beruht auf diesem Eiweisskörper, der aber weniger stark wirkt als Globulin.

3. Serum-Albumin, das ebenfalls giftig ist und Apoplexie bewirkt.

t. In einigen Proben zeigten sich Spuren von Hemialbumose und zweifelhafte Spuren von Pepton; letztere sind wohl als zufällig zu betrachten.

Das Gift der indischen Viper (Daboia Russelii) enthält:

1) Fayrer, Med. Times and Gaz. Febr. 2. 1884.

$\left.{ }^{2}\right)$ Wolfenden, Journ. of physiol. VII. 327. 
1. Globulin, das mehr vorherrscht als im Cobra-Gift.

2. Serum-Albumin in kleiner Menge.

3. Einen Eiweisskörper, der viele Eigenschaften einer Albumose besitzt.

Wahre Peptone kommen darin nicht vor, und wahrscheinlich waren auch die von Weir Mitchell und Reichert als Peptone bezeichneten Substanzen in den Giften der amerikanischen Schlangen in Wirklichkeit Albumosen.

Auch das Cobra-Gift soll als wirksamen Bestandtheil eine Albumose (Protoalbumose) enthalten, welche dieselbe toxische Wirkung hat wie das Gift selbst ${ }^{1}$ ); ausser dieser ist wahrscheinlich noch eine Heteroalbumose darin vorhanden.

Das Globulin Mitchell's ist vielleicht nichts Anderes als ein Gemisch von Heteroalbumose und Dysalbuminose und entsteht nur secundär nach gewissen Manipulationen in Schlangengifte. So scheint andauerndes Erhitzen die Protoalbumose in jene beiden Körper zu zerlegen, die wohl harmlos sind.

Auch in dem Gifte der australischen Schlange Pseudechis porphyriacus sind die einzigen giftigen Bestandtheile primäre Albumosen ${ }^{2}$ ).

Das Gift der europäischen Giftschlangen soll enthalten ${ }^{3}$ ):

1. Eine Art Ptyalin (nach Lucien Bonaparte "Viperin" oder "Echidnin").

2. Albumin und Schleim.

3. Eine in Alkohol lösliche Substanz.

4. Gelben Farbstoff.

5. Fett.

6. Chlorüre und Phosphate wie der Speichel (kein Rhodankalium).

1) Kanthack, Journ. of Physiol. XIII. 3 and 4. p. 272. 1892.

$\left.{ }^{2}\right)$ C. F. Martin, Jonrn. of Physiol. XV. 1893. p. 380.

3) Le Gage, Journ. de Chim, méd. 5. sér. IV. p. 178. Avril 1868. 
Das Viperin stellt dem Tannin ähnliche Schüppchen dar, es enthält Stickstoff, reagirt neutral, färbt Kupferoxydhydrat violett und wird von Bleiessig nicht gefällt; es ist geschmacklos. Man gewinnt es durch Alkoholbehandlung aus dem Schlangengift. Es entspricht offeubar ganz dem Crotalin Mitchell's und besteit aus mehreren, wahrscheinlich den Eiweisskörpern verwandten Substanzen ${ }^{1}$ ).

Aus allen Untersuchungen ergiebt sich also das Eine mit Sicherheit, dass das Gift sowohl der europäischen als auch der ausländischen Giftschlangen als wirksames Prinzip Eiweissstoffe enthält. Welcher Art dieselben sind, ist als noch nicht definitiv festgestellt $\mathrm{zu}$ betrachten.

Es dürfte interessiren, an dieser Stelle darauf hinzuweisen, dass merkwürdigerweise auch in einer Pflanze, nämlich in den Samen von Abrus precatorius, dem bekannten Jequirity, ein Stoft, das Abrin, enthalten ist, welcher ebenso wie clas Schlangengift ans zwei Eiweisskörpern besteht, von denen der eine zu den Globulinen gehört, wïhrend der andere eine Albuminose ist. Er erzeugt, wie auch Schlangengift häufig, bei subcutaner Injection Gastroenteritis mit hlutigen Ausleerungen. Diese Aehnlichkeit des Abrins mit dem Schlangengifte dürfte vielleicht noch einmal für die Therapie des Schlangenbisses Bedeutung erlangen.

Unschädlichwerden des Schlangengiftes.

Die Gifte der amerikanischen Schlangen ertragen im getrockneten Zustande eine Temperatur von $110^{\circ}$ C. 30 Minnten lang, olne eine Abschwächung ihrer Wirkung zu erleiden. In wässrigen Lösungen bis zu $76,5^{\prime \prime} \mathrm{C}$. erhitzt, erfährt das Gift von Crotalus adamantinus eine beträchtliche Schwïchung. Bei den peptonreicheren Giften anderer Schlangen (z. B. der Hocassinschlange) ist die Abschwächung durch Kochen lange nicht so energisch. Bei nur 10 Minuten langem Kochen

1) M. Kaufmann 1. c. 
wirkt das Gift oft noch sehr stark. Das Gift der Lanzenschlange wird zerstört, wenn man es eine Minute lang auf $100^{n}$ erhitzt. Von den indischen Schlangengiften wird das der Daboia durch Erwärmen auf $80^{\circ}$ unwirksam, Cobra-Gift dagegen nach Fayrer noch nicht ganz bei einstündigem Erhitzen auf $107^{\circ}$, wohl aber bei zweistündigem.

Calmette ${ }^{1}$ ) jedoch fand, dass schon 20 Minuten langes Erhitzen auf $98^{\circ}$ die Virulenz des Cobra-Giftes zerstörte, während auf $90^{\circ}$ erhitztes Gift bereits nicht mehr local entzündend wirkte. Das Gift von Hoplocephalus curtus verliert seine toxischen Wirkungen erst, wenn man es mindestens 15 Minuten lang bei $100-102^{\circ}$ erhitzt, das von Pseudechis porphyricus bei $99-100^{\circ}$, das der Kreuzotter bei $95-97^{\circ}$ oder bei noch geringeren Hitzegraden. Die Resistenz der einzelnen Gifte gegen Hitze ist also verschieden, und selbst das Gift einer bestimmten Schlangenart verhält sich in dieser Hinsicht nicht immer gleich.

Wenn man Viperngift 20-25 Secunden lang sieden, dann wieder erkalten lässt und es nun Thieren einimpft, so zeigt es sich, dass jetzt keine örtlichen Erscheinungen mehr auftreten und die Allgemeinsymptome schwächer sind als nach Einimpfung eines nicht in dieser Weise behandelten Giftes. Auch bewirkt erhitrtes Gift Erhöhung der Temperatur, während nicht erhitztes diese meist erniedrigt. Vielleicht sind zwei verschieden wirkende toxische Substanzen im Gifte enthalten, eine entzündungserregende („Echidnase“), die durch Hitze zerstört wird, und eine allgemein wirkende, und Hypothermie verursachende ("Echidnotorin"), welche durch Erhitzen nicht zerstört wird ${ }^{2}$ ).

Hohe Kältegrade (bis zu- $15^{\circ} \mathrm{C}$.) und selbst wochenlanges Gefrierenlassen vermögen die Wirkung des Schlangengiftes nicht $\mathrm{zu}$ schädigen.

1) Calmette, Annales de l'institut Pasteur. 1892. IX. p. 160. 1894. p. 275.

2) $\mathrm{Ph}$ is alix et Bertrand, Compt. rend. de l'Acad. des sciences. T. CXVIII. 1894. p. 288.

Brenuing, Die Vergiftungen durch Schlangen. 
Von chemischen Mitteln vermögen Alkohol, Terpentinöl, Silbernitrat, Ammoniak, Kali oder Natron die Wirkungen des Klapperschlangengiftes weder zu alteriren noch aufzuheben, wenn nicht diese Reagentien von ätzender Stärke sind. Eben so wenig zerstören Mineralsüuren, Chlorwasser oder Jod das Gift. Dagegen wird dasselbe durch Pepsin oder Trypsin seiner Giftigkeit beraubt.

Bei Filtration durch Thierkohle werden die giftigen Eiweisskörper durch diese zurückgehalten; das eiweissfreie Filtrat ist ungiftig.

Cobra-Gift wird schon nach 5-10 Minuten durch $10 \%$ ige Kali- oder Natronlange wirkungslos, bei längerer Einwirkung auch durch Chlorwasser, Jodtrichlorid, Kaliumpermanganat; weniger wirksam sind Carbolsäure und Pankreatin. Silbernitrat, Sublimat, Gerbsäure, Alkohol heben die Wirkung dadurch auf, dass sie die Albumose fällen; ziemlich wenig wirksam sind Citronensäure, Pepsin und selbst das so oft als eines der besten Mittel gegen Schlangenbiss empfoblene Ammoniak.

Es scheint demnach, als ob das Gift der Brillenschlange weniger widerstandsfähig gegen Chemikalien ist als das der Klapperschlange. 


\section{Die Wirkung des Schlangengiftes und die Symptomatologie der Vergiftung.}

Es lässt sich denken, dass bei der Jahrtausende alten Geschichte der Vergiftungen durch Schlangengift, entsprechend der Zeitbildung und der individuellen Schärfe der Auffassung, die verschiedenartigsten Ansichten über die Wirkung des Schlangengiftes zu Tage getreten sind.

Im Alterthume finden wir neben einzelnen wahren die übertriebensten und vom krassesten Aberglauben beeinflussten Vorstellungen über die Symptome des Schlangenbisses verbreitet. So sagt Aristoteles, wer von der Hyder gestochen sei, gebe sogleich einen üblen Geruch von sich, Vergessenheit überfalle ihn, und tiefe Dunkelheit verbreite sich über seine Augen, Wahnsinn folge darauf und heftiges Zittern; am dritten Tage sterbe er.

Der Biss der Aspides tödtet nach Plinius ${ }^{1}$ ) durch Schlaf und Erstarrung. Wenn das Gift in eine alte Wunde komme, so tödte es nicht so schnell; verschluckt schade es nicht. Eine Schlange soll überhaupt nur giftig sein, wenn sie in dem laufenden Monat durch Einwirkung des Mondes aufgereizt sei. Nach Dioskorides schwillt beim Vipernbiss der ganze Körper an; dann folgen Schaudern, Frost, Stupor, Schwere des Kopfes, galliges Erbrechen, Schluchzen, Fieber, Athemnoth, zuweilen Gelbsucht. Die Ge-

1) Plinius, Hist. nat. 28, 42. 
bissenen seien bald blass, bald grün, bald gelb, je nach ihrem Temperament; bei den Biliösen ergiesse sich die Galle in das Blut und es entstehe bleiche und gelbe, bei den Melancholikern grüne und,schwarze Färbung. Am gefährlichsten sei der Biss in nüchternem Zustande und von einer nüchternen Schlange, im Sommer bei grosser Hitze, und wenn die Schlange gereizt sei. Der Tod erfolge sicher, wenn Synkope eintritt, Blut aus der Nase fliesst, die Lippen grünlich, die Nägel kalt werden und der ganze Leib zittert, und zwar meist innerhalb sieben Stunden, selten noch am dritten Tage. Durch den Biss der Hornviper sollen an der verwundeten Stelle eine harte Geschwulst und Pusteln entstehen; es erscheine daselbst eine bald schwarze, bald gelbliche Jauche, und der ganze Körper werde dunkelgelb. Der Tod trete unter Ohnmachten und Convulsionen ein.

Galen ${ }^{1}$ ) erzählt, dass denjenigen, der von der Dipsas gebissen ist, ein brennender Durst befalle; er müsse unaufhörlich trinken, bis er zerplatze. Auch Nikander und A elian sprechen von dieser Wirkung des Dipsas-Bisses.

Nach Aelian soll die Libysche Aspis den, der sich ihrem Anhauche aussetat, wenn sie den Hals aufbläst, der Sehkraft berauben. Die indische Purpurschlange soll nicht beissen, sondern speien und bewirken, dass die getroffenen Glieder abfatulen. Sie soll zwei Arten von Gift haben, ein bernsteinartiges und ein schwarzes. Wer das erstere verschluckt, den ergreift zuerst ein heftiger Krampf, dann verdreht er die Augen, das Gehirn fliesst ihm durch die Nase herab, und er stirbt je nach der Menge des Giftes schnell oder nach einiger Zeit. Nimmt er von dem schwarzen Gift aus der todten Schlange, so fängt er an zu eitern und stirbt nach einem bis zwei Jahren an der Auszehrung. Nach dem Biss der Natter soll Sticken, Krampf und Schluchzen eintreten. Wer eine Wasserschlange berühre, sterbe ohne Biss durch die faulende Kraft derselben. Das Gift der Aspis bleibe nicht

1) Galen, Theriaca ad Pis. c. 8. 
oben, sondern schleiche in die inneren Gänge hinab; es tödte, wenn man es aussaugt, ohne Wasser nachzutrinken, und zwar ohne Schmerz, indem es ganz unvermerkt Zahnfleisch und Mund verzehre (auch Plutarch ${ }^{1}$ ) sagt, der Biss der Aspis sei nicht schmerzhaft, sondern mild). Die von der Echis Gebissenen sollen Zuckungen bekommen, nicht aber die von der Echidna Gebissenen. Die Bissstelle der Echidna soll weiss, die der Echis schwarzblau sein, und die des Hämorrhus sofort blau werden. Der Gebissene bekomme Herzweh und profuse Diarrhöe. In der ersten Nacht fliesse Blut aus $\mathrm{Nase}$, Hals und Ohren mit einem galligen Gifte. D er Urin sei blutig. Alte Narben brächen auf. War der Haemorrhus ein weibliches Exemplar, so komme Blut aus den Fingernägeln, und das Gift verbreite sich in das Zahnfleisch, wobei sich viel Blut ergiesse und die Zähne ausfielen. Die Bisswunde des Sepedon fresse um sich und faule nach unten; das Gift dringe durch den ganzen Körper mit grosser Schnelligkeit. Selbst das Haar faule weg und schwinde, Augenbrauen und Wimpern fielen aus, Dunkel bedecke die Augen und diese bekämen Flecken. Das Gift der Schlange Seps verursache sogleich Fäulniss und tödte schnell. In Indien soll es geflügelte Schlangen geben, deren Urin, wenn er auf den Leib fällt, Fäulniss verursache. Der Biss der Schlange Prester mache träge und schwer beweglich, dann vergesslich und schwer athmend, er hemme die Urinentleerung, die Haare fallen aus, und es folgen Sticken, Krampf und Tod.

Bedeutende Fortschritte in der Auffassung und Darstellung der Symptomatologie sind in späteren Jahrhunderten zu beobachten, wenn wir auch hier noch manche übertriebene Berichte in Folge des weit verbreiteten Aberglaubens verzeichnet finden. Um nur eins zu erwähnen, so glaubte man noch bis weit in die Neuzeit hinein fest an die sogen. Fascinationskraft der Schlangen, vermöge welcher sie im Stande sein sollten, durch ihren Blick nicht nur Thiere, son-

1) Plutarch, Vit. Anton. c. 71. 
dern auch Nenschen zu bezaubern und fest an den Boden zu bannen, so dass sie unfähig wären, zu entfliehen.

Manche Autoren indessen liefern uns bereits ziemlich objective und der Wahrheit entsprechende Schilderungen.

So führt Gessner als Symptome des Schlangenbisses an: hitriges Fieber, Unruhe, Erstarrung oder Erschlaffung des ganzen Leibes, Unempfindlichkeit desselben, heftige Schmerzen an der Wunde, Röthung oder Schwarz- und Blaufärbung des gebissenen Gliedes.

Nach Mercurialis bewirken die Aspides Gesichtsstörung, Gesichtsschwellung, geringen Schmerz, Taubheit, andere Schlangen dagegen Stupor, Blïsse, Herzklopfen, Frost und läufiges Gähnen. Das Herz scheine am ersten afficirt zu werden, dann Leber und Gehirn. Die Vipern sollen Blntungen und einen Tumor hervorrufen, der erst roth, dam schwarz oder grün werde.

Selbstverständlich lag es nahe, um bindende Schlüsse bezuiglich der Angriffspunkte des Giftes an Organen und Organfunctionen zu erlangen, das Verhalten der Thiere für eine solche Erkenntniss mit heranzuziehen.

Hier wurden Ergebnisse gezeitigt, denen eine allgemeinere Bedeutung zuzuschreiben ist.

Die interessanteste Frage auf diesem Gebiete war zweifellos die, wie sich Giftschlangen selbst gegen ihr eigenes Gift oder das anderer Species verhielten.

Hier sind nun die widersprechendsten Ansichten zu Tage getreten, und es scheint, dass die einzelnen Schlangenarten in dieser Hinsicht Unterschiede aufweisen. Nach einigen Beobachtungen sollen Giftschlangen durch ihre eigenen Bisse sterben, nach anderen dagegen nicht. Die Klapperschlangen starben bei den Versuchen Weir Mitchell's alle ausser einer einzigen durch ihre eigenen Bisse.

Ebenso gehen Lanzenschlangen zu Grunde, wenn man ibnen ihr eigenes Gift einspritzt ${ }^{1}$ ). Dagegen ist die Brillen-

$\left.{ }^{1}\right)$ 'Tricard, Arch. de méd. navale. LXI. 1894. p. 357. 
schlange immun gegen Injection von $2 \mathrm{cg}$ ihres Giftes ${ }^{1}$ ), und auch die Kreuzotter scheint gegen ihr eigenes Gift unempfindlich zu sein ${ }^{2}$ ). Nach noch nicht veröffentlichten Untersuchungen von L. Lewin trifft dies letztere selbst für mehrere tagsüber veranlasste Selbstbisse zu; doch schien ihm die Schlange danach einen auffallenden Zustand von Erschlaffung; die an Muskelschwäche erinnerte, aufzuweisen. Gegenseitige Bisse von Giftschlangen, die ein und derselben Art angehören, sollen in der Regel ohne Einfluss auf die Schlangen sein, wenigstens wird dies von verschiedenen Vipern Europas und Afrikas, sowie auch von Trigonocephalus piscivorus und den ostindischen Giftschlangen behauptet. Auch hierbei konnte Lewin feststellen, dass wenige Bisse, die eine Kreuzotter der anderen versetzte, scheinbar wirkungslos waren, dass aber eine grössere Zahl das gebissene Thier allgemeine Befindensänderung aufweisen liess. Dass sich dagegen Giftschlangen verschiedener Art gegenseitig tödten können, ist sicher constatirt. So sah man z. B. durch den Biss der Brillenschlange andere Giftschlangen sterben ${ }^{3}$ ). Indessen sollen nach Fayrer Giftschlangen auch gegen Bisse anderer Arten relativ wenig empfindlich sein, und nur selten soll eine Cobra oder eine Daboia einen Bungarus coeruleus tödten und umgekehrt. Nur Bungarus fasciatus zeigt eine starke Empfänglichkeit gegen Cobra-Gift.

In Bezug auf die nicht giftigen Schlangen ist im Allgemeinen die Ansicht verbreitet, dass sich dieselben den Giftschlangen gegenüber wie alle anderen Thiere verhalten, also durch sie getödtet werden. Neuere Untersuchungen anf diesem Gebiete haben aber das interessante Resultat geliefert, dass auch manche von den zu den giftlosen Schlangen gerechnete Arten gegen Viperngift immun sind. Schon Fontana hatte die Beobachtung gemacht, dass Ringelnattern

1) Calmette, Compt. rend. de la soc. de biol. 9. sér. T. VI. 1894. p. 11.

$\left.{ }^{2}\right)$ L en z, Schlangenkunde. 1832.

3) Russe11, Account of Indian serpents. 1796. p. 56. 
ohne Gefahr zahllose Bisse der Viper, sowie auch Einimpfungen von deren Gifte vertragen. In letzter Zeit wurden nun diese Versuche von französischen Forschern ${ }^{1}$ ) wiederholt, und es zeigte sich dabei, dass eine Ringelnatter (Tropidonotus natrix) von $50 \mathrm{~cm}$ Länge eine intraperitoneale Injection von $5 \mathrm{mg}$ trockenen Viperngiftes ertrug, eine Dosis, welche 15-20 Meerschweinchen zu tödten vermag. Ausser Tropidonotus natrix sollen auch T. viperinus, Elaphis Aesculapii, Coronella laevis und Rhinechis scalaris gegen Viperngift immun sein ${ }^{2}$ ).

Eine Erklürung dieser wunderbaren natürlichen Immunität giftiger und nicht giftiger Schlangen gegen das Gift der ersteren hat man dadurch zu geben versucht, dass man auch bei letzteren die Existenz eines Giftapparates und eine nahe Beziehung des Giftes zu dem Blute annahm. Wie Claude Bernard für die Leber ein gewisses Verhältniss ihres Secretes zu der Zusammensetzung des Blutes nachgewiesen hat, so ist es auch möglich, dass die wirksamen Stoffe des Schlangengiftes von den Giftdrüsen aus durch ,interne Secretion" derselben in das Blut gelangen, mit diesem den ganzen Organismus imprägniren und so eine Gewöhnung des letzteren an selbst grössere Giftdosen bedingen. Verschiedene Beobachtungen scheinen auch in der That darauf hinzuweisen, dass sich im Blute der Schlangen toxische Substanzen befinden, welche denen des giftigen Drüsensecretes analog sind. So scheint das Blut der Brillenschlange in hohem Grade giftig zu sein; $2 \mathrm{ccm}$ frischen Cobrablutes, in die Banchhöhle eines Kaninchens von $1^{1 / 2} \mathrm{~kg}$ eingespritzt, tödten dasselbe in sechs Stunden; spritzt man eine gleiche Dosis defibrinirten Cobrablutes einem Kaninchen in eine Vene, so tritt der Tod schon in drei Minuten ein. Bei subcutaner Blutinjection sind die auftretenden Vergiftungssymptome dieselben,

1) Phisalix et Bertrand, Arch. de physiol. 5. sér. T. VI. 2. 1894. p. 423.

$\left.{ }^{2}\right)$ Jourdain, Compt. rend, de l'Acad, des sciences. 'T. CXVIII. 1894. p. 207. 
wie bei Injection reinen Giftes. Für Frösche, Fische und eine kleine ungiftige Natternart zeigt sich das Cobrablut nicht giftig; diese Thiere sind übrigens auch gegen Cobragift selbst wenig empfindlich ${ }^{1}$ ). Aehnliche Erfahrungen wie mit dem Blute der Cobra hat man auch mit dem der Viper gemacht.

Besonders erwähnenswerth sind Versuche mit dem Blute der Ringelnatter. Spritzt man $3 / 4 \mathrm{ccm}$ Blutserum von Tropidonotus natrix oder $T$. viperinus Meerschweinchen ein, so erfolgt der Tod in weniger als sechs Stunden unter den gleichen Symptomen wie nach Viperngift. Dieselbe Wirkung würden etwa $3 / 10 \mathrm{mg}$ trockenen Viperngiftes haben. Im Blute der Natter scheint also eine wenigstens ebenso grosse Menge analoger toxischer Substanzen vorhanden zu sein, wie in dem der Viper. Es hat sich nun weiter herausgestellt, dass die Oberlippendrïsen der Ringelnatter ein sehr actives Gift absondern, dessen Eigenschaften ganz den im Blute derselben befindlichen toxischen Substanzen entsprechen. Wenn man z. B. einen Auszug aus diesen Drüsen einem Sperling unter die Haut bringt, so stirbt dieser unter unzweifelhaften Vergiftungssymptomen ${ }^{2}$ ). Alle anderen Organe der Natter, namentlich auch die unteren Speicheldrïsen, sind dagegen ungiftig. Aus diesen Versuchen kann man schliessen, dass, ähnlich wie bei den eigentlichen Giftschlangen die toxischen Substanzen aus den Giftdrüsen in das Blut gelangen, so auch bei den Nattern und anderen nicht zu den giftigen gezählten Schlangen Giftstoffe aus den Oberlippendrüsen durch „interne Secretion" derselben vom Blute aufgenommen werden und so auch diesen Schlangen Immunität gegen das Viperngift verleihen. Wie weit sich diese Immunität auch gegen Gifte anderer Schlangen erstreckt, scheint noch nicht untersucht worden zu sein.

Die übrigen Reptilien, sowie auch die Amphibien, 1894. p. 11.

$\left.{ }^{1}\right)$ Calmette, Compt. rend. de la soc. de biol. 9. sér. T. VI. $\left.{ }^{2}\right)$ B lanchard, Compt. rend. de la soc. de biol. 9. sér. 1894. p. 35. 
Fische und die wirbellosen Thiere hielt man früher nach den negativ ansgefallenen Versuchen Fontana's für völlig unempfindlich gegen Schlangengift. Indessen hat es sich doch gezeigt, dass das Gift der Kreuzotter wenigstens für Blindschleichen, Eidechsen, Salamander und Frösche tödtlich ist. Trotzdem kam man allgemein sagen, dass Kaltblüter weniger durch Schlangengift afficirt werden, und dass der Tod in der Regel langsamer bei ihnen eintritt als bei Warmblütern. Von letzteren sind Vögel am empfindlichsten. So starben Tauben oft schon wenige Minuten nach dem Biss. Je kleiner ein Thier ist, desto empfindlicher pflegt es in der Regel gegen Schlangengift zu sein. Was die Süugethiere betrifft, so ist es bekanntlich ein weit verbreiteter Glaube, dass dem Igel die Bisse der Kreuzotter nicht schaden, und auch Lenz behauptet, dass Igel und Iltisse durch Kreuzotterbisse nicht afficirt würden. Indessen hat es sich jetzt doch herausgestellt, dass künstliche Inoculation des Giftes für Igel tödtlich ist, und auch Herr Professor Lewin sah zwei Igel, welche er, den einen in der Aethernarkose, durch Kreuzottern in die Schnanze heissen liess, nach einem kurzen Stadium der Erregung unter soporösen Erscheinungen in fünf resp. neun Tagen zu Grunde gehen. Der Igel ist also wohl sicher nicht immun gegen Schlangengift. Aehnliche Immunität schrieb man früher dem wilden Schweine, dem Mungo, dem Ichneumon und anderen Thieren zu; doch bei allen ist die vermeintliche natürliche Immunitait wohl nur durch äussere Umstände bedingt, welche, wie beim Igel die Stacheln, beim Schweine die dicke Haut, ein Eindringen der Giftzähne in blutfïhrende Theile erschweren. Ganz junge Säugethiere sind infolge der geringeren Entwickelung der Nervencentren weniger empfindlich. Auch wirbellose Thiere sind, so weit sie ein Nervensystem besitzen, nicht unempfänglich für Schlangengift.

Die Gefahr, welche der Schlangenbiss dem Menschen bringt, wird im Allgemeinen sehr überschätzt. An dem Biss der europäischen Giftschlangen sterben nur sehr wenige Men- 
schen, und auch von den von der Klapperschlange Gebissenen sollen nach Mitchell 7/8 von selbst genesen.

Gefährlicher ist jedoch der Biss südamerikanischer und ostindischer Schlangen, von denen manche Arten durch ihren Biss fast immer den Tod herbeiführen.

Schon Celsus, Plinius und Galen wussten, dass Schlangengift nur dann schadet, wenn es, wie beim Bisse der Schlangen, in Wunden gelangt, dass es aber, wenn innerlich genommen, unschädlich ist. Verschiedene Untersucher haben dies später durch Thierversuche und Versuche an sich selbst bewiesen.

Das Gift wird also von der unverletzten Schleimhaut des Magendarmcanals entweder gar nicht oder doch so langsam resorbirt, dass meistens keine Vergiftung erfolgt.

Nach Mitchell-Reichert tritt eine Resorption des Klapperschlangengiftes im Magen nur in den Zwischenpausen der Verdauung, aber nie während derselben ein, da es, wie schon erwähnt, durch Pepsin zerstört wird. Dagegen ist constatirt worden, dass Najagift selbst bei 48stündiger Vermischung mit Magensaft nicht nur nicht zerstört wird, sondern dass sich bei Thierversuchen seine Wirkung dadurch sogar um das Doppelte des Normalen verstürkt zeigte ${ }^{1}$ ). Für die Naja und für die ostindischen Schlangen überhaupt wurde die Wirksamkeit des Giftes sowohl vom Magen als von der Conjunctiva aus bestimmt nachgewiesen.

Ein Arzt, dem etwas Najagift ins Auge gekommen war, bekam eine heftige Entzündung und Augenschwäche ${ }^{2}$ ). Auch in älteren Krankengeschichten findet sich Augenentzündung und Blindheit als Folge des Hineingerathens von Schlangengift ins Auge.

Wenn aber behauptet wird, dass es gefährlich sei, Schlangenbisswunden auszusaugen, weil das Gift, auch wenn in den Mund gelangt, rasch resorbirt werde, so haben wahrschein-

$\left.{ }^{1}\right)$ Gautier, Bull. de l'Acad. de méd. 2. sér. X. p. 950. 1881.

2) Fayrer, Med. Times and Gazette. Febr. 2. 1884. 
lich in den betreffenden Fällen kleine, nicht wahrnehmbare Verletzungen der Mund- oder Rachenschleimhaut vorgelegen.

Auch Calmette sah keine Resorption vom Verdauungscanal aus eintreten.

Ein Forscher ${ }^{1}$ ) hat sogar von Vipern gebissenen Tauben wiederholt die Wunden ohne Nachtheil ausgesogen, obgleich er blutendes Zahnfleisch hatte, und uach $\mathrm{Husemann}$ können selbst grössere Giftinengen ohne Nachtheil verschluckt werden. Dagegen ist eine Absorption des Giftes von der Trachea, den Bronchien und der Lunge aus möglich; denn zwei Tauben, denen man Gift durch die Glottis in die Bronchien einbrachte, starben, und ihre Lungen zeigten Blutextravasate. Ferner beobachtete man, dass ein Hund sogar starb, als ihm etwas Brillenschlangengift auf die Oberfläche des Gehörorganes gebracht worden war $^{2}$ ).

Das Gift wird bei Fröschen auch von der unverletzten Haut, bei Warmbliitern vom Peritoneum aus, jedoch langsam, resorbirt ${ }^{3}$ ).

Oertliche Symptome nach dem Schlangenbiss.

Dieselben sind bei den verschiedensten Giftschlangenarten im Wesentlichen die gleichen.

Zunächst folgt auf den Biss in der Regel sogleich ein heftiger stechender Schmerz an der Bissstelle, welcher allmählich an Intensität zunimmt. Alsbald entsteht an dem betreffenden Theile fast stets eine Anschwellung, welche sich häufig schon in sehr kurzer Zeit nicht nur über das ganze gebissene Glied, sondern auch, je nach der Stelle des Bisses, auf Schulter, Hals, Kopf, Zunge, oder auf den Unterleib, in manchen Fällen sogar über den ganzen Körper aus-

1) Viaud Grand-Marais, Gaz. des Hôpitaux. 26. 1870.

${ }^{2}$ Bellanger, Journ. de Chimie méd. III. 590.

3) Feoktistow 1.c. 
breitet. In zwei Fällen barsten die Hautvenen des gebissenen und stark angeschwollenen Gliedes an mehreren Stellen ${ }^{1}$ ).

Auch die L y mphdrüsen und $L$ y $m p h$ gefüsse pflegen mehr oder weniger stark geschwollen zu sein. Während die Bisswunde selbst sich bald bleigrau färbt, nimmt die Umgebung derselben und oft das ganze Glied entweder eine blasse oder häufiger eine blaurothe Färbung an und ist dabei eigenthümlich glänzend und gespannt. Die Lymphgefässe machen sich oft als dunklere, zuweilen fast bleifarbene Streifen besonders bemerkbar. Die Bisswunde ist in der Regel so klein, dass eine Blutung aus derselben entweder ganz fehlt oder doch nur sehr unbedeutend ist; in ihrer Umgebung entsteht eine heftige Entzündung aller Weichtheile, die sich rasch centralwärts, besonders längs der Lymphgefässe, ausbreitet und sich bis zur intensivsten, das ganze Glied einnehmenden eitrigen Phl e g m on e steigern kann. Oeffnungen und Fistelgänge bilden sich, und mitunter bedecken brandartige Blasen nicht nur die Umgebung der Bissstelle, sondern auch das ganze Glied, das in manchen Fällen steinhart, völlig unbeweglich und bei der geringsten Berührung enorm schmerzhaft ist.

Aus gemachten Einschnitten entleert sich dann weniger Blut als iubelriechende, schleimartige, gelbliche Flüssigkeit. Einige Beobachter nahmen an der Bissstelle ein Knistern, herrührend von Gasansammlung im Unterhautgewebe, wahr. Zuweilen geht der Schmerzhaftigkeit eine Gefïhllosigkeit um die Wunde herum voraus. In seltenen Fällen verfällt das ganze Glied dem Brande.

Von diesen Symptomen sind natürlich in der Regel nur einzelne vorhanden; Schmerz, Schwellung und Verfärbung pflegen jedoch nie zu fehlen.

S. 271.

1) Rengger, Meckel's Archiv f. Anatomie u. Physiologie. 1829. 
Resorptive Vergiftungsymptome.

Neben lokalen Symptomen liommen nun noch eine lieihe von Allgemeinwirkungen zur Beobachtung. Dieselben erscheinen schon sehr früh, meistens bereits nach einigen Minuten. Dahin gehören eine eigenthümliche Beängstigung mid Unruhe, Schwindel, Eingenommensein des Kopfes, Kopfschmerzen, Uebelkeit, Erbrechen, zuweilen von grün gefürbtem Wasser oder von Blut, kaltes Schaudern, Fieber, heftiger Durst, Durchfall oder Verstopfung ${ }^{1}$ ), in schweren Fällen Schluchzen, unwillkürliches Stöhnen und Gelbsucht. Fast stets macht sich eine mehr oder weniger grosse Schwäche bemerkbar. Das Gesicht ist eingefallen, blass oder livide und ebenso wie der ganze Körper mit kaltem, klebrigem Schweisse bedeckt. An Stelle des letzteren tritt mitunter nach einiger Zeit ein warmer Schweiss, den man, jedoch mit Unrecht, als Krisis angesehen hat. Zuweilen ist dagegen auch die Haut völlig trocken. Die Augen sind starr und glänzend oder matt und trübe und in die Höhlen zurückgesunken, die Pupillen dilatirt, seltener verengt und reactionslos, die Extremitiiten fïhlen sich kalt an, der Puls ist zuweilen so schwach, dass er kaum fühlbar ist, dabei meist beschleunigt und unregelmässig. Die Athmung ist erschwert und ebenfalls beschleunigt. Die Zunge ist häufig mit gelben Massen belegt. Zuweilen beobachtet man auch copiöse Harnentleerungen, während in rler Regel die Harnmenge, entsprechend der Herabsetzung des Blutdruckes, eher vermindert zu sein scheint. Der Harn enthält in einigen Fällen Eiweiss.

Von Störungen der Empfindung stellt sich, abgesehen von der Schmerzhaftigkeit resp. Gefühllosigkeit an der Bissstelle und in dem betroffenen Gliede, in manchen Fällen Reissen und Ziehen in allen Gliedern, sowie eine starke Emptindlichkeit am ganzen Körper ein, von der auch alle

$\left.{ }^{1}\right)$ Nach Weix Mitchell ist Verstopfung die Regel, während Durchfall nur eintritt, wenn sich die Vergiftung lange Zeit hinzieht. 
Muskeln betroffen werden können, so dass dann jede Bewegung schmerzhaft wird; in anderen Fällen dagegen kommt es zu einer vollständigen Anästhesie des ganzen Körpers, welche an dem gebissenen Gliede, auch wenn der Fall in Genesung endet, noch dauernd zurückbleiben kann. In einem Falle sah man heftige Schmerzen in der Stirn und in den Augenhöhlen eintreten.

Wichtiger sind die nach Schlangenbiss auftretenden Bewe gungss törungen. Sie bestehen anfangs theils in leichtem Zittern am ganzen Körper, theils in Convulsionen der Extremitäten, und zwar besonders der Beugemuskeln derselben. Der Gang eines Gebissenen wird infolge dessen mitunter stark schwankend. Nach Weir Mitchell sollen Krämpfe ein seltenes Symptom des Schlangenbisses sein. Später kommt es zu einer Lähmung der Extremitäten, so dass diese oft völlig unbeweglich werden.

Die Krämpfe können sich auch auf andere Muskeln ausdehnen. So sollen Convulsionen des Kehlkopfes und Schlundes ein constantes Symptom beim Biss der Brillenschlange bilden ${ }^{1}$ ). Auf Krämpfen der betreffenden Muskeln beruhen auch folgende Symptome: Verzerrungen des Gesichtes, Trismus, Opisthotonus, Schluckbeschwerden, unverständliche Sprache, Aphasie, Zusammenschnüren der Kehle, Schluchzen, asthmatische Beschwerden, Tenesmus, Strangurie. Infolge der nachfolgenden Lähmung treten an Stelle dieser Symptome zum Theil die entgegengesetzten, also Lähmung des Unterkiefers, der Zunge, des Gaumens, Kehlkopfes, der Darm- und Blasenschliessmuskeln.

Nach Bissen der ostindischen Brillenschlange soll Ptosis ein häufiges Symptom sein. Auch Accommodationslähmung ist beobachtet worden. Während in der ersten Zeit nach dem Biss in der Regel ein eigenthümlich unruhiges Wesen, Schlaflosigkeit und zuweilen sogar die heftigsten Delirien zur Beobachtung kommen, so tritt dagegen später häufiger Schlafsucht und völlige Apathie bei dem Gebissenen ein. Von

1) Asiatic Researches. Vol. II. 1799. 
Störungen der Sinnesorgane ist noch Blindheit zu erwähnen, die schon von den Autoren des Alterthums als Symptom des Schlangenbisses angeführt wird und unter Umständen dauernd bestehen bleiben kann, sowie vorübergehende T' a u b heit.

Die Reflexe gehen meist verloren.

Von vasomotorischen Störungen treten als ein sehr wichtiges und sehr häufiges Symptom Blutungen aus Nase, Ohren, Augen, Mund, Magen, Darm und Blase auf. Auch in der Haut und in fast allen inneren Organen kommen in manchen Fällen Hämorrhagieen vor. Hämaturie lässt sich iibrigens auch auf experimentellem Wege durch Schlangengift bei Hunden hervorrufen. Als selteneres Symptom ist endlich noch Speichelfluss zu erwähnen.

Während die Temperatur anfangs erhöht ist, pflegt sie später zu sinken.

Zuweilen bemerkt man ein langes Bestehenbleiben von Hautröthung nach Streichen mit dem Fingernagel; dies sowie die anhaltende Pupillenerweiterung, die andauernd erhöhte Pulsfrequenz, das Auftreten von Albuminurie weisen auf eine vasodilatatorische Wirkung des Giftes hin ${ }^{1}$ ).

Der Symptomencomplex eines von der Surucueú Gebissenen soll dem des intensivsten Scorbuts entsprechen, wïhrend dem Bisse der Jararacá die Erscheinungen eines Typhus im vorgerückteren Stadium folgen sollen. Der Biss von Bothrops atrox erzeugt vorwiegend örtliche Läsionen.

Das Eindringen von viel Gift in eine Vene ist wohl in der Regel als tödtlich zu betrachten, oder führt doch wenigstens die schwersten Zufälle herbei. So wurde eine kräftige Frau von einer Kreuzotter in einen Varixknoten gebissen; es trat sofort nach dem Biss Ohnmacht und Bewusstlosigkeit ein, der Körper wurde eiskalt und livide, es erfolgte Erbrechen und Abgang blutiger Massen aus dem Mastdarme,

$\left.{ }^{1}\right)$ Schilling, Deutsche Medicinal-Zeitung. 1888. S. 867. 
und (i Stunden mach dem Bisse kam es zum Abort eines fünfmonatlichen Fötus ${ }^{1}$ ).

In einem anderen Falle erkrankte ein Kind, nachdem es an die Brust der gebissenen und krank gewordenen Minter gelegt war; die letztere starb, während das Kind gerettet wurde $)$. Es scheint hiernach, dass das Schlangengift anch im Stande ist in das Brustdrüsensecret überzugehen.

\section{Nachwirkungen des Schlangengiftes.}

Eigenthümliche chronische IV irkungen des Śchlangenbisses beobachtete man in Australien. So wurde ein Gebiss.ner melancholisch und beging schliesslich Selbstmord, und eine gebissene Frau wurde Sänferin und gebar ein idiotisches Kind.

In einem Falle sah man Blödsinn mit partieller Lähmung der unteren Extremititen und der Harnblase zurückbleiben. Von sonstigen Nachkrankheiten kommen zuweilen grosse, dauernde s'chwäche, kuchektischer Zustand, krätzeartige Ausschläge, Neigung zu ölematösen Geschwïlsten, Driisenschwellungen an gebissenen Theile, allgemeine Wassersucht. Nasenbluten vor; in manchen Fïllen entwickelt sich eine ansgesprochene hämorrhagische Diathese. Häufig beobachtet man ein eigenthümliches periodisches A uftreten gewisser Affectionen, so von neuralgischen Schmerzen an der Bissstelle, von einer fieherhaften Lymphangitis, die von der Narbe ihren Ausgang nimmt, von Exanthemen, Schmerzen in den Fingern und lirampfartiger Flexion derelben. Besonters oft sieht man ein periodisches Wiederaufbrechen der alten Bissstelle, rerbunden mit langdanernden Eiterungen. Die Ternarbung dauert üherhaupt, besonders bei Bissen tropischer Giftschlangen, oft sehr lange nnd kann sich sogar ïber mehrere Jahre hinziehen; die Narbe bleibt aber anch dinn meist sehr dünnhüutig, etwas aufgeschwollen und blan gefürbt, entzündet sich bei der geringsten Veranlassung und bricht dann wieder

1) Eisner, Therapeutische Monatshefte. 1892. Nr. 6.

$\left.{ }^{2}\right)$ Lowther, Madras Quart. Journ. of med. sc. Vol. V. p. 742. Brenning, Die Vergiftungen durch Schlangen. 
anf.' 'Mureilen werden an der Wunde schliesshich die Knochen vom Perioste antblüsst, werden nekrotisch und fallen heraus. Bri IInnden wurden nach Schlangenbissen periodische Anschwellungen der Bissstelle wahrgenommen.

An diesen Holgezuständen kann, wenn der Gebissene nicht sleich nach dem Bisse zu Grunde geht, sogar noch nach Jahren der Tod erfolgen.

Das Schlangengift scheint theils durch die Haut und Nieren theils aut der Magenschleimhaut ausgeschieden und dadurch wenigstens theilweise unschädlich gemacht zu werden ${ }^{1}$. Bei seinem Lurchgang durch die Leber soll es ebenso wie Nicotin, Hyoscramin und Curarin durch dieselbe zerstört werden ${ }^{2}$ ).

1) Alt, Münch. med. Wochenschr. XXXIX. 41. 1892.

2) L a u ten bach, Philad. med. Times. VII. p. 387. May 26. 1877. - Dujardin-Beaumetz, Bull. de l'Acad. de méd. 2. sér. X. p. 954. 1881. 


\section{Ursachen und Mechanismus der Giftwirkungen und des Todes.}

Wenn wir von einer alten Angabe absehen, wonach ilem Schlangengifte selbst gar keine Bedeutung zukommt, sondern nur der starke Reiz, den die Schlange beim Biss auf Haut

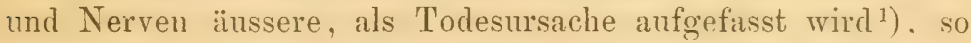
waren die meisten Autoren bis in die neneste Zeit hinein der Ansicht, der Tor erfolge durch "Blutzersetzung ${ }^{*}$ oder "Blutvergiftung". Wenn anch bereits Mercurialis") erwïhnt, dass das Herz zuerst, dann Leber und Gehirn afficirt zu werden scheinen, und zu Anfang dieses Jahrhunderts die Ansicht ausgesprochen wurde, dass das Gift nicht durch Einwirkung auf das Blut, sonderu auf das Nervensystem, und zwar besonders auf das Rückenmark, den Tod herbeiführe ${ }^{3}$ ), so ist doch erst in neuester Zeit nachgewiesen worden, dass in acuten Fällen eine Blutzersetzung überhaupt nicht vorhanden ist, und dass auch in chronischen Fïllen nicht diese das Wesentliche ist, sondern dass der Haupteffect des Giftes darin besteht, die vitale Kraft des Herzens und des Athmungscentrums herabzusetzen. Später stellte man auf experimentellem IVege fest, dass das Schlangengift ein sich über die ganze motorische Sphäre des Centralnervensystems verbreitendes Gift ist. Alle Vergiftungs-

1) Friccius, Pardoxa medica. VII.

2) Mercurialis, De venenis. 1584.

3) Rengger 1. c. 
wrsheinmenen lassen sich demnach anf Parese und Paralyse motorischer Nervenzellen zurïckführen. Die scheinhare Verschiedenheit der Wirkungen des Giftes einzeher Schlangenarten beruht wahrscheinlich darauf, dass diese Wirkungen sich mit verschiedener Intensitit auf einzelne Gruppen jener Zellen concentriren. An neisten scheinen die Nedulla oblongrata, der Plexus cardiacus und die Siplanchnici zu leiden: daher ist fast stets Athmungs- oder Herzlähmung die Todesursache. Aus der Splanchnicuslïhmung lassen sich manche abdominalen Symptome (Erbrechen, Icterus etc.) erklitren. Dir Lähmung der Extremitäten hat ihren Grund in einer anfsteigenclen Riüchemmarkinaralyse, der eine Reizung. entsprechend den anfänglichen Convulsionen, vorausgehen kann. An die Rückemmarkslähmmng schliesst sich eine solche der ITectulla oblongata nud des Gehirns. Auf die motorischen Nervenendigungen wirkt das Gitt nicht ein, eben so weniy auf den Muskel als solchen, obschon man an den quergrestreiften Muskelfisern in der Nähe der Injectionsstelle des Giftes stellenweise einen granulösen Zerfiall der Bowmanschen scheiben beohachtete. Die IIuskeh bleiben aber stets direct elektrisch reizbar, und es tritt keine Veränderung der Huskelcurve ein, ansser wem die Muskeln direct mit Gitt hehandelt werden. Dit Herzenden des $\Lambda^{T}$. vigus werden sehr früh gelïhnt, ebenso die intratadialen Hemmungsganglien. Das Vagniscentrum wird in Anfang gereizt. Das Respirationscentrum wird ebenfalls anfangs gereizt. dam aber gelïhmt. Die motorischen Ganglien und die Muskulatur des I)armes werden nicht tangirt. Der Bhtdruck wird stark herabgesetzt. und zwar unter Lähmung der peripheren Endigungess der Nervi splanchnici. Vom Sinken des Blutdrucks hïngt der bei schwangeren Thieren oft eintretende Ahort. sowie die: Terminderung der Harnibsonderung ab. Wahrschemlich ist das Sinken des Blutdrucks die Folge einer depressorischen Wirkung des Giftes auf die vasomotorischen C'entra der Medulla oblongata, das spötere Wiederansteigen descelthen die Folge riner peripheren Reizung der Capillaren. 
und der schliessliche dituernde Abfall die Folge der abnehmenden Kraft der Herzschläge.

Auch ïher den Einfluss des Giftes auf die Herzthätigkeit liegen genauere Beobachtungen vor. Nach Injection der genuinen Gifte wird die Pulsfrequenz meist etwas beschleunigt, noch mehr nach Durchschneidung der Nn. ragi. Waren diese und das Rückenuark durchschnitten, so tritt meist gar keine Pulsbeschlemigung ein, woraus man schliessen kann, dass auch die Accelerationscentra des Rückenmarkes durch das Gift erregt werden. Der anfünglichen Vermehrung der Pulszahl folgt eine Verminderung.

Waren die Vagi vor der Injection durchschnitten, so bewirken die Globuline des Schlangengiftes in Gegensatze zu dem genuinen Gifte keine Pulsheschleunigung. Waren die Vagi nnd das Rückenmark durchtrennt, so stellt sich nach der Globulininjection eine directe Abnahme der Herzschliige ein durch die schärlliche Wirkung der Globuline auf das Herz. Die Resultate mit den isolirten Giftpejtonen stimmen ganz mit denjenigen nach Injection des genuinen Giftes ïberein; auch diese Peptone schiidigen das Herz direct. Die injicirten Gifte rufen ferner mit Ausnahme des sogenannten "KupferGift-Globulins" eine dentliche Steigerung der Respirationsfrequenz hervor, und zwar am stiirlisten das Peptou. Nach Durchschneidung beider Vagi bleibt dieselbe ans, und es stellt sich vielmehr eine Verminderung der Athemthätigkeit ein. Die Beschlemigung bei intactem Vagus ist zu erklären durch eine Erregung der peripheren Vagusendigungen durch das Gift, das aber auf das Athmungscentrum depressorisch wirkt.

Es bleibt nun noch eine Erscheinung zu besprechen, nïmlich die nach Schlangenbiss so häufig auftretenden Blutungen. Nan führte dieselben frïher fülschlich allein auf die abnorm veründerte Beschaffenheit des inficirten Blutes zurück. Nach Beobachtungen am mit Gift bepinselten Froschmesenterium kommen dieselben jedoch dadurch zu Stande, dass das Gift einen Erweichungsprocess an den Gefïsswandungen hervorruft, wodurch plötzlich Unmengen rother Blutkörperchen 
nebst reichlichem Sermu per diapedesin aus den Gefüssen auswandern. Von einer Ruptur der letzteren ist nichts zu bemerken; ihr Endothel wird trübe und sieht rauh aus. Vor der Diapedese sah man eine anf örtliche Lähmung der vasomotorischen Nervenendigungen und vielleicht auch der Gefüssganglien \%u bezichende enorme Austelnumg der Gefässe an der mit Gilt bepinselten Stelle eintreten. Eine Stase braucht in den Gefïssen dabei nicht vorauszugehen. Weisse Blutkörperchen wandern nur sehr vereinzelt aus. Diese Capillardilatation und die mit ihnen verbundenen Blutungen sind am stïrksten am Herzen, in Verdaunngstractus und in den Nieren. Vielleicht ist sogar die durch die Apoplexie des gastrointestinalen Apparates nud der Nieren hervorgerufene Anämie der ïbrigen ()rgane an des Todesursache betheiligt. Sie tritt allerdings zurück hinter der Lähmung der Herz- und Athmumgsthätigkeit. Beim Vipernbiss soll die letztere stets vor der ersteren erlöschen. Die schwache Reizbarkeit des Diaphragmas und der diaphragmatischen Nerven nach dem Tode scheint eine lähmende Wirkung des Giftes auf diesen Muskel anzudeuten.

Das bisher Gesagte gilt von der weitaus grössten Zahl der bekannten Schlangengifte, namentlich von denen der eurupäischen und amerikanischen Schlangen. Ein etwas abweichendes Verhalten scheinen indessen die ostindische Brillenschlange und die australischen Schlangen zu zeigen.

Das Gift der ersteren soll nämlich in kleinen Dosen ausschliesslich eine Lähmung der intramuskulïren Nervenendigungen, besonders frühzeitig auch derjenigen des Zwerchfells, erzengen, die sich von der Curarelähmung durch die bei grösseren Giftdosen eintretende schwere Schädligung der Muskelsubstanz unterscheidet ${ }^{1}$ ). Das Rückemmark und die vasomotorische Sphäre zeigen bei Vergiftung durch Cobra-Gift ein verschiedenes Verhalten. Während nämlich bei einigen Versuchen beide, ebenso wie auch die sensible Sphïre, gar nicht rom

1) Rargotzi, Virchow's Archiv. 122.2. S. 201. 1890. 
Gifte beeinflusst wurden, so konnte man bei anderen eine deutliche Irerabsetzung der Erregbarkeit des Rückemmarkes, sowie eine auffallende Blutdrucksenkung in Folge einer Lähmung des peripherischen vasomotorischen Apparates wahrnehmen ${ }^{1}$ ). Bei rascher intravenöser Injection grösserer Giftmengen werden nicht die hemmenden Vagusendigungen, sondern nur der Herzunskel afficirt. Die Blutkörjerchen werden biconvex, und ihre Schädigung giebt sich durch Uebertritt von ()xyhämoglobin in die Galle zu erkemen. Auch liessen sich beronters in den Lungen Thrombosirungen durch multiple intravitale Blutgerinnungen nachweisen.

Dass diese Veränderungen des Blutes jedoch nicht das Wesentliche sind, und dass das Blut mit den Vergiftungserscheinungen nichts $\mathrm{zu}$ thun hat, wurde dadurch zur Fridenz bewiesen, dass bei Fröschen, bei denen das Biut durch 0,7 "nige Kochsalzlösung ersetzt worden war: dennoch genau die gewöhnlichen Vergiftungssymptome anftraten. Das Cobra-Gift schädigt vielmehr direct das Nervensystem, nun es ist jetzt mit Sicherheit festgestellt, dass die eigentliche Torlesursache hierbei eine nach einem kurzdanemden Erregungsstadium eintretende Lähmung der Athmungsentren ist.

Die acuten Symptome nach dem Biss der australischen Schlangen sollen wesentlich verschieden sein von dem nach dem Cobrabiss anftretenden ${ }^{2}$ ). Letzterer verinlasst Schnerz an der Bissstelle, sowie Schwellung und Blutextravasate um dieselbe herum. Der Biss der Tigerschlange dagegen verursacht keine locale Schwellung und nur sehr geringen Schmerz, aber in wenigen (höchstens 30) Minuten verliert der Gebissene die Spontanbeweglichkeit in Folge Lähmung der motorischen Centra, und sehr bald daranf folgen Sopor und tödtliches Coma. Nanchmal kehrt das Bewusstsein wieder, aber der Tod erfolgt doch noch an Herzschwäche. Der Biss der

1) Vollmer, Archiv f. experim. Path. u.Pharm. XXXI. 1. S.1. 1892.

2) A. Müller, Austral. med. Journ. May 15. 1888, und Austral. med. Gaz. VIII. 2. 3. 5. Nov. 15, Dec. 15. 1888. Febr. 15. 1889. 
bchwarten schlange hringt selten Coma, lähmt aber in Lohem Graile die motorischen und vasomotorischen Centra und den ganzen Sympathicus. Die Gehfähigkeit ist fast stets verloren, die Arme aher bleiben relativ frei, der Tod erfolgt meist an Herzschwiche. Beim Biss der Braunen Schlange liegen die Symptome zwischen denen der beiden vorigen richlingen; es entstehen hier complete Muskelparalyse, tiefes Coma und Herzschwäche, die bald zum Tode führt.

Bei den australischen Giftschlangen scheint also im Gegensatz zum Cobrabiss stets Lähmung der Herzthätigleit die Todesursache $z$ u sein.

Anch die anstralischen Schlangengifte, wengstens das der Schwarzen Schlinge (Pseudechis porphyricus), scheinen keinen directun Einfluss auf die rothen Blutkörperchen des Menschen zu hahen; dieselben zeigten sich bei Behandhung des Blutes mit dem Gift ganz unverïndert, und die weissen verloren nur ihre amöboide Bewegung ${ }^{1}$ ).

Die Zeit, welche bis zum Eintritt des Todes vergeht, ist in den einzelnen Fällen sehr verschieden. Nach Fayrer sterben in weniger als 2 Stmmen 2.290\%, zwischen --6 Stunden nach dem Biss 24,53 "n, zwischen 4-12 Stunden $23,05 \%$, zwischen 12-24 Stunden $9,36 \%$ und nach mehr als 24 Stunden 21,10" ". Ein sehr rascher Tod scheint besonders dem Bisse der Brillenschlange zu folgen. Man lat hier Fälle beobachtet, wo die Gebissenen fast augenblicklich mach dem Bisse, wie vom Blitze getroflen, bewusstlos nierlexstiirzten und schon nach wenigen Minuten todt waren. In 1.'. Regel erfolgt der Tor jedoch erst nach mehreren Stunden oder Tagen, in manchen chronisch verlanfenden Fällen sogar prit nach Monaten und Jahren, und zwar hier mehr durch allgemene Erschöpfung in Folge fortwihrenden Aufbrechens und Eiterung der IVunde, durch Blutverluste, Lungenödem, oder durch allgemeine Wassersucht.

1) (. J. Martin, Journ. of Physiol. XV. 1893. p. 380. 
VII.

\section{Pathologisch-Anatomisches über die Vergiftung durch Schlangenbiss.}

Die Leiche eines an Schlangenbiss Gestorbenen pHegt. im Gegensatz zu der gewöhnlichen Ansicht, nicht schneller in Fäulniss ïberzugehen als andere Leichen: dagegen soll eine schnelle und intensive Todtenstarre eintreten. Die Section ergieht in der Regel hauptsächlich zahlreiche Blutextravasate in fast allen Organen. besonders in denen des Verdanungscanals. Der Panniculus adiposus und das Unterhantgewebe sind in ler L'mgebung der Bissstelle häufig bis zwischen die Muskelfasem hinein in eine schleimartige, höchst widerlich riechende Masse umgewandelt. Das Blut ist gewöhnlich dumkelroth und flüswig. Wie schon erwähnt. zeigt dasselbe in acuten und primären Fällen von Tergiftung durch Schlangenbiss fast gar keine Veränderung; namentlich sind die rothen Blntkörperchen dabei durchaus normal. Einige Untersucher fanden neben den normalen biconcaven scheibenförmigen auch kugelförmige oder hiconvexe rothe Blutkörperchen. Bei mehr subacutem Terlanfe nehmen dieselhen häufig eine zackige Gestalt an und verlieren ihre Füligheit. Gelirollen zu bilden; auch sollen sie in manchen Fällen kleiner und blasser werden. Wenn man anserhalb des Körpers viel Schlangeugift zum Blute hinzusetzt, so werden die rothen und weissen Blutkörperchen anfgelöst, das Blut nimmt eine Picrocarminfarbe an und giebt in mässion dicken Schichten gar kein Absorptionsspectrum. Bei gewöhnlichen Vergiftungsfällen ist jedoch der normale Ḧ̈moglobinstreifen erhalten. Nur ein- 
mal wmede bisher mach Sichlangenbiss dex Blutfarbstoff verändert gefunden. Auch ein Hangel der Bizzozzero'schen Bhutplättchen wurde wahrgenommen. IV as die dunkle Farbe des Blutes betrifft. so glaubte man früher, dass dieselbe von Gifte selbst herriihre, indessen scheint die dem Tode vorangehende Apnoe dio Ursache davon zu sein. Fast alle Forscher stimmen darin überein, dass die Gerimmugsfïhigkeit des Blutes. Aurch schlangengitt herabgesetzt oder ganz aufgehoben wird. Nach Fayrer bewirken jedoch die Gifte von Naja und Bungarus Gerimung, die von Echis und Daboia dagegen Terflissigung des Blutes. In einer Versuchsreihe ${ }^{1}$ ) war die Gerinmungstendenz des Blutes meistens schon eine Minute nach der Injection des Giftes miter der Norm: in einzelnen Fällen jedoch k:m eine anfïingliche, voribergehende Erhöhung der Gerinnungstendenz zum Vorschein, gुefolgt von einer sehr bald dirauf eintretenden Herabsetzung derselben. Dat letztere niemals fehlte, so ist wohl anzunehmen, dass in allen Fïllen beide Phasen dex Blutveränderung vorhanden waren. In allen Versuchen funden sich schliesslich die Leucocyten beträchtlich vermindert. Die vorühergehende Erhöhung der Gerinnumssfiihigkeit war, wie alle Versuche ergaben, die nothwendige Folge jeder plötzlichen Steigerung des Leucocyłenumsatzes im circulirenden Blute. Merabgesetzt wird sodann die Gerinnungstendenz dadurch, dass das Gift das Protoplasma der farblosen Blutkörperchen so angegziffen und veründert hat, datss die betreffenden Bestandtheile desselben ihre Spaltharkeit. einbüssten.

Eine eigenthïmliche und wohl talsch gedentete Beobachtumg über die Veründerung des Blutes durch Cobra-Gift wurde von einem englischen Arzte gemacht"). Danach soll nimlich, wenn ein Mensch von der Cobra gebissen ist, organische, keimfähige Materic in das Blut desselben gelangen

1) Heidenschild, Untersuchungen über die Wirkung des Giftes der Brillen und der Klapperschlange. Inaug.-Diss. Dorpat 1886.

2) H a l ford, Brit. med. Journ. July 20. 1867. p. 43. 
und sich zu Zellen weiter entwickeln. welche auf liosten des bei der Inspiration aufgenommenen Sauerstoffes in kiirzester Zeit auf viele Millionen anwachsen und das Blut functionsunfühig mathen. Sie haben im Durchschnitt einen Durchmesser ron "17 100 " und enthalten einen ${ }^{1} 28 n 0 "$ grossen Nucleus: letzterer schliesst wieder noch kleinere Molekïle der erwähnten keimförmigen Materie in sich.

Ein bei Zusat\% ron Magentaroth an einer Stelle der Peripherie dieser Zellen anftretender rother Fleck unterscheidet sie von Lrm;h- und Eiterliörperchen. Ihre Vermehrung scheint durch Kerntheilung stattzufinden: sie sind noch mehrere Tage nach dem Tode der Thiere im Blute zu finden und sollen dasselbe ror cadaveröser Fäuhniss schützen. Sie wurden für belebte kleinste ()rganismen gehalten. Dicse Zellen sollen sich schon zwei Stunden rach dem Biss atis einer im Blute entstandenen granulirten, nebelartigen Masse entwickelt haben, welche letztere wielex sich in wenigen Minuten über die ganze Blutmasse des gebissenen Thieres verbreitet. Das Blut ron vier jumgen, aus dem Uterus einer gebissenen trïchtigen Katze entfernten Kätzchen enthielt dieselbe oben beschriebene keimfähige Materie wie das ler Katze: also müssen die kleinsten Partikel der genannten Materie anch die feinsten Poren thierischer Membranen durchdringen können.

Diese Körper waren wahrscheinlich nichts weiter als umgervandelte Leucocyten.

Bei nach mehrfach wiederliolten Vergiftungen zu Grundes gegangenen Hunden fand man eine Degeneration der Hinterstrünge des Rückenmarkes, in denen an einzelnen Stellen die Axencylinder fast völlig geschwunden waren.

Wie man sieht, sind also die pathologisch-anatomischen Verïnderungen, welche nach Schlangenbissen eintreten, nur sehr unbedentend und lassen keinen Schluss auf den Angriffspunkt des Giftes zu. 
VIII.

\section{Therapie des Schlangenbisses.}

\section{Die Schlangenbeschwörer.}

Es dürfte wohl kaum eine Krankheit geben, gegen welche si) viele, theils erprobte, theils aus mystischen und abergläubischen Vorstellungen hervorgegancrene Mittei empfohlen worden sind, wie bei der Vergiftung durch Schlangenhiss. Ich kamn davon absehen, alle jene Einsalbungen des Kïrpers: Räucherungen, Ausstrenen ron stark riechenden substanzen, hesonders von Pflanzen, wodurch man glaubte the Schlangen von sich fernhalten und so einem Bisse uiberhaupt aus den Wege gehen zu können. zu erwähnen. Was aber der Besprechung werth ist, das sind die sogenannten Schlangenbeschwörer. Schon im Alterthume gab es hesondere Menschenklassen, die sich speziell mit der Abrichtung ron Giftschlangen und mit der Heilung von Bissen derselben beschïftigten. So werden verschiedentlich die am IJellespont wohnenden Ophiogenen erwähnt, deren Ahnherr. wie Strabo (XIII. p. 588) erzählt, ein ans einer Schlange verwandelter Held gewesen sein soll. Sie heilten den Schlangenhiss durch Anrühren und trieben, wie man glaubte, das Gift durch Auflegen der Hände aus dem Körper.

Den Ophiogenen entsprachen in Italien die Marsier, die rom Solme der Circe herstammen sollten, und die nach ihrem Könige Psillo henamnten Psillier oder Psyllen in Afrika. Plutarch erzählt, dass Cato in seinem Heere in Afrika viele Psyllen hatte, um die etwa vorkommenden shlangenhisswunden durch dieselben aussangen zu lassen. 
Nach Nikander genügt in leichten Fälen schon Bestreichen der Wunde mit dem Speichel derselben, in schweren soll der Psyllier sich den Mund mit Wasser spülen und dasselhe damn dem Gebissenen zu trinken geben; nimmt aber das Gift überhand, so solle er nackt bei dem Verwundeten liegen. Aelian meinte, dass giftige Thiere einem Psyllen nicht schaden, sondern ., erschlafft" und entlinïtet wïrden, bis derselbe vorïber gegangen sei. Nach Damukrates können die Psyllen aber doch gebissen werten, und gebrauchen damn zur Heilung Alexipharmaka. Auch Aelian selbst erzählt einen Fall, wo ein Gankler in Lom, der sich absichtlich hatte beissen lassen und das Gitt ausgesogen hatte, starb. weil das zum Nachtrinken bestimmte Wasser in böser Absicht mmgestos-en war. Celsus schreibt den Psyllen keine besondere Wissenschaft, sondern nur gewohnte Külmheit zu, und meint, das: andere Leute eben so gat die WTunden anssangen können. ebenso Galen. Dieser erklïrte die angebliche Immunität de's Gaukler dadurch. dass sie lie Schlangen zu stetigem Beissen zwängen und dadurch das Gift abschwächten, oder dass sis ihnen einen Teig vorwürfen, der die Oeff̈nungen der Giltzähne verstopfe.

Nach Gessner werfen die Gaukler den Schlangen hartes Fleisch vor, in das sie durch Hineinbeissen das Gift entleeren.

Bei den Mohanedaner!n werlen bei Schlangenbissen the Sayetten, meist Nachkommen Mahomets, zu Hülfe herheigerufen. Diese machen unter Hersagen einiger Koranverse an der Bissstelle einen leichten Einschnitt, saugen die Wumle kräftig ans, legen gekauten Kinoblauch darauf und benetzen unter beständigem Segensprechen Lippen und Zunge des Grbissenen mit ihrem Speichel ${ }^{1}$ ).

Nach Amerika wurde die Kunst des Schlangenbeschwïrens von den Negern ans Afrika gebracht. Nach den voni

1) Gmelin, Allgemeine Geschichte der thierischen und mineralischen Gifte. 2. Aufl. Erfurt 1811. S. 29. 
Sack ${ }^{1}$ ) in Surinam gemachten, aber melr als skeptisch gedeuteten Beobachtuigen soll die Kunst der Schlangenzauberer darin bestehen, dass sie mit der grössten Schnelligkeit die Schlange an einem Theile. walnscheinlich den Nieren, ergreifen und festhalten, an dem sie sehr empfindlich sind, und sie dadurch in Furcht setzen und unschädlich machen. Der Beschwörer entfernte während der ganzen Dauer seiner Production die Hand nicht ron der Stelle, wo er die Schlange zuerst erfasst hatte. Gegen das Versprechen, nie aus einer geborstenen Kalabasse zn trinken. erhot sich der Mann, auch Sack gegen das Sohlangengift zu schützen. Xach gegehenem Tersprechen machte jener an beiden Armen und Beinen dieses Reisenden cinen leichten Einschitt und rieb ihm ein schwarzes Pulver ein, das ans der Asche von drei Pflanzenarten bestehen sollte. Hierin bestand das Verfahren, das ohne bestimmte Beweise nicht als Gaukelei aufunfassen ist, sondern vielleicht eine wirkliche Impfung darstellt.

R. Schombux $\mathrm{gk}^{2}$ ) erwähnt, dass die Neger Klapperschlingen, olne ihnen die Iünge anszureissen, so abzurichten verstehen, dass sie sich ihnen ruhig um die Arme schlingen. ohne sie zu beissen.

Zur grössten Sicherheit scheinen es aber die indischen Schlangenbeschwörer gebracht zu haben. Nach Forbes") haben dieselben ein festes Vertrauen zu dem Nutzen ihrer Gevengifte und rämmen mu ein, dass diese, wenn nicht reitig genug angewandt, wirkungslos bleiben können, oder dass vielleicht ein in dem Terwundeten vorhandener Krankheitsstoff die Wirkung beeinträchtigt. Forbes sah zwei Wurzeln, nit denen der gebissene Theil über der Bisswunde schnell, aber gelinde bestrichen wird, $u$ zu verhüten, dass das Gift höher steige. Die Pflanzen scheinen von den indischen

1) v. Sack, Beschreibung einer Reise nach Surinam. 1821. Bd. II. S. $125 \mathrm{ff}$.

2) R. Schomburgk, Reisen in Britisch-Guyana. 1847/48. IJ. p. $129 \mathrm{ff}$.

3) Forbes. British-Burma. London 1878. 
Schlangenbeschwörern aus Birma mitgebracht zu sein. Die Beschwörer in Britisch-Birma verlassen sich ganz auf die Wirkung eines Arzneimittels. das sie an Rumpf und Gliedern eimimpfen. Wenn sie gebissen sind, so tätowiren sie den ganzen Körper mit der Medicin. Der Schüler eines Beschwörers wurde gebissen und fiel nieder: der Lehrer brachte mit einer Nadel eine gewisse Quantität des Heilmittels in verschiedene Körpertheile. Der Verwundete wurde ganz schwarz und etwa eine Stunde lang stöhnte und zitterte er, dann erholte er sich nach und nach, obgleich er schon aufgegeben war.

Die Beschwörer behaupten zweierlei Medicamente zu haben. eine, welche die Schlange anzieht, und eine, die sie abschreckt; mit der ersten tätowiren sie auf einer Hand und einem Schenkel die Gestalt einer Schlange, mit der zweiten auf der anderen Hand und dem anderen Schenkel die Gestalt eines Adlers.

Ob jene Angabe der Beschwörer wahr ist, konnte Forbes nicht entscheiden, doch sah er ifter, dass die Schlange gehorsam den Bewegungen der mit ihrem Abbille verzierten Hand folgte, dagegen sofort zurïclifuhr, wem ihr die Hand mit dem Adler entgegengehalten wurde, und bewegungslos liegen blieb, bis die Hand weggenommen wurde.

Forbes bestätigt ebenfalls, dass die Beschwörer den Schlangen nicht vorher die Giftzähne ausgerissen haben, und dass sie eben so wenig denselben vorher ein wollenes Tuch oder irgend einen anderen Gegenstand vorwerfen, damit sie durch Hineinbeissen ihr Gift entleeren und bei den Productionen ihren Meistern selbst durch etwaige Bisse lieinen Schaden mehr bringen können. Dass vielmelı die Schlangen in Vollbesitze ihres Giftes sind. geht daran hervor, dass Forbes innerhalb zehn Jahren drei Zuschaner bei den Productioneu und zwei Beschwörer selbst an erlittenen Bissen sterben sah.

Es scheint nicht unmöglich, dass eine Kaste, welche Jahrhunderte hindurch ihr ganzes Interesse einem solchen Gegenstande widmete, schliesslich ein geheimes Mittel ent- 
Aecken lionnte. dats ant Schlangen eine Wirkung in tem angegebenen Sinne ausübt.

Es ist auch nicht unmöglich, ja, für uns sogar wahrscheinlich. dass manche Schlangenbeschwörer die Imp fung mit. schlatigengift an sich vollzichen und dadurch immun werlen. Ws ist lieinesfalls für den grösseren Theil dieser Individnen zutreffend, wenn man ihre Kunst darauf zurïckführt. dasm sie die Giftschlangen rorher so oft in Thiere oder Gegenstände beiwen lassen. dass sich der Giftrorrath erschöpft. UnWahrsheinlich ist es mch, dass the Schlangenkünstler nur mit in der Verdinumg begrifienen. und darmm träigen, indolenten Schlangen operiren. Wohl ist es denkbar, dass auch eine Giftschlange sich an das häufige Berïhren gewöhnen kam und nicht jedesmal zubeisit. also in gewissem Simne gezühmt ist dies würde aber nicht anserehen, um gerade mit Rücksicht auf den Charakter der meisten Giftschlangen, welche Berührumg nicht gut rertragen und Freund und Feind beissen. eine Sicherung dus mit denselben operirenden Menschen zu geben.

Mnnche ślnlangenbeschwörer, wie die Aïssakais in Algier. lassen sich beissen, nachdem sie sich durch wildes Tanzen in eine'n Exaltationszustand versetzt haben. Minutoli erzählt, dass sich die afrikanischen Schlangenbeschwörer bei ihren Proluctionen wie hasende gebarden, und ihnen der Schaum vor den Mund tritt; doch sollen sie gleichzeitig ein narkotircher Frant kanen. das starke Vermehrung hes speichels erzengt. Möglicherweise verfolgen diese Beschwörer dadurch. dass sie sich in einen solchen Erregungszustand versetzen, den $\%$ werk, den depressorischen Wirkungen des Schlangengiftes anf dis Nervensystem entgegenzuarbeiten und durch den dabei erzeugten Schweiss zugleich das etwa in den Kïrper hineingelangte Gift wenigstens zum Theil wieder zur Ausscheidung zu bringen.

Wahrscheinlicher ist es jedoch, lass das gekaute Kraut eine prophylaktische IVirkung ausïbt. Es fehlt auch nicht an solchen. Welche die Krmst mancher Schlangenbeschwörer 
durch die bei den Productionen gemachte Musik erklären, wodurch die Schlange willenlos gemacht werden soll. Dass in der That die Musik, welche einige Autoren des Alterthums sogar als Heilmittel gegen Schlangenbiss rühmten, im Stande ist, die Bervegungen der Schlangen zu beeinflussen, ist nach sicheren Beobachtungen nicht zu bezweifeln.

Eine zufriedenstellende Erklärung für das sichere Hantiren mit diesen Thieren giebt aber auch diese Vermuthung nicht ab.

Welcher Art aber auch die Mittel sein mögen, durch welche sich die Schlangenbeschwörer gegen das Schlangengift zu sichern suchen, sei es Impfung mit Schlangengift selbst oder einem anderen Stoffe, sei es die innere oder äussere Anwendung von sonstigen Mitteln, besonders von pflanzlichen, so viel steht fest, dass auch sie nicht alle dauernd immun gegen Schlangengift sind. Es ist indessen wohl kaum zu bezweifeln, dass wenigstens manche von ihnen im Besitz von Mitteln sind, welche ihnen, wenn auch keine absolute, so doch eine ziemlich grosse Immunität gegen dieses Gift verleihen.

\section{Operative und mechanische Mittel.}

Bei der Beurtheilung eines Gegenmittels gegen den Schlangenbiss ist man leicht Täuschungen ausgesetzt. In vielen Fällen ist es dem Gebissenen gar nicht bekannt, ob die Schlarige giftig war oder nicht, und, wenn es sich wirklich um eine Giftschlange handelt, wie viel Gift durch den Biss in die Wunde hineingelangt ist. Der letztere Umstand ist, wie bereits erwähnt wurde, bedentungsvoll, da die Schlange kurz vorher durch Beissen eines Thieres ihren Giftvorrath grösstentheils erschöpft haben kann. Auch wird vielleicht nicht selten die Haut nur durch die nicht giftigen Zähne des Unterkiefers verletzt. Es darf auch nicht unerwähnt bleiben, dass die meisten Gebissenen, wenigstens in unseren Gegenden, ohne Hülfe genesen. Man darf also nicht immer 
behaupten, daw. wenn ein Gebissener nach Anwendung eines Mittels gesund wurde, das letztere die Ursache der Rettung war. Es ist ferner die Zeit zu berücksichtigen, die bis zum Beginn der Behandlung verstreicht, sowie die etwaige Mitwirkung eines zugleich angewandten anderen Mittels (z. B. Ligatur) bei Darreichung eines innerlichen Medicamentes oder eines Stimulans, in dem das Antidot enthalten ist.

Es folgt also hieraus, dass es nicht thunlich ist, allein aus der Thatsache, dass Dieser oder Jener nach einem Schlangenhiss unter Anwendung von Gegenmitteln am Leben blieb, den Werth der letzteren zu beurtheilen.

Versteht man unter einem Gegenmittel einen Stoff, welcher das Gift selbst chemisch bindet oder anf irgend eine andere Weise im Körper selbst unschïdlich macht, so besitzen wir für das Schlangengift ein nach dieser Richtung hin wirkendes noch nicht. Da die activen Giftbestandtheile des Schlangengiftes Eiweisskörper sind, so müsste, wenn das Gift erst in den Blutkreislinf aufgenommen ist, das Gegengift electiv nur das Eiweiss de's Schlangengiftes treffen, die diesem verwandten Eiweisskörper des Blutes und überhaupt des ganzen Tïrpers aber unherïhlut lassen - eine Präsumption, die möglich, bisher aber noch nicht erwiesen ist. Versteht man dagegen unter "Gegenmittel" eine Substanz, welche dem Gifte antagronistisch, ג.h. symptomatisch entgegenwirkt, ohne nothwendiger WVeise las Gift selbst zu verändern, so stehen uns gegen das Schlangengift eine ganze Anzahl von zum Theil sehr wirlssamen Mitteln zur Verfügung.

Hierhin gehören zunächst eine Reihe von operativen und mechanischen Eingriffen. Dieselben sind noch heute im Wesentlichen dieselben geblieben, welche bereits ron den Autoren des Alterthums erwähnt werden. So empfiehlt Dioscorides tiefe Excisionen zu machen, die Wunde mit dem Munde oder mit IIülfe ron Schröpflöpfen auszusaugen, und durch Eingiessen von scharfen, ätzenden Arzneien das Gift zu zerstören. Ausserdem empfahl man, zerschnittene junge Hühner anfzulegen, welche durch ihre Wärme fähig sein 
sollten, allerlei schädliche Stoffe aus den vergifteten Körperstellen auszustossen und aufzusaugen. Aehnliche Vorschriften ertheilen auch die übrigen Schriftsteller des Alterthums.

Celsus ${ }^{1}$ ) empfiehlt, sofort nach dem Biss oberhalb der Wunde eine Ligatur anzulegen, damit das Gift nicht zum Herzen dringen köune, aber nicht so stark, dass eine Schwellung eintritt. Sodann solle man Incisionen machen, damit mehr inficirtes Blut herauskommt, und das Gift mit einem Schröpfkopf oder nit dem ganz unverletzten Munde aussaugen. Darauf solle der Gebissene an einem warmen Orte so hingelegt werden, dass der gebissene Theil nach unten geneigt ist. Ist Niemand da, um die Wunde auszusaugen, so solle man ein zerschnittenes Huhn oder Lamm oder Böckchen noch warm auflegen, und zwar so, dass der innere Theil die Wunde berührt. Auch Pflaster, besonders das Ephesische (bestehend aus Terpentin, Galbannm, Mennige und anderen Stoffen), könne man auflegen. Plinius erwähnt bereits als einziges Rettungsmittel gegen die Bisse mancher Schlangen die Amputation. Von den Schriftstellern des Mittelalters empfiehlt Avicenna ausser den schon erwähnten und ihm ebenfalls bekannten Mitteln noch Ausbrennen der Wunde mit dem Glüheisen und besonders den Aderlass.

Hiermit wäre bereits im Wesentlichen die Zahl der mechanischen Mittel erschöpft. An Stelle des Aussaugens und der Schröpfköpfe trat eine Zeit lang das Festbinden von Vögeln, besonders von Hühnern oder Tauben mit dem Anus auf die Wunde. Starb hierbei eines der Thiere, so sollte man ein anderes nehmen und damit so lange fortfahren, bis keines mehr stürbe. Gessner, der dieses Verfahren erwähnt, empfiehlt ausser den schon von Celsus angegebenen Mitteln noch die Wunde mit Essig und Wasser auszuwaschen oder ein Pflaster von Essig und Asche (besonders vom Feigenoder Lorbeerbaum oder vom Rebholz) aufzulegen, Blutegel anzusetzen und bei Blutreichen einen Aderlass vorzunehmen.

1) Celsus, De medicina. V. Cap. 27. 
Ist das Gift schon tiefer gedrungen, so solle man das Glied rings um die Bisswunde mit einer Lanzette aufschneiden und zerhacken oder die Wunde mit glühendem Eisen ausbrennen; denn das Fener verzehre leicht das Gift und lasse die Wunde nicht zu schnell zuheilen. Auch nit gesalzenen Stoffen, mit gestossenem wilden Knoblauch, Zwiebehn oder Succus Cyrenaicus kömme man die Wunde einige Zeit lang offen halten, damit das Gift herauskomme. Ausserdem solle man verhindern, dass der Gebissene schlafe. Derjenige, welcher die Wunde aussaugen will, solle zuvor zu seiner eigenen Sicherheit etwas essen, den Mund mit Wein ausspülen, sodann Rosen- oder Veilchenöl in den Mund nehmen und das Ausgesogrene ausspeien. Den zum Ausziehen des Giftes und zur Linderung der Schmerzen aufgelegten zerschnittenen Thieren (Hühnes, Tauben, Geisslein, Lämmlein, Ferkel) könue man noch einen Frosch ansetzen, der Blut und Gift aussaugen soll. Nach Gessuer brennen die Aegypter die Bisswunde mit glühendem Eisen oder siedendem Oele aus. Auch binden sie das Glied mit in Pech getuuchten Binden fest zu, schneiden die Wunde auf und tropfen Pech hinein; später lösen sie die Binde und bestreichen den Biss mit Zwiebeln und Knoblauch.

Von sonstigen früher angewandten mechanischen Mitteln sind noch zn erwähnen Erdbïder, Baden des gebissenen Theiles in heissem Wasser, heissem Oel, besonders Terpentinöl, in Milch, Kalliwasser oder in Wasser, in dem Kochsalz aufgelöst war; ferner Anflagen eines mit Grünspan überzogenen Stiickes Ḱupfer, von ungelöschtem Kalk, von einsaugenden Erden, besonders englischer Pfeifenerde, von frischem Ziegenküse, warmen Umschlägen, Kräutern und Fröschen, Annähermug eines ghlühenden Messers an die Wunde, so lange es der Gebissene aushält, und in nenerer Zeit sogar die Elektricität.

Einer grossen Beliebtheit erfreute sich auch seit den ältesten \%eiten der sogen. "Schlangenstein". Schon Plinius erzählt, dass die Scythen, wem sie von einer Schlange 
erschreckt wurden, den Kopf derselben aufschnitten und den darin befindlichen Stein verschluckten. Der Glaube, dass sich in dem Gehirne der Schlangen ein Stein befinde, hat sich bis in die Neuzeit fortgepflanzt, und verschiedene Autoren, wie Redi, Charas und Mead, stellten sogar mit solcheu ostindischen Schlangensteinen, die aus dem Kopfe der Cobra stammen sollten, Experimente an. Manche Steine sollten auch im Magen oder Darm von Thieren, besonders von der Bezoarziege (Capra Aegagrus), gebildete Kalkconcretionen darstellen. Es ist später gezeigt worden ${ }^{1}$ ), dass die noch jetzt in Indien unter dem Namen "zehr mohereh" verkanften Steine theils eine, wahrscheinlich aus Serpentin bestehende, mineralische Substanz darstellen, theils aus gebrannten Knochen oder Hirschhorn mit bisweilen dazu gemischter Kalkerde bereitet werden. Man legt einen solchen Schlangenstein anf die Wunde, wo er in Folge seiner Porosität festhaftet, um nach etwa einer halben Stunde abzufallen. In dieser Zeit soll er, wie man glaubt, das Gift aus dem Blute angezogen haben. Auch die Indianer von Paraguay legen, nachdem sie die Wunde ansgesangt haben, zuweilen noch einen Schlangenstein auf, der ebenfalls aus halbcalcinirten Knochen, aus Kreide oder ans gebrannter Thonerde besteht ${ }^{2}$ ). Uebrigens beschränkte man sich nicht auf den Gebrauch dieser Steine gegen Schlangenbiss allein, sondern wandte sie auch schliesslich als ein Heilmittel gegen alle Krankheiten, als ein sogen. „Bezoar", an.

In ähnlicher Weise wie Schlangensteine gebrauchen noch jetzt die holländischen Colonisten in Südafrika die sogen. "Herrenbohne", welche, zerschnitten aufgelegt, das Gift aussaugen und dann von selbst abfallen soll. Auch das Auflegen von frisch zerschnittenen Hühnern soll daselbst noch jetzt in Gebrauch sein.

Die erwähnten mechanischen Mittel gegen Schlangenbiss,

1) Herbert, Asiatic Researches. Vol. XVI. 1828. p. 382 ff.

2) Rengger 1. c. 
wie Incision, Excision, Aussaugung, Schröpfköpfe, A usbrennen, Ligatur, Scarificationen und Amputationen, haben nur dann einen Nutzen, wenn sie so früh angewanlt werlen, dass das Gift noch nicht in den Blutkreislauf aufgenommen ist. Was die Amputation betrifft, so wird man sich hentzutage in Anbetracht des Umstandes, dass die meisten Fälle von Schlangenbiss nicht tödtlich verlanfen, wohl nux sehr selten noch entschliessen, eine so eingreifende Operation gleich von vornherein rorzunehmen. Wem dagegen die nach dem Bisse auftretenden Folgezustinde, wie Vereiterung oder Gangrïn des Gliedes, dazn nöthigen, so wird man sie ansführen müissen. Es sind mehrfach Fälle beschrieben worden, wo die Gebissenen den Muth besassen, sich selbst sofort nach dem Bisse das verwundete Glied abzuschneiden oder abzuhanen, um so sicher einer Vergiftung vorzubeugen.

Die Scarificationen sollen nach Weir Mitchell den Zweck haben, die vasculären Verbindungen der IVunde mit den Centren zu zerstören und so ein Veiterdringen des Giftes zu verhindern.

Durch Aussaugung kann das Gift wohl nur bei einer ungewöhnlich grossen Bisswunde oder nach vorher gemachten Incisionen wieder herausbefördert werden. Nach Fayrer ist Aussaugung gefährlich, auch wem sich im Munde des Anssaugenden keine Verletzungen befinden; sicherer ist es jedenfalls, sich, wenn möglich, eines Schröpfk opfes zu bedienen. Auch in Afrika soll in manchen Gegenden Jeder eine oben mit einem Loche versehene Hornspitze mit sich führen, um damit nöthigenfalls eine Bisswunde auszusaugen. Natürlich kann man auch durch Abwaschen und Ausdrücken der Wunde so viel Gift wie möglich zu entfernen suchen. Blutegel diirften jetzt wohl bei Schlangenbiss kaum noch angewandt werden. Schröpfliöpfe und Aussangung halten auch die Allgemeinvergiftung besonders durch Verlangsamung der örtlichen Circulation auf.

Die gleirl, nach dem Bisse oberhalb und möghichst nahe 
der Wunde umgelegte Ligatur ist anch heute noch einer der einfachsten und bewährtesten Eingriffe. Wenn es möglich ist, so sind Ligatur und Schröpflöpfe mit einander zu verbinden, oder, wem die Beschaffenheit des verletzten Theiles es verlangt, letztere allein anzuwenden. Geht aber beides nicht, wie z. B. an der Nase, so bleibt Aussaugung das einzige Mittel. Wenn durch Schwellung und unterbrochene Circulation Gangrän des gebissenen Gliedes einzutreten droht, so muss die Ligatur wieder gelöst werden.

Zweclimässig scheint die auch von Weir Mitchell empfohlene "intermittirende Ligatur" zu sein. Man giebt nach dem Anlegen der Binde alkoholische Getränke, bis eine genügende Excitation dadurch erreicht ist, und lockert dann die Binde ein wenig; sobald aber Zeichen einer Depression eintreten, zieht man sie wieder fest zu und giebt wieder Stimulantien. Auf diese Weise fährt man abwechselnd fort, damit das Gift nicht anf einmal, sondern portionenweise, also in geringerer Wirkungsstärke den Organismus durchsetzt. Später wird die Binde weiter oben angelegt, um zu grosse Constriction des afficirten Theiles zu vermeiden. Eine plötzliche Entfernung der Ligatur ist geführlich. In einem Falle war das Gift 16 Stunden lang durch die Ligatur zurückgehalten worden, wïhrend schon 2 Stunden nach dem Lösen derselben der Tod eintrat. Die erste Lockerung (nicht Beseitigung) der Ligatur soll nicht vor 6 Stunden erfolgen und dann alle 2 Stunden wiederholt werden. Als Material für die Ligatur kann man nehmen, was man gerade zur Hand hat, z. B. einen vom Kleide abgerissenen Tuchstreifen, einen Lederriemen, eine Schnur oder dergl. Durch Unterstecken eines Stabes unter die Ligatur und Herumdrehen desselben kann man die Circulation in dem unterbundenen Gliede mit noch grösserer Sicherheit vollständig hemmen. Die Hauptsache bleibt immer, dass die Ligatur möglichst sofort nach dem Bisse und möglichst fest angelegt wird. Ein einfaches Umfassen des Gliedes mit den Fingern oder Händen ist nicht ausreichend. Die Eingeborenen Indiens pflegen sogar mehrere Ligaturen umzu- 
legen, z. B. wenn sich die Bisswunde am Finger befindet, eine um den Finger, eine zweite um den Vorderarm und die dritte um den Oberarm, um so ganz sicher zu sein, dass nichts von dem Gifte in den allgemeinen Blutkreislauf hineingelangt. Diese mehrfachen Ligaturen sind empfehlenswertl.

Vereinzelt wurde auch geäussert ${ }^{1}$ ), dass die Ligatur schädlich wirke, und dass die Intoxicationserscheinungen ohne dieselbe allerdings schneller auftreten, aber anch leichter vorïbergehen. Statt dessen empfiehlt man, gleich nach dem Biss durch die Bissstelle einen nur die Haut durchtrennenden Schnitt zu machen, Blut und Gift auszudrücken und in die Wunde Ammoniak zu träufeln.

Durch das Ausbrennen der Bisswunde sollen nicht nur die Gewebe zerstört und absorptionsunf:ihig gemacht werden, sondern auch das Gift selbst vernichtet werden. Am sichersten erreicht man dies mit dem Glüheisen oder Paquelinschen Thermocanter, wenn man diese Operation, um das Gift sicher zu treffen, in sehr grossem Umfange vornimmt. Jäger, die in der Wildniss gebissen worden sind, legen hüufigg Schiesspulver auf die Wunde und zünden dasselbe an.

Besser als das Ausbrennen ist das sofort nach dem Bisse vorgenommene Ausschneiden der ganzen Bissstelle, eine auch den Wilden wohlbekannte Operation. So erzählt Pöppig ${ }^{2}$, als er sellost einmal von einer Giftschlange gebissen war, habe ein "Calderon" ilmm die Haut mit einer Nadel durchstossen, sie gewaltsam emporgehoben und bis auf die Muskeln kreisförmig weggeschnitten; sodamn legte er ein glühendes Goldstiick auf, da Silber oder Eisen nach dem in Peru verbreiteten Aberglauben schaden sollen.

Die in Dentschland zuerst gegen Schlangenbiss empfohlene Bluttransfusion ${ }^{\circ}$ ), von der man auch in anderen Länderu einige Male günstige Resultate sah, hat aus allgemein toxikologischen Gründen mit Recht wenig Verwendung gefunden.

1) Veth, Wiener med. Wochenschr. XXXVI. 1. S. 10. 1886.

2) Pöppiğ, Reise in Chile und Peru. II. 1836. S. 230.

3) Schiltz, De transfusione sanguinis. Bonn 1852. 
Dagegen scheinen Versuche an Hunden dafür zu sprechen, dass bei Vergiftung durch Schlangenbiss Mage en a usspülungen besonders günstig wirken, da wie man es anch bei subcutanen Morphiuminjectionen beobachtet hat, ein Theil des Giftes auf der Magenschleimheit ausgeschieden werden soll ${ }^{1}$ ). Schon Fontana erwiihnt, dass Hunde, die nach Vipernbiss viel erbrachen, eher genasen als andere. Auch die Wirkung starken Branntweins bei Schlangenhiss erkliirt man sich zum Theil durch Fällung der in dem Magen ausgeschiedenen Toxalbumine; durch den nachfolgenden Brechact würden dieselben dann aus dem Organismus entfernt. Verwendet man also Alkohol als Ausspülungsflïssigkeit, so würde man erstens das Gift im Magen niederschlagen, zweitens dasselbe herausbefördern und drittens auch noch eine stimulirende Wirkung erzielen.

Alle Arten von Umschlägen, Kränteraufgüssen, Auflegen vou rohem Fleisch, Bäder etc. können höchstens gegen die secundäre Gangrän etwas nützen.

Auch das Auflegen eines Breies von animalischer Kohle wurde empfohlen ${ }^{2}$ ), und R. Schomburgk schreibt den von einigen wilden Stämmen in Britisch-Guyana angewandten warmen erweichenden Umschlägen aus Cassada-Brot eine spezifische entgegenwirkende Kraft zu, aber wohl mit Unrecht.

Um den depressorischen Wirkungen des Schlangengiftes zu begegnen und zugleich die Ausscheidung desselben durch die Haut zu begünstigen, hat man empfohlen, den Körper in angestrengte Bewegung und in Transpiration zu versetzen. Das ebenfalls darauf hinzielende Verfahren der Schlangenbeschwörer habe ich bereits erwähnt. Auch die Eingeborenen von Indien halten den Gebissenen fortwährend in Bewegung. Ja, man construirte in England sogar eine mechanische Vorrichtung nach Art einer Tretmühle, um bei Gebissenen Hyperkinese und Transpiration zu erzeugen ${ }^{3}$ ).
1) Alt 1. c.
$\left.{ }^{2}\right)$ Garrod, Lond. Gaz. Dec. 1843.
3) Hood, Lancet. I. T. 1868. p. 221. 
Als Beweis für den Nutzen solcher rerstärkten körperlichen Leistung wird angefühnt, dass ein von einer Cobra Gebissener dadurch gerettet worden sei, das der Arzt ihn mit den Händen hinten an seinen Wagen band und ihn so zwang, eine englische Meile weit hinter demselben herzulaufen.

Zur Erzeugung von Schweiss kann man natürlich auch warme Bäder oder sonstige Mittel gebrauchen lassen. Auch das Einreiben ron Bammöl, das ausserdem die Spamung der Haut des geschwollenen Gliedes vermindern soll, wurde zur Vermehrung der Hautausdünstung empfohlen.

Uu die Wirkung des Giftes zu hemmen, übte man früher einen starken Druck auf die Wunde aus, indem man, gestuitat auf Versuche von Bouillant, glaubte, dass während dessen liein Gift eingesogen würde ${ }^{1}$ ). Von diesem sehr zweifelhaften Mittel ist man aber schon lauge abgeliommen.

In Anbetracht des Umstandes, dass bei vielen Schlangengiften, namentlich bei dem der ostindischen Brillenschlange, Lähmung der Athmung die eigentliche Todesursache ist, hat man in neuerer Zeit versucht, die küustliche Athmung als lebensrettendes Mittel anzuwenden. Allein reicht dieselbe indessen auch nicht aus, um das Leben zu erhalten, da durch das Gift gleichzeitig auch die motorischen Herzganglien gelähmt werden. Immerhin verdient sie aber doch bei Schlangenbiss nöthigenfalls berücksichtigt zu werden, da sie nach den früher schon von verschiedenen Aerzten ") angestellten Versuchen im Stande ist, wenigstens einige Stunden das Leben zu erhalten, und man während dessen Zeit gewiunt, andere geeignete Mittel anzuwenden, welche die Elimination des Giftes befördern und eine erregende Wirkung entfalten.

1) I, enz, Schlangenkunde. 1832.

2) Weir Mitchell 1. c. - Vincent Richards, Indian Med. Gaz. May 1.1873. - F a y e r, Med. Times and Gaz. Sept.6. 1873. p. 249. 


\section{Thierische Mittel.}

Im Gegensatze zu den grösstentheils noch heute angewandten operativen und mechanischen Mitteln gehören die thierischen Mittel gegen Schlangenbiss fast ausnahmslos der Vergangenheit an. Von den benutzten Thieren sind zuächst die Schlangen selbst zu erwähnen. Schon Plinius empfiehlt den frisch abgerissenen Kopf einer Viper oder dessen Asche oder die Eingeweide von Schlangen auf die Bisswunde zu legen und innerlich aus der Viper bereitete Theriakkïgelchen, Brühe ron Schlangen oder gekochte Vipernleber zu nehmen, welche bewirken soll, dass man nie wieder gebissen wird. Auch könne man die Schlange im Trasser zerstampfen und damit die Wunde bähen.

Nikander liess aus gekochtem Vipernfleisch cine Salbe bereiten, welche nicht nur gegen Schlangengift, sondern überhaupt gegen alle animalischen Gifte helfen sollte. Avicenna erwähnt Vipernpastillen, die aus zerstossenem Vipernfleisch mit geröstetem Brot bereitet wurden. Weder vor noch nach dem Trocknen dürfe die Some auf sie fallen, da dieselbe die Kraft des Vipernfleisches zerstöre. Sogar bis weit in die Neuzeit hinein wurden Kopf, Fleisch, Herz, Leber und andere Organe von Schlangen nicht nur änsserlich angewandt, sondern auch als Antidote gegessen; die Bisswunde wusch man mit Vipernblut. Der Jesuit Athanasius Kircher ${ }^{1}$ ) behauptete, dass der innerliche Gebrauch von Schlangeneingeweiden nur den Biss gleicher Schlangen heile, und Aldrovandus, dass aufgelegte Vipern das Gift wie ein Magnet ausziehen. Ettmüller empfahl eine Axungia serpentina gegen Schlangenbiss, und Gessner glaubte, ebenso wie Plinius, dass gegessene Schlangenleber immun gegen Schlangenbiss mache.

In neuester Zeit will man gegen Klapperschlangenbiss eine Lösung von Klapperschlangengalle in 10 Theilen Spiritus bei gebissenen Kaninchen mit bestem Erfolge angewandt haben. Eine grosse Rolle spielte anch das "Vipernsalz". Schon

$\left.{ }^{1}\right)$ A th. Kircher, Mundus subterraneus. Amstelod. 1678. lib. IX. 
die Alten kannten ein solches, das durch Verbrennen und Calcination der Schlangenknochen gewonnen und zum Theil mit Meer- und anderen Salzen gemischt wurde. Charas ${ }^{1}$ ) gal) ein genaues Recept zur Bereitung eines guten Vipernsalzes an, das in der Hauptsache in einer Abkochung von Vipern und Zusatz von Seesalz besteht. Wirksamer soll dasselbe noch werden, wenn man statt des Seesalzes die Salze einiger theriakalischer Pflanzen zufügt, wie von den Wurzeln von Valeriana, Imperatorium, Angelica, Meum, von den Blättern von Scordium, Centaurea, Cardobenedicten u. a.

Für eins der besten Mittel in der Medicin iberhaupt erklïrt aber Charas das sogenannte, flüchtige Vipernsalz", bei dessen Bereitung es sich wesentlich um einen Destillationsprocess von Viperntheilen zu handeln scheint. Zahlreiche andere gegen Schlangenbiss gebrauchte zusammengesetzte Arzneimittel enthalten das Vipernsalz als Basis. Auch ein Vipernöl und Vipernfett wurden empfohlen.

Nach Mead ${ }^{2}$ ) soll das Aufstreichen des letzteren auf die Wunde verhindern, dass sich die flüchtigen Salze der giftigen Flüssigkeit in die spitzen Krystalle verwandeln (die Mead, wie oben erwähnt, im Viperngift gefunden haben wollte).

In manchen Gegenden Brasiliens verbindet man die Bisswunde mit dem öligen Decocte des Kopfes einer alten Schlange derselben Gattung ( el aceite de Cascavel“) oder reibt die Galle der aufogeschnittenen Schlange in die Bisswunde ein.

Auch in Surinam werden die in Rauch getrockneten und dann in eisernen Töpfen verkohlten Köpfe giftiger Schlangen zusammen mit einigen getrockneten Pflanzen bei Schlangenbiss äusserlich und innerlich angewandt ${ }^{3}$ ).

Offenbar sind aber hierbei die betreffenden Pflanzen das

2) Charas, Nouvelles expériences sur la vipère. Paris 1694. p. $163 \mathrm{ff}$.

$\left.{ }^{2}\right)$ Mead, De vipera. Opera medica. Vol. II. 1749.

3) K. Martin, Bericht über eine Reise nach Niederländisch-Westindien. I. S. $29 \mathrm{ff}$. 
Wesentliche. Ebenso wendet man auf Martinique Liopf, Herz und Galle von Giftschangen als Antidot gegen deren Biss an ${ }^{1}$ ). Nach Fontana essen die Mohamedaner, sobald sie gebissen sind, die Schlange roh mit viel Salmiak oder Kochsalz, und in Indien sollen Einige einen Balsam aus Leber und Herz der Schlange, niit etwas Salmiak und Zimmtessenz versetzt, einreiben und zugleich daron einen Löffel voll mit der doppelten Menge Oel innerlich nehmen.

Uebrigens wurden auch gegen zahlreiche andere Krankheiten Viperntheile angewandt; so empfiehlt Dioscorides gekochtes Vipernfleisch gegen Augenkrankheiten, nervöse Leiden und Kröpfe; Vipernpastillen sollten bei Elephantiasis nützlich sein. Auch bei Aussatz und bösen Geschwïren wurden Vipern gebraucht, und in den verschiedenen Arten von Theriak spielten Vipern gewöhnlich eine Hauptrolle. Noch jetzt wird Vipernbrühe in Italien gegen chronische Krankheiten, wie Lähnungen, Hautkrankheiten, Marasmus senilis, Phthisis pulmonum angewandt, und das Oel aus den Eiern der Klapperschlange wird in Connecticut gegen Rheumatismus und Neuralgie gebraucht. Es soll starkes Brennen auf der Haut erregen. Axungia Viperarum stand noch in der Pharmacopoea Wirtembergica von 1760 .

Auch zur Bereitung von Pfeilgiften wird Schlangengift, meist zusammen mit giftigen Pflanzenstoffen, noch heute von vielen wilden Völkerschaften benutat. So besteht das Pfeilgift der Barineger aus dem Safte einer Baumwurzel und dem Decocte von Köpfen giftiger Schlangen. Die GonaquaHottentotten nehmen zu ihrem Pfeilgifte eine Milchsaft liefernde Pflanze und einige Schlangenarten, die Buschmänner Hornvipern. Auch die Muntschi in den Haussaländern, sowie verschiedene Volksstämme auf der Malayenhalbinsel, den Sundainseln und noch in anderen Gegenden bedienen sich des Schlangengiftes zur Anfertigung ihrer Preilgifte ${ }^{2}$ ).

1) Rufz l, c. p. 169 .

2) L. Lew in, Die Pfeilgifte. Virchow's Archiv. Bd. 136. 138. 1894. 
Ton ans anderen Thieren bereiteten Mitteln gegen Schlangembiss ist zunächst das Skorpionenöl zu erwähnen, womit das gebissene Glied eingerieben werden soll. Vom Hirsche, den man für immun gegen Schlangeugift hielt, writen verschiedene Organe, namentlich Nagen und Leber, mit sehr verschiedenartigen anderen Substanzen, Wein etc. rersetzt und auf mannigfaltige Weisen zubereitet, schon von Plinius als ein imnerlich zu nehmendes Mittel empfohlen. Auch das aus dem Uterus einer jungen Hirschkuh geschnittene Coagulum soll gute Dienste leisten.

Gilbertus Anglicus empfahl, die Ligatur mit einem Hirschfelle zu machen. Charas gab in einem Falle vou Schlangenbiss geraspeltes Hirschhorn innerlich, und ein Abt Tecmeyer rühmte gebranntes Hirschhorn als Gegenmittel. Auch Me ad empfiehlt Hirschlorn mit warmem Wein. Ton sonstigen Thieren, z. B. wilden Schweinen, Ziegen, Hasen, Flusspferden und vom Rhinozeros gebrauchte man verschiedene Organe, wie Gehirn, Leber, Magen, Hoden, ferner Blut, Galle, Magensaft und Talg. Verwendet wurden auch Bienen und spanische Fliegen innerlich und äusserlich.

Plinius behauptet, Hühner, die von Wanzen gebissen seien, sterben nicht an Schlangenbissen, eben so wenig Menschen, die solches Hühnerfleisch gegessen haben, und empfiehlt Auflegen von Wanzen mit Schildkrötenblut, sowie auch Galle rom Wiesel, oler aufgeschnittene Mï̈use, frisch zerrissenes Tauben- oder Schwalbenfleisch, gebrannte Uhubeine mit Bleiwurz, das Blut von Eledermäusen mit Disteln gemischt, Auflegen von Hühnergehirn, Trinken von Hahngehirn mit Wein, Fleischbrühe von Hühnern, Asche von Ziegenhörnern, Milch, Harn, Küse, Talg und zahllose andere Mittel von der Ziege. Auch das Her\% eines Raubvogels solle gegen Schlangen schützen. Avicenna empfiehlt, verbrannte und gepulverte Menschenzähne aufzustrenen.

Petrus de Abano ${ }^{1}$ ) will zerriebene Krebse auflegen

1) Petrus de Abano, De venenis. 1473. 
lassen, und der schon erwähnte Abt Tecmeyer hält es sogar für möglich, dass ein Zahn des Caiman, wenu man ihn nur in der Tasche trïgt, den Vipernbiss heilen könne.

Von Thierproducten spielte die Milch, wie noch hente bei vielen anderen Vergiftungen, von jeher eine grosse Rolle. Man bevorzugte Ziegenmilch, die innerlich und äusserlich, und geronnene Hasenmilch mit Wein, die innerlich verordnet wurde. Einige Indianerstïmme Guyanas glauben sogar in Frauenmilch ein wirksames Gegengift entdeckt zu haben, die sie zugleich mit Umschlägen aus Cassada-Brot anwenden. Auch die Neger sollen die Bisswunde von Coluber haje mit Frauenmilch auswaschen. Celsus empfiehlt das Trinken von Enten-, Schaf- oder Kalbsbrühe, andere Autoren Froschbrühe mit Salz und Oel. Auch rohes Eiweiss, sowie Käse wurde vielfach verwendet.

Sogar die Excrete von Thieren und Menschen wurden als Gegenmittel betrachtet. So erzählt Plinius, dass nach M. Varro der Gebissene durch Trinken des eigenen Urins geheilt werde. Das Gleiche behauptet auch Mercurialis ${ }^{1}$ ), und noch neuerdings empfahl ein französischer Arzt ${ }^{2}$ ) Auswaschen der Wunde mit dem eigenen Harn. Auch die Darmexcrete von Katzen, Hunden, Ziegen, Schafen, zum Theil mit Essig oder Wein gekocht oder geknetet, wurden theils innerlich, theils äusserlich angewandt, - bei den Indianern Perus und Brasiliens sogar der Menschenkoth ${ }^{3}$ ).

In Bolivia und Südafrika gebraucht man - falls die Eingeborenen nicht absichtlich in einem solchen Falle, um das wahre Mittel zu verheinlichen, die Unwahrheit sagten Turen mit schreissgetrïnkten alten Nützen und anderen Gegenständen, wie es schien, mit wunderbarem Erfolge ${ }^{4}$ ).

1) Mercurialis, De venenis. 1584.

$\left.{ }^{2}\right)$ Desmartis, Gaz. hebd. V. 1858.

3) Pöppig l. c. II. S. 268. - S pix, Serp. Brasil. Spec. novae. p. 65 .

$\left.{ }^{4}\right)$ Keller-Leuzinger, Vom Amazonas und Madeira. Stuttgart 1874. S. 51. 
Linem gebissenen Hunde wurde zunächst fein zerschnittener und in Wasser eingeweichter Minastabak eingegeben; später wusch ein alter Neger ein von Schuntz starrendes Täschchen, das er an einer Sichnur um den Hals trug, und gab das Waschwasser dem Thiere ein, worauf der Hund alsbald wieler völlig gesund wurde, nachdem vorher sein Gang wankend gewesen war, sich Würgen eingestellt hatte, und an der Bissstelle eine beinahe sichtlich zunehmende Geschwulst entstanden war.

Die Indianer Louisianas legen auf die Bisswunde Smegma praeputii und unterbinden das gebissene Glied mit einem Baumwollfaden, den sie stets unter dem Präputium tragen ${ }^{1}$ ).

In der Provinz Sào Paulo wird nach Tschudi den verlrohlten Federn und Kinochen eines rebhuhnartigen Vogels, des Macuco (Tinamus brasiliensis), auch „Nabú-Assú" oder "Toua" genannt, eine spezifische Heilwirkung bei Bissen giftiger Schlangen zugeschrieben. In anderen Theilen Brasiliens wird noch heute bei Schlangenbiss das Fett einer grossen Eidechse (Lacerta Teguixia L.) eingegeben. Anch legt man daselbst geglühte Kuochenstücke (vielleicht von Hirschhorn), die mit der schleimigen, aus Krrokodilshoden exprimirten Flüssigkeit getränkt sind, auf die Bisswunde.

Auf den Andamanen legt der Gebissene, falls er die Schlange gretödtet hat, Nierenfett anf die Wunde; im anderen Falle wendet er die Unterbindung und Cauterisation an.

Auch der menschliche Speichel wurde mehrfach als Antidot gegen Schlangenbiss empfohlen. So rïhmen Plinius, Galen u. A. den Speichel eines nüchternen Menschen als nützlich, und auch von den Negern wird derselbe bei Bissen von Coluber haje angewandt.

\section{Chemische Mittel.}

Von chemischen Mitteln waren vom Alterthume bis in tie Neuzeit hinein in Folge der kleinen bekamnten Zahl derselhen nur wenige gegen Schlangengift in Gebrauch. Eigent-

1) Spix 1. c. p. 66 . 
lich gab es deren früher nur drei, nämlich Essig, Wein und Kochsalz. Das Trinken von reinem Wein wird von Dioscorides, Celsus, Plinius, Avicenna und Anderen empfohlen. Celsus meint, statt reinen Weines mit Pfeffer könne man auch etwas Anderes trinken, "quod calori movendo est, nec humorem intus coire patitur"; denn die meisten Gifte gingen durch Kälte zu Grunde. Kochsalz soll nach Celsus trocken in die Wunde gestrent werden. Die genannten und auch spätere Autoren empfehlen ebenfalls Trinken von Essig und Auswaschen der Wunde mit demselben, indem man glaubte, er setze den sich eindickenden Saft im Menschen wieder in Bewegung. Nach Mercurialis liessen auch die Aegypter reichlich Essig trinken. A vicenna rühmt einen Oxymel aus Essig, Salz und Honig, und Gessner die äussere Anwendung von Essig, Salzwasser, Essig mit Salzbrïhe vermischt und ein Pflaster aus Essig und Asche. Von Avicenna wird ausserdem noch ein Schwefelmittel von nicht näher angegebener Zusammensetzung erwähnt. Auch Erdöl wurde, wenn auch selten, gebraucht.

Von chemischen Mitteln der Neuzeit ist zumïchst das auch heute äusserlich und innerlich noch häufig angewandte A mmoniakzu erwähnen. Es wurde zuerst im vorigen Jahrhundert von Jussieu, Chaussier, Sage und Anderen als eines der sichersten Mittel bei Schlangenbissen gerühmt. Wie es scheint, kam man deswegen auf ein Alkali, weil Mead das Viperngift für sauer erklärt hatte. Smith ${ }^{1}$ ) empfahl als bestes Mittel bei Schlangenbiss nach vorheriger Anlegung einer Ligatur um das verletzte Glied möglichst bald nach dem Bisse eine Dosis von $2 \mathrm{~g}$ Ammoniak auf einmal innerlich zu geben, und zwar nur in solcher Verdünnung mit Zuckerwasser, dass ein Hinunterschlucken eben noch möglich sei. Andere beschränken die Einzeldosis auf 20 Tropfen (gehörig mit Zuckerwasser verdüunt) und rathen, nicht über $4-12 \mathrm{~g}$ davon zu geben. Auch subcutane Injectionen von mit 4 Theilen Wasser

1) Sm ith, Brit. med. Journ. Febr. 22. 1868, p. 164.

Brenning, Die Vergiftungen durch Schlangen. 
verdünntem Ammoniak zu 1/2-1 Spritze, oder intravenöse Injectionen ron 10_40 Tropfen einer Lösung von Ammoniak in 2-3 Theilen Wasser sind empfohlen worden ${ }^{1}$ ). Selbst unverdiinntes Ammoniak, zu $0,5 \mathrm{~g}$ subcutan injicirt, hatte bei Meerschweinchen stets nur günstige Wirkungen "). Die ebenfalls Ammoniak enthaltende und am Cap der guten Hoffnung unter dem Namen „Croft's drops" bekannte Flüssigkeit wird daselbst geradezu als ein Specificum gegen Schlangenbiss gerühmt.

Statt des Ammoniaks wurde früher vielfach auch der Liquor Ammonii succinici ("Eau de Luce") angewandt und soll auch jetzt noch in Ostindien in Gebrauch sein, ebenso das Ammoni um carbonicum (Hirschhornsalz), das vor dem Ammoniak den Vorzug hat, innerlich genommen weniger zu ätzen.

Neueren Untersuchungen und Beobachtungen gegenüber hat jedoch das Ammoniak semen Ruf als Antidot gegen Schlangengift nicht zu wahren vermocht. Schon Fontana fand dasselbe bei seinen Experimenten nutzlos gegen Viperngift, ebenso zahlreiche spätere Forscher auch gegen andere Schlangengifte. Sicher ist, dass das Ammoniak durchaus nicht auf das Gift selbst chemisch einwirkt und so etwa dasselbe zerstört und unwirksam macht. Höchstens kann man annehmen, dass es bei äusserer Anwendung, falls ihm in geeigneter Weise die Gelegenheit dazu geboten wird, durch Verätzung der Gewebe dieselben unfähig macht, das Gift zu absorbiren. Bei innerlicher Darreichung ist es indessen im Stande, durch Anregung der Herzthätigkeit unzweifelhaften Nutzen zu stiften, jedoch stehen uns zu diesem Zwecke, wir wir später sehen werden, andere Mittel zur Verfügung, die besser wirken als das Ammoniak. Immerhin gehört dieses zu denjenigen Stoffen, welche man nicht ohne Weiteres als unbrauchbar verwerfen darf.

$\left.{ }^{1}\right) \mathrm{Halford}$, Med. Times and Gaz. Dec. 27. 1873.

$\left.{ }^{2}\right)$ J. Schulz, Ueber Schlangengift. Inaug.-Diss. Berlin 1881. 
Da man auch, um das Schlangengift durch die Hautthätigkeit aus dem Körper zur Ausscheidung zu bringen, auf eine diaphoretische Wirkung des Ammoniaks Gewicht legte, so wandte man in neuester Zeit statt desselben ausser anderen schweisstreibenden Mitteln besonders subcutane Injectionen von Pilocarpin an. Indessen fehlen bis jetzt noch genügende Beweise für die Wirksamkeit der Diaphoretica bei Schlangenbiss.

Aehnlich wie das Ammoniak verhalten sich auch die übrigen äusserlich als Aetzmittel gebrauchten Chemikalien, wie Kalilauge, Natronlauge, ungelöschter Kalk, Schwefelsäure, Salpetersäure, Essigsäure, Eisenchlorid, Butyrum Antimonii. Alle diese Mittel, die jetzt wohl nur noch selten angewandt werden, haben nur dann einen Zweck, wenn sie möglichst bald nach dem Biss applicirt werden, ehe noch eine grössere Quantität des Schlangengiftes in den Blutkreislauf gelangt ist, und wenn zuvor die Bisswunde hinreichend erweitert wurde, damit sie in gehöriger Weise auf die Gewebe resp. das in denselben enthaltene Gift selbst einwirken können. Denn, wie bereits an einer früheren Stelle erwähnt wurde, vermögen namentlich Kali- und Natronlauge in genügender Concentration und bei längerer Berührung mit Schlangengift dieses unwirksam zu machen, und verdienen deswegen in allen frischen Fällen wohl in Anwendung gezogen zu werden.

Was die Carbolsäure betrifft, so hat dieselbe zwar nur eine geringe Wirkung auf das Gift selbst, jedoch soll sie sich gut zu Ueberschlïgen auf den verletzten Theil eignen, weil sie die Circulation in den Blutgefässen und dadurch auch die Resorption des Giftes angeblich wesentlich verlangsamt ${ }^{1}$ ). Als innerlich zu nehmendes Mittel wurde die Carbolsäure gegen den Biss der australischen Tigerschlange empfohlen, hat aber wohl als solches ebenso wenig Nutzen wie das in Mittelasien gebräuchliche Bestreichen der Bisswunden von Trigonocephalus halys mit Theer.

$\left.{ }^{1}\right)$ Mitchel1, Med. Times and Gaz. Febr.6. 1869. p. 137. 
Der Neuzcit gehört ferner als Nittel gegen Schlangenbiss das übermangansaure Kali an, über dessen Werth die Meinungen selr getheilt sind. Schon vor ca. 25 Jahren behauptete man von demselben, dass es das Gift neutralisire und vollkommen wirkungslos mache ${ }^{1}$ ). Auch Lacerda ${ }^{2}$ ) empfahl dasselbe, da er es in mehr als 40 Versuchen wirksam gefunden hatte. Selbst dann noch sollte es vorzügliche Dienste geleistet haben, wenn das Schlangengift direct ins Blut, also in eine Vene gespritzt wurde. Innerhalb 15-25 Minuten nach der Injection sollten sämmtliche Vergiftungssymptome verschwunden sein, so dass die Versuchsthiere keinerlei Abweichuugen von ihrem normalen Verhalten zeigten. Lacerda schrieb dem Kalipermanganat allerdings keine specifische Wirkung gegen das Schlangengift zu, sondern war der Ansicht, dass das Schlangengift ähnlich den Verdauungssäften nach Art eines Fermentes wirke und durch das Mittel seiner fermentativen Eigenschaften beraubt werde, indem der active Sauerstoff, der sich durch Zersetzung des mit der organischen Materie in Contact gebrachten Kaliumpermanganats bilde, die chemischen Eigenschaften des Giftes ändere.

Von 30 Experimenten, bei denen Lacerda das Gift direct in die Venen spritzte, zeigte sich nur bei zweien das übermangansaure Kíali wirkungslos, und zwar, wie er glaubte, deshalb, weil die betreffenden Thiere schlecht genährt, schwach und sehr jung waren, und ausserkem die Anwendung des Mittels zu lange hinausgeschoben war.

Während es hei sofortiger Injection des Kalipermanganats gleich nach dem Biss genügen soll, das Mittel nur an der Bissstelle zu appliciren, rieth Lacerda, wenn das Mittel erst spät zur Anwendung gelange, auch im gesunden Gewebe mehrere Injectionen damit zu machen.

1) Shortt, Madras Monthly Journ. of Med. Sc. Vol. V. 1872. p. 361 .

2) Lacerda, O Permanganato de Potassa como antidoto de peçonha das Cobras. Rio de Janeiro 1881. - Leçons sur les venins des serpents du Brésil. Rio 1882. 
Im Gegensatze zu Lacerda, welcher sich bei seinen Versuchen der Gifte mehrerer zu der Familie der Crotalidae gehöriger Schlangen Südamerikas bediente, fanden aber andere Untersucher das Kaliumpermanganat entweder ganz nutzlos, selbst beim Crotalusgift, oder doch wenigstens lange nicht so wirksam wie jener.

Bei spüteren Versuchen hat übrigens Lacerda selbst eingesehen, dass dieses Mittel durchaus nicht die Eigenschirften besitzt, welche er ihm früher zuschrieb. Die meisten Autoren der neuesten Zeit kommen darin iiberein, dass Kaliumpermanganat nur dann die Wirkung des Giftes mehr oder weniger zerstört, wenn es ausserhalb des Körpers längere Zeit nit demselben gemischt wurde, oder wenn es unmittelbar nach der Injection des Giftes oder nach dem Bisse an der Bissstelle selbst eingespritzt wird ${ }^{1}$ ). Bei dem Gifte der Brillenschlange ist aber auch dieses Verfahren unsicher und kamn oft den Eintritt des Todes nur verzögern, aber nicht verhindern. Ganz zwecklos ist es jedoch, das Kaliumpermanganat erst dann anzuwenden, wenn bereits deutliche Erscheinungen der stattgefundenen Vergiftung aufgetreten sind.

Das Viperngift soll durch örtliche Behandlung mit Kaliumpermanganat allein die Localwirkungen verlieren, während die Allgemeinwirkungen nur abgeschwächt werden.

Da also dem Kalipermanganat gewisse neutralisirende Wirkungen gegen Schlangengitt nicht abgesprochen werden können, so kamn man immerhin versuchen, durch multiple Injectionen einer 3-50 0 igen Lösung des Mittels tief in die ganz frische Bisswunde hinein das Gift zu zerstören oder wenigstens abzuschwächen. Uebrigens haben diese Injectionen den Nachtheil, dass sie caustische Wirkungen zurïcklassen, und dass die Wunden danach, im Gegensatze zu denen, bei welchen die noch näher zu besprechende Chromsäure angewandt wurde, erst nach längerer Zeit zuheilen.

1) Richards, Lancet. I. Jan. 1. 1882. p. 35. - Calmette, Journ. de Pharm. et de Chimie. 1892. - Tricaxd, Arch. de méd. navale. LXI. p. 357. 1894. 
Sehr geringe Erfahrungen liegen über das Natrium salicylicum vor. Dasselbe soll rings um die Wunde in einer Concentration ron 1:12 Wasser subcutan injicirt, und ausserdem alle 2 Stunden ein Esslöffel einer Lösung ron $1 \mathrm{~g}$ Acidum salicylicum in $150 \mathrm{~g}$ Orangenblüthenwasser genommen werden ${ }^{1}$ ).

Eine grössere Beachtung als das zuletzt genannte Mittel verdient wohl die äusserliche Anwendung ron Jod resp. der Lugol'schen Lösung gegen Schlangenbiss.

Ein französischer Forscher ${ }^{2}$ ) empfahl solche Injectionen von etwa $+-5 \mathrm{~g}$ einer Lösung von $0,6 \mathrm{~g}$.Jod und $1,8 \mathrm{~g}$ Jodkali in $30 \mathrm{~g}$ Wasser. Der gebissene Theil wird zuerst geschröpft, oder es wird eine Ligatur um das Glied gelegt, bis die Gewebe genügend durch Ansammlung ron Serum geschwollen sind, so dass sich die injicirte Flüssigkeit durch die ausgedehnten areolären Räume verbreiten kann. Dann wird die Injection seitwärts in das Glied gemacht, unterhalb des noch 10 Minuten lang liegen bleibenden Schröpfkopfes. Ist bereits eine Schwellung eingetreten, so nimmt man weniger von den wirksamen Stoffen und mehr Wasser, damit diese grössere Flüssigkeitsmenge sich über die ganze geschwollene Partie verbreiten kann. Leider ist der nothwendige Apparat, namentlich Injectionsspritze und Schröpfköpfe, in den seltensten Fällen gleich zur Stelle.

Die günstige Wirkung dieser Jodinjectionen wurde dem, das Schlangengift selbst verïndernden Einflusse des Jods zugeschrieben. Demgegenüber wurde jedoch später festgestellt, dass das Jod das Gift nicht verändert. Man erhielt bei Versuchen mit Gerbsäure dieselben Resultate wie mit Jod und schloss daraus, dass Jod und Gerbsäure mehr durch ihren Einfluss auf die Gewebe als auf das Gift selbst wirken. Indessen, wenn auch durch Jodinjectionen die Localsymptome geringer wurden oder ganz fehlten, und der Eintritt der allgemeinen

1) Bull. de l'Acad. de méd. 3. sér. XX. 1888. p. 603.

2) Brainard, Gaz. de Paris. 24. 25. 1854. 
Wirkungen des Giftes von Crotalus verzögert wurde, so liess sich der Tod in den für diesen Zweck rorgenommenen Thierversuchen schliesslich doch nicht vermeiden. Empfohlen wurde freilich das Mittel nicht gegen den Biss von Crotalus, sondern von Crotalophorus tergeminus. In neuester Zeit wurde auch die Wirksamkeit der Brainard'schen Jodinjectionen gegen das Gift der Lanzenschlange auf Martinique untersucht ${ }^{1}$ ). Es zeigte sich hierbei, dass das Mittel, wenn es ausserhalb des Körpers mit dem Schlangengift gemischt wurde, das letztere allerdings unwirksam machte; wurde aber die Jodlösung selbst unmittelbar nach der Giftinoculation und an derselben Stelle wie das Schlangengift applicirt, so konnte dadurch auch nicht ein einziges der zu den Versuchen benutzten Thiere (Tauben, Hühner, Ratten, junge Hunde) gerettet werden. Es ist indessen wohl möglich, dass mit grösseren Thieren bessere Resultate erzielt worden wären. Beim Menschen ist das Brainard'sche Mittel nur einmal benutzt worden, jedoch zugleich mit dem später zu besprechenden Bibron'schen Mittel.

Das ebenfalls von Brainard als Injection angewandte milchsaure Eisen $(0,5: 30,0$ Wasser $)$ steht an Wirksamkeit noch dem Jod nach.

Günstigere Erfolge sind vielleicht von subcutanen Injectionen einer $1 \%$ igen Chromsäurelösung zu erwarten ${ }^{2}$ ). Dieselbe scheint die Giftwirkungen zum Theil zu zerstören und die Ausbreitung der Localaffectionen zu hindern, und zwar sowohl wenn sie mit dem Gifte gemischt (2 Tropfen der Lösung zum Gifte zugefügt), als auch wenn sie einige Zeit nach demselben injicirt wurde. Sogar die bereits begonnenen Wirkungen des Schlangengiftes konnten dadurch bei Thieren völlig wieder aufgehoben werden, selbst wenn das Mittel erst 15 Minuten nach dem Bisse applicirt wurde. Auch gegen das Gift der Lanzenschlange erwies sich die Chromsäure wirksamer als Jod-

1) Tricard 1. c.

2) M. Ka ufmann, Du venin de la vipère. Paris 1889. - Compt. rend. de la Société de Biologie. 9. sér. T. VI. 10. Févr. 1894. p. 113. - Karlinski, Fortschritte der Medicin. VIII. 16. 1890. 
lösungen $\left.{ }^{1}\right)$. Die Heilung soll danach schnell eintreten, ohne dass caustische Wirkungen entstehen. Die Chromsäure muss aber genau da injicirt werden, wo das Gift ist, und zwar möglichst früh; später, wenn erst Schwellung eingetreten ist, sind mehrere Injectionen in dieselbe nöthig. Bei grösserer Ausbreitung der Schwellung soll man vorher Scarificationen machen. Die Allgemeinwirkungen des Schlangengiftes sollen jedoch durch die Chromsïure nicht aufgehoben, sondern nur abgeschwächt werden. K a u fmann nimmt deshalb zwei verschiedene im Gifte enthaltene Stoffe an, von denen nur der eine, welcher die Localwirkungen veranlasst, durch Chromsäure zerstört werden soll.

Die Schwierigkeit dieser, wie mancher anderer ähnlicher Therapie liegt darin, dass man das Gift nicht so leicht mit dem Mittel treffen kann.

Der Chromsïure ähnlich soll das Chlorwasser wirken. Lenz ${ }^{*}$ ) glaubte der nach Schlangenbiss vermeintlich eintretenden fäulnissartigen Zersetzung des Blutes durch äussere und besonders innerliche Anwendung des Chlorwassers, dessen füulnisswidrige Eigenschaften bei brandigen Wunden er kennen gelernt hatte, entgegenwirken zu können. Strich er das Mittel nur auf die Wunde, so vermochte es nicht zu retten, wandte er es dagegen innerlich an, so rettete es selbst dann noch das Leben, wenn das Gift bereits resorbirt und im ganzen Körper verbreitet war. Er gab seinen sebissenen Hühnern täglich ca. $31 \mathrm{~g}$ Chlorwasser (=0,125 $\mathrm{g}$ Chlor), und kein einziges von ihnen starb an den Folgen des Bisses.

Auch in der neueren Zeit sah man vom Chlor güustige Resultate"). Man verwandte eine durch Glaswolle filtrirte Lösung von Chlorkalk und fand, dass dieses Mittel zuverlässiger wirkt als das übermangansaure Kali, und zwar sowohl wemm man eine Mischung von Chlorkalklösung und Schlangen-

1) Tricard 1. c.

2). Lenz 1. c.

$\left.{ }^{3}\right)$ Aron, Zeitschrift f. klin. Med. VI. 1883. S. 332 u. 385. 
gift, als auch wenn man erst das Schlangengift und darauf Chlorkalklösung injicirte. Noch in letzter Zeit hat man auch in Frankreich, nachdem bereits Roux und Vaillard günstige Wirkungen durch Anwendung unterchlorigsaurer Alkalien gegen Tetanustoxin gesehen hatten, mit Lösungen von Chlorkalk und unterchlorigsaurem Natron bei verschiedenen Schlangengiften gute Erfolge erzielt ${ }^{1}$ ). Es zeigte sich hierbei, dass Thiere, welchen eine sonst in zwei Stunden zum Torle führende Giftdosis inoculirt war, mit dem Leben davonkamen, wenn ihnen innerhalb der ersten 20 Minuten nach der Giftinoculation eine Lösung von unterchlorigsaurem Kalk oder Natron in einer Concentration von 1:36 rings um die Einimpfungsstelle und auch an verschiedenen anderen Körperstellen injicirt wurde. Sogar nach 20 bis zu 30 Minuten wirkten diese Mittel noch in dem Falle, wenn zugleich auch eine schwache Morphiumlösung eingespritzt wurde. Während sich subcutane Injectionen jener Salze stets wirlisam erwiesen, war dies bei intravenösen Injectionen nicht immer der Fall. Uebrigens verdient Chlorkalk den Vorzug vor dem unterchlorigsauren Natron, weil die Einspritzungen von Lösungen des ersteren schmerzlos sein sollen, die des letzteren dagegen nicht.

Es würde sich also empfehlen, nach Anlegung einer: elastischen Ligatur um das gebissene Glied möglichst bald $20-30 \mathrm{cem}$ einer etwa $2 \%$ iggen Lösung von Chlorkalk in die Wunde an mehreren Stellen rings um dieselbe und auch weiter centralwärts einzuspritzen, und zwar so tief, wie die Giftzähne eingedrungen sind; darauf kann man die Ligatur wieder abnehmen. Die Wunde selbst ist mit einer concentrirten Chlorkalklösung reichlich auszuwaschen. Die Chlorkalklösung muss wegen ihrer leichten Zersetzlichkeit fest verschlossen und im Dunkeln aufbewahrt werden.

Ob sich aber dieses Mittel auch bei seiner praktischen

1) A. Calmette, Compt. rend. de la Soc. de Biologie. 9. sér. T. VI. 1894. p. 120. - Annales de l'Institut Pasteur. T. VIII. 1894. p. 275. 
Anwendung beim Menschen eben so wirksam zeigen wird wie bei den Versuchsthieren - das ist eine Frage, die bis jetzt noch nicht zu entscheiden ist.

Auch dem Goldchlorid schrieb man die Fähigkeit zu, durch Bisse von Schlangen, insbesondere der Brillenschlange, vergiftete Thiere durch Neutralisation des absorbirten Giftes heilen zu können, vorausgesetzt, dass dieses Mittel noch vor Eintritt der Athmungslähmung in und um die Wunde, sowie auch an anderen Körperstellen in $1 \%$ iger sterilisirter Lösung eingespritzt würde ${ }^{1}$ ). Indessen hat sich das Goldchlorid nicht bewährt ${ }^{2}$ ). Es schlägt allerdings, wenn man es ausserhalb des Körpers mit den Schlangengifte mischt, die toxisch wirkenden Albumosen desselben nieder, aber seine Heilwirkungen sind selbst bei sofortiger örtlicher Anwendung und selbst bei Inoculation mit dem Cobra-Gifte zugleich sehr zweifelhaft, und von den Kaninchen, welche wirklich von der Brillenschlange gebisseu worden waren, wurde durch Goldchloridinjectionen kein einziges gerettet. Ganz ohne Wirkung bleibt anch die Einspritzung des Mittels in die Venen. Besser als gegen Cobra-Gift scheint das Goldchlorid gegen das Gift der Lanzenschlange zu wirken. Eine Mischung dieses Giftes mit 1 "oiger Goldchloridlösung zeigte sich nämlich bei Thieren stets unwirksam bei Injectionen, und wurde das Goldchlorid sofort nach dem Gifte injicirt, so wurden die Thiere in der Regel gerettet. Bei nicht directem Contacte des Mittels mit dem Gifte trat jedoch nur eine Verzögerung der Giftwirkung ein ${ }^{3}$ ).

Ausser Goldchlorid soll auch Platinchlorid, wenn vor der Einspritzung mit dem Gifte gemischt, die Giftigkeit des letzteren zerstören. Andere, zum Theil schon oben erwähnte Stoffe, wie Zinkchlorid, Jodtinktur, Sublimat, Silber-

1) A. Calmette, Annales de l'Institut Pasteur. 1892. p. 160. Journ. de Pharm. et de Chimie. 1892.

$\left.{ }^{2}\right)$ Kanthack, Lancet. I. 11. June 1892. p. 1296. - Vgl. auch IVall, Indian snake poisons, their nature and effects. London 1883.

$\left.{ }^{3}\right)$ Tricard l. c. 
nitrat, Carbolsäure, Eisenchlorid, schwächen nur die Wirkung des Giftes ab.

Ausser dem Sublimat wurden von Quecksilberpräparaten früher Einreibungen mit grauer Salbe empfohlen.

In Brasilien sollen gegenwärtig rielfach Injectionen von doppelkohlensaurem Natron angewendet werden ${ }^{1}$ ).

Alle diese zuletzt genannten Stoffe haben aber nur eine untergeordnete Bedeutung.

In neuester Zeit liat man durch subcutane Injectionen von Strychnin günstige Erfolge bei Bissen der australischen Giftschlangen erzielt*). Die Veranlassung, mit demselben Versuche anzustellen, gab die Beobachtung, dass das Gift dieser Schlangen eine specifische lähmende Wirkung auf alle die Bewegung bewirkenden und regulirenden Centraltheile des Nervensystems hat, und zwar sollen gerade diejenigen Ganglienzellen von der Lähmung betroffen werden, welche vom Strychnin gereizt werden. Allen australischen Giftschlangen scheint allerdings diese dem Chloralhydrat ähnliche, und schon oben besprochene Wirkung zuzukommen, was man aber nicht auch von den Giften anderer Schlangen in gleicher. Weise behaupten kann, so dass also Strychnin keineswegs als Universalantidot für jeden Schlangenbiss angesehen werden kamm. Das Verdienst, das sich Müller durch Einführung der Strychninbehandlung in Australien erworben hat, wird, vorausgesetzt, dass noch weitere günstige Erfolge mitgetheilt werden sollten, durch diese Einschränkung nicht geschmälert. Die Anwendungsweise besteht in subcutaner Injection von $10 \mathrm{mg}$ Strychnin, eine Dosis, die je nach Umstïnden noch ein- bis zweimal wiederholt werden kann.

Auch bei Bissen der in Ostindien vorkommenden Echis carinata und des Bungarus coeruleus haben sich Strychnin-

1) M. Schanz, Das heutige Brasilien. Hamburg 1893. S. 112.

2) A. M üller, Austral. med. Journ. May 15. 1888. - Austral. med. Gaz. VIII. 1888/89. IX. 1890. - Virchow's Archiv. CXIII. 1888. S. 393. 
injectionen als günstig bewährt ${ }^{1}$ ). Ebenso werden in Nordamerika jetzt vielfach Strychnininjectionen, verbunden mit innerlichem Gebrauche von Alkohol, mit gutem Erfolge angewandt.

Von den innerlich angewandten chemischen Witteln wurde bereits das Ammoniak erwähnt. Aeltere Beobachter empfahlen auch bei Schlangenbiss ein starkes Brechmittel aus Brechweinstein, den man auch auf die Wunde streuen soll. Das letztere ist wohl insoweit werthlos, als die Zerstörung des lebenden Gervebes erst so spät begimnt, dass die Resorption des Giftes damn schon längst beendet sein kann.

Eine Zeit hindurch hatte der Arsenik eine grosse Beriilmmtheit als Gegengift. Sein Gebrauch stammt aus ()stindien, wo er als "Tanjore-Pillen" oder "tanschaurische Pillen" viel angewandt wurde ${ }^{2}$ ). Dieselben bestehen aus weissem Arsenik, von dem jede Pille 0,0).5 g, also eine ziemlich starke Dosis, enthält, ferner aus zwei gepulverten Wurzeln, nämlich velli-navi und nervi-visham, den gepulverten Kernen einer abführend wirkenden Pflanze nervalam, aus Pfeffer und Quecksilber, und zwar alles zu gleichen Theilen. Man bereitet sie in rer Weise, dass man zunïchst Quecksilber mit dem Saft der wilden Baumwollpflanze (Asclepias gigantea) verreibt, bis die Kügelchen unsichtbar geworden sind, dann werden Arsenik und die übrigen Ingiedienzien in gepulvertem Zustande hinzugefügt und das Ganze mit Baumwollsaft zur Pillencousistenz verarbeitet. Nach dem Biss einer Brillenschlange giebt man eine gepulverte Pille mit etras warmem Wasser gemischt; wem die Vergiftungssymptome zunehmen, nach einer Viertelstunde weitere zwei Pillen und eventuell nach einer Stunde noch eine Pille. Dies genüigt im Allgemeinen. Ausserdem soll man die Wunde dilatiren und die warme Leber eines Vogels darauf legen. Beim Biss der

1) Banerjie, Lancet. I. 22. May 1892. p. 1183.

$\left.{ }^{2}\right)$ Russe 11, Account of Indian serpents. I. 1796. p. 74 ff. 
Viperı giebt man zwei Pillen, und wenn diese nicht wirken, nach einer halben Stunde noch zwei. Ist das Leben des Gebissenen augenscheinlich in grosser Gefahr, so verabfolgt man vier Pillen und macht auf dem Scheitel des Kopfes einen Einschnitt, reibt eine pulverisirte Pille in die Wunde ein und legt eine Vogelleber auf diese Stelle. Für den Biss weniger giftiger Schlangen ist eine Pille jeden Morgen für drei Tage genügend. Sechs Tage lang darf der Gebissene nur Reiswasser und Reis oder Milch und Reis geniessen; er muss Salz vermeiden, darf nur warmes Wasser trinken und in den ersten 24 Stunden auch nicht schlafen. Die frisch bereiteten Pillen wirken stärker als alte.

Russell fand bei seinen Thierversuchen diese Arsenikpillen nur sehr unsicher wirkend, und es scheint auch, dass dieselben in neuerer Zeit selbst in Indien ihren guten Ruf rerloren haben. Die Indier besitzen übrigens noch andere, unbekannte Mittel gegen Schlangengift.

Nach Pöppig wird auch in Peru und Columbien der Arsenik sehr gerühmt, ebenso Sublimat.

Ein neueres Mittel ist das Bibron'sche Antidot. Dasselbe hesteht aus $18,75 \mathrm{~g}$ Brom, $0,24 \mathrm{~g}$ Jodkali und $0,12 \mathrm{~g}$ Sublimat. Davon werden 10 Tropfen mit 1-2 Esslöffel Wein oder Branntwein gegeben und nach Umstïnden stiundlich wiederholt; auch soll man die Bissstelle damit einreiben. Der Erfinder dieser Zusammensetzung erprobte es an sich selbst und auch mehrere andere Untersucher ${ }^{1}$ ) empfahlen dasselbe. Hunde sollen unter dem Einflusse des Mittels für einige Zeit gegen Klapper'schlangengift geschützt sein. So soll in $17 \mathrm{Ex}-$ perimenten, bei denen drei Hunde zu verschiedenen Zeiten durch 17 verschiedene Schlangen gebissen waren, in keinem Falle das Mittel versagt haben. Es fehlen aber nähere Angaben über den Zustand der Schlangen, die Zahl der Biss-

1) Hammond, Americ. Journ. XXXV. p. 94. 1858; ibid. p. 375. - De Vesey, Ibid. April 1858. - Walker and Sabal, Ibid. Oct. 1858. - Henry, Ibid. XXXVIII. - Jones, Philad. med. and surg. Report. July 20. 1889. p. 61. 
stellen und den Ort des Bisses. Ein Wolf wurde einmal durch das Brom augenscheinlich gerettet, starb jedoch, als er zu einer anderen Zeit dreimal gebissen war. Ja, in einem Falle wurden sogar bei einem gebissenen Menschen die Localsymptome durch den Gebrauch des Mittels schnell leichter, und in einem anderen, fast hoffinungslosen Falle liessen die schlimmsten Symptome nach dem Gebrauche zweier Dosen des Mittels schnell nach. Weir Mitchell vernisste jedoch bei seinen Versuchen die prophylactische Wirkung des Bibronschen Mittels und fand es auch sonst ziemlich unzuverlässig.

Weitere gegen Schlangenbiss empfohlene innerlich zu nehmende Mittel sind Calomel und Cyanquecksilber. Gegen den Biss von Coluber Ammodytes L. sollte die Plenck'sche Quecksilberlösung das beste Gegennittel sein. Croft ${ }^{1}$ ) rühmt eine starke Lösung von Jod in Jodkalium. Auch Bromkali und $\mathrm{Ch}$ inin wurden früher zuweilen gegen Schlangenbiss angewandt.

Alle diese Mittel stehen aber an Bedeutung weit zurück hinter einem anderen, welches gegenwärtig als das zweckmässigste von allen innerlich gegen Schlangengift zu nehmenden die allgemeine Anerkennung gefunden hat, nämlich hinter dem Alkohol, der hierbei als kräftiges, durch ähnliche Stoffe nicht genügend zu ersetzendes Stimulans wirlit. Ehe seine Anwendung gegen Schlangenbiss allgemein wurde, war derselbe schon lange in Dalmatien gegen Vipernbiss in Gebrauch. Er muss in grossen Quantitäten, bis zum Stadium des Rausches, resp. leichten Trunkenseins verabfolgt werden. Tiefe Trunkenheit ist jedoch zu vermeiden, da sie einen Zustand der Sedation, nicht der Excitation darstellt. Tief betrunkene Leute sind, wie die Erfahrung lehrte, wenn sie von Schlangen zufällig grebissen werden, nicht immun gegen das Gift. Der Einwand, der gegen die Anwendung von Alkokol erhoben wurde, dass nämlich das mit diesem gemischte Gift, wemu injicirt, schnell tödtlich sei, ist unberechtigt, da der Alkohol ja gar nicht als

1) Croft, Chem. News. XVIL. 1882. p. 165. 
chemisch auf das Gift wirkendes Antidot angesehen wird. Wenn häufiges Erbrechen das Verweilen des Alkohols im Magen vereitelt, so kamn man vorsichtig Alkoholdämpfe oder auch A ether inhaliren lassen oder Alkoholklystiere verabfolgen.

Auch die Wilden wissen die günstige Wirkung alkoholischer Mittel bei Schlangenbiss wohl zu schätzen. So gebrauchen die Indianer Mexikos einen Aloë-Branntwein (mescal), der durch Gährenlassen und nachherige Destillation des Saftes der Agave mexicana septentrionalis gewonnen wird und die Stärke eines $40 \%$ igen Spiritus hat ${ }^{1}$ ).

Statt des Alkohols kann man auch andere excitirende Mittel anwenden, namentlich Aether, starken Kaffee, starken heissen Thee, Campherinjectionen u. s. w. Paletta empfahl als diaphoretisch wirkendes Excitans besonders das Trinken von Glühwein.

Es hat übrigens auch nicht an Leuten gefehlt, welche die Anwendung von analeptischen Mitteln wenigstens bei allen schweren Fällen von Vergiftung durch Schlangenbiss gänzlich verwarfen, weil sich bei Thierversuchen gezeigt hatte, dass jene Mittel durch Erhöhung des Blutdruckes eine ungeheure Steigerung der nach Schlangenbiss so häufig eintretenden hämorrhagischen Processe (Lungenblutung u. a.) hervorriefen ²). Indessen stehen doch diese Resultate in einem solchen Widerspruche zu den Erfahrungen, welche man mit den Stimulantien bei von Giftschlangen gebissenen Menschen gemacht hat, dass es sicherlich nicht gerechtfertigt ist, diese Mittel als schädlich bei Schlangenbiss zu erklïren und deshalb ihre Anwendung zu unterlassen.

Zum Schlusse seien noch zwei Mittel, Atropin und Coffeïn, erwähnt, die in Thierversuchen zum Theil mit Erfolg benutzt wurden ${ }^{3}$ ). Das erstere wurde gewählt, weil es

1) Naphegyi, Philad. med. and. surg. Rec. XVIII. 12. p. 249. March 1868.

2) Feoktistow, Mém. de l'Acad. des scienc. de St. Pétersbourg. T. XXXVI. 1888. No. 4 .

3) Aron, Zeitschr. f, klin. Med. VI. 1883. S. 332 u. 385. 
gegen das ähnlich wie Schlangengift auf Herz und Athmung wirkende Morphium als Gegenmittel gegeben wird; es erregt heftig das Gehirn, wirkt indirect erregend auf die Herzaction durch vorübergehende Lühmung der hemmenden Vagusendig'ungen, steigert dadurch gleichzeitig den Blutdruck, und beschleunigt endlich auch die Athmung durch directe Erregung des Respirationscentrums in der Medulla oblongata. Alle diese Wirkungen entsprechen allerdings denen, welche ein ideales Gegenmittel gegen Schlangengift besitzen müsste. Indessen erreichte man mit dem Atropin nur, dass zwar die Herzaction der damit behandelten Thiere eine regere zu sein schien, der Tod aber mur in einem Falle dadurch hinausgeschohen wurde.

Das ähnlich wie Atropin wirkende C offe ïn liefert leider auch keine besseren Resultate.

Als neuestes innerliches Antidot gegen Schlangengift wird auf Grund nur eines Falles das Cocaïn bezeichnet ${ }^{1}$ ). Bei einem von einer Kreuzotter Gebissenen wurde, nachdem bereits schwere Erscheinungen eingetreten waren, 1/1 Spritze einer 5 foigen Cocaïnlösung subcutan eingespritzt, und der Kranke gerettet. Da ausser dem Cocaïn keine anderen Hedicamente angewandt waren, so meinte man, dasselbe müsste in diesem Falle als Antidot gegen Schlangengift gewirkt haben, bedenkt aber dabei nicht, dass Kreuzotterbisse selbst nach Eintritt schwerer Symptome in der Regel doch noch von selbst in Heilung übergehen, und dass ausserdem in dem betreffenden Falle dem Gebissenen zugleich Wein, schwarzer Kaffee etc. verabreicht worden waren. Das Vorstehende ist selbstverständlich keineswegs geeignet, dem Cocaïn den Charakter eines Antidotes zu geben.

\section{Pflanzliche Mittel.}

Von allen Heilmitteln gegen Schlangenbiss haben von Tem frühesten Alterthum an bis in die neueste Zeit die Pflanzen ohne Zweifel die grösste Bedeutung gehabt und haben sie in den Tropen zum Theil auch heute noch. Zahllos ist in allen

1) Harlander, Wiener med. Presse. XXXVII. 1893. S. 1455. 
Ländern, in denen überhaupt Giftschlangen vorkommen, und zwar besonder's in Ostindien und Südamerika, die Menge derjenigen Pflanzen, welche als specifische Gegenmittel gegen den Schlangenbiss empfohlen worden sind, und manche von ihneri, bei denen häufig schon die Namen, wie Schlangenwurzel, Schlangenholz, Serpentina, Dracontium, Dracunculus etc., auf den Zweck ihres Gebrauches hinweisen, hatten als unfehlbar eine allgemeine Berühmtheit erlangt. Nachdem aber unbefangene Beobachtungen und wissenschaftliche Untersuchungen ergeben haben, dass von den bekanntesten und am häufigsten angewandten Pflanzen keine einzige als sicheres Heilmittel gegen Schlangenbiss zu betrachten ist, und dass auch die viel gerühmte Mikania Guaco kein Specificum ist, so hat sich gegenwärtig ärztlicherseits die Anwendung von Pflanzen in der Therapie des Schlangenbisses vermindert, und man überlässt es selbst in den Tropenländern meistens nur noch den Eingeborenen, die Gebissenen mit Pflanzenpräparaten zu behandeln. Fast überall sind die letzteren rurch die chemischen Mittel verdrängt worden.

Diese Missachtung der Pflanzen ist aber durchaus nicht gerechtfertigt, denn wenu auch viele von ilınen, namentlich in Alterthum und Mittelalter, nur aus reinem Aberglauben angewandt wurden, z. B. weil sie die "Signaturen" von Schlangen trügen, d. h. weil ihre Wurzeln schlangenförmig gekrümmt wären, oder ihre Dornen Vipernzähnen glichen. oder ihre Bliiten in der Zeichnung Vipernköpfen oder -zungen ähnlich sähen u. dgl., so sind doch, wie wir später sehen werden, viele Pflanzen darunter, welche durch ihre Wirkung als Diuretica, Diaphoretica, Purgantia und Emetica die Ausscheidung des Schlangengiftes aus dem Körper befördern oder durch ihre stimulirende Wirkung die Herzthätigkeit und die Athmung aufrecht erhalten können, bis durch die Elimination des Giftes jede Gefahr vorüber ist. Jedenfalls ist nicht zu bezweifeln, dass derartig wirkende Pflanzen als physiologische Gegenmittel bei Vergiftung durch Schlangenbiss ausgezeichnete Dienste leisten können. Freilich angeblich specifisch

Brenning, Die Vergiftungen durch Schlangen. 
wirkende Ptlanzen sind bisher in Europa noch nie in rationellen Versuchen als solche erkannt worden. Es ist aber auch hervorzuheben, dass derartige Experimente bisher nur ganz vereinzelt angestellt wurden, und dass es ein Postulat ist, diejenigen Pflanzen. die von Reisenden als Antidota geriihmt unıl von den Eingeborenen tropischer Länder gebrancht werden. dem Laboritoriumsversuche zu unterwerfen. Erst nach solchen Prüfungen wird sich beurtheilen lassen, in welchem Umfange Wahrheit oder Aberglaube bei der Beurtheilung solcher tropischer Pflanzen eine Rolle spielen.

Ich habe mich im Folgenden bemüht, möglichst alle Pflanzen aufzuzählen, welche jemals als Mittel gegen Schlangenbiss gehraucht worden sind und noch jetzt gebraucht werden. Yon den im Alterthum angewandten Pflanzen habe ich alle diejenigen berïcksichtigt, welche sich überhaupt mit einiger Sicherheit bestimmen lassen. Auch von den in der Neuzeit gebrauchten Pflanzen hoffe ich keine irgendwie wichtigere übergangen zu haben, obwohl es sehr wohl möglich ist, dass in dieser oder jener Reisebeschreibung noch Pflanzen erwähnt werden, deren Anwendung gegen Schlangenbiss in den von mir benutzten Werken mit Schweigen ïhergangen ist.

\section{Ramunculacere.}

Die Ptlanzen dieser Familie spielen in der Therupie des Schlamgenbisses nur eine untergeordnete Rolle; auch im Alterthum gebrauchte man nur wenige von ihnen.

Nigella sativa L., Schwarzkümmel, von Plinius ${ }^{1}$ ) als Gith, Melanthion, Melaspermon angeführt, legte man mit Essig und Honig zusammen auf die Bisswunde. Die Samen der PHanze. früher als Semen Nigellae s. Melanthii officinell, enthalten ein ätherisches Oel, einen glycosidähnlichen Körper, zwei Alkaloide und ein Glycosid Melanthin. Die Wirkung ist vorzugsweise eine diuretische. Das Hauptalkaloid, Nigellin genannt, bewirkt bei intravenöser Injection grösserer

1) Plinius, Hist. nat. XX. 71. 
Mengen eine Curare-artige Lähmung; hohe Dosen lähmen den Herzmuskel, erregen ähnlich dem Pilocarpin Speichel- und Thränenfluss und rufen Anfälle von Athemnot hervor. Das: zweite Alkaloid, Conigellin, bewirkt ebenfalls Herzlähmung ${ }^{1}$ ).

$\mathrm{N}$. aristata Sm. ist die von den Alten ${ }^{2}$ ) als $\mathrm{Cuminum}$ oder Cuminum silvestre bezeichnete Pflanze, welche wohl ähnlich wie die vorige wirkt.

Paeonia officinalis L. (P. peregrina Mill.), die Glykyside, Paeonia, Pentorobos des Plinius ${ }^{3}$ ). Man gałs die schwarzen Samen der Pflanze in Wein. Dieselben enthalten ausser anderen Bestandtheilen auch ein Alkaloid.

P. corallina Retz. wurde ebenso gebraucht und ebenso bezeichnet wie die vorige Art.

Delphinium Staphisagria L., die Staphis oder Astaphis der Alten. Die zerriebenen Blüthen sollen nach Plinius ${ }^{4}$ ) mit Wein innerlich und äusserlich angewandt werden.

Von auch in neuerer Zeit angewandten Pflanzen sind zu nennen:

Helleborus antiquorum Braun, der Helleborus melas des Hippokrates und

H. niger L., die schwarze Nieswurz, deren Wurzel früher officinell war $^{5}$ ).

Die Wurzeln und Wurzelblätter der Gattung Helleborus enthalten neben fetten Oelen, scharfen Harzen und anderen Stoffen als wesentliche Bestandtheile die beiden Glycoside Helleboreïn und Helleborin. Das Helleboreïn ist ein Herzgift (2-4 dg tödten Katzen in 2-5) Stunden) und wirkt wie Digitalin. Ausserdem wirkt es auf den Darm als Drasticum, auf die Respiration, die Secretionsorgane, besonders Speicheldrüsen und Nieren, und auf das Nervensystem in der

1) Pellacani, Arch. f. experim. Pathol. u. Pharmakol. XVI. 1883. S. 440.

2) Plinius, Hist. nat. XX. 57.

3) Ibid. XXVII. 60.

4) Ibid. XXIII. 13.

5) Gazette de Santé. 5. Nov. 1822. 
Art, dass sich lähmungsartige Schwäche und Convulsionen einstellen. Die örtliche Wirkung ist eine irritirende. Das Helleborin dagegen hat narkotische Eigenschaften und tödtet durch Lähmung der Nervencentra. Auch auf den Darm wirkt es ein, doch schwächer als Helleboreïn.

In Nordamerika ${ }^{1}$ ) gebrauchte man früher und vielleicht auch noch jetzt bei Schlangenbiss:

Actaea racemosa L., welche die dort officinelle, sehr bittere Radix Cimicifugae Serpentariae liefert, sowie einige Arten der Gattung Thalictrum. Das in einigen derselhen enthaltene Thalictrin wirkt dem Aconitin ähnlich, jerloch weit schwïcher und mehr lähmend, aber weniger brechenerregend und Athemstörung herrorrufend. Die Diurese wird angeregt.

Ranunculus repens L. und andere Arten der Gattung Ranunculus. In derselben scheint bei vielen Arten das Anemonin vertreten zu sein, welches eine lähmende Wirkung auf Gehirn und Medulla oblongata ausübt.

Aconitum ferox Wall., Mahoor (Hind.), Vashanavi (T'am.) gilt in Indien als Mittel gegen Schlangenbiss ${ }^{2}$ ). Die Pflanze enthält ebenso wie Aconitum Napellus und andere Aconitum-Arten giftige Basen. Das Extract bewirkt Athemnoth, Schwäche, Lähmung, die bei den Hinterextremitïten beginnt, Schwindel, Convulsionen, Pupillenerweiterung und Tod durch Asphyxie.

\section{Magnoliaceae.}

Drimys granatensis L. ist in Südamerika, besonders in Columbien, unter den Namen Malambo, Bejuco de (tuayaquil, Canelo de la costa als Mittel gegen Schlangenbiss bekannt ${ }^{3}$ ).

1) Schöpf, Reisen durch einige der mittleren und südlichen Vereinigten nordamerikanischen Staaten nach Ostflorida und den Bahamainseln. Erlangen 1788. Bd. I. S. 191.

$\left.{ }^{2}\right)$ Drury, The useful Plants of India. 2. ed. London 1873. p. 12.

3) Saffray, Voyage à la Nouvelle Grenade (in le T'our du monde, t. XXIV. p. 98). 


\section{Menispermaceae.}

Aus dieser Familie werden in Südamerika und in Ostindien folgende Pflanzen gegen Schlangenbiss angewandt:

Cissampelos glaberima St. Hil., "Erva de Nossa Senhora*, "Sipo de cobras", in Brasilien ${ }^{1}$ ).

C. ebracteata St. Hil. (C. ovalifolia D. C.) in Brasilien (.Orelha de onça“") ${ }^{1}$ ).

C. Caepeba L. in Südamerika.

C. convolvulacea Willd. (C. Pareira L.) in Südamerika und Ostindien ${ }^{2}$ ).

Die gegen Schlangenbiss benutzten Wurzeln ier Cissampelos-Arten wirken diaphoretisch und diuretisch.

Cocculus Filipendula Mart., "Abuta miuda", in Brasilien ${ }^{1}$ ).

C. acuminatus D.C. (hindustanischer Name: b a ga mushadee) in Ostindien (Stengel) ${ }^{2}$ ).

Abuta rufescens Aubl. (Cocculus Pahni Mart.) in Guyana (Wurzel und Stengel) ${ }^{3}$ ).

Die angeführten Arten der Familie scheinen bisher nicht genauer chemisch untersucht $\mathrm{zu}$ sein. Vielleicht enthalten die Cocculus-Arten, wie die bekannte Colombo-Wurzel (Jateorrhiza palmata Miers., Cocculus palmatus Wallich.), in ihren Wurzeln den Bitterstoff Columbin und die Columbosüure, oder in ihren Fruchtkernen, wie die Kokkelskörner (Anamirta Cocculus Wight u. Arnod, Cocculus suberosus Dec.), das als Hirnkrampfgift wirkende Pikrotoxin.

Tiliacora acuminata (Miers.), Bagaluta (Hind.), Tilia-kora (Beng.), Vullycaniram (Mal.), wird in Indien zwischen zwei Steinen zerrieben und mit Wasser gemischt bei Schlangenbiss angewandt ${ }^{4}$ ).

\footnotetext{
1) v. Martius, Syst. mat. med. veget. Brasil. 1843. p. 42.

$\left.{ }^{2}\right)$ Waring, Madras Quart. Journ. of Med. Sc. IV. p. 5.

3) Lanessan, Les plantes utiles des colonies françaises. Paris
} 1886. p. 364 .

$\left.{ }^{4}\right)$ Drury l. c. p. 427 . 


\section{Berberidaceae.}

Von Leontice Leontopetalum L. gebrauchte man im Alterthum die Wurzel gegen Schlangenbiss.

\section{Papaveraceae.}

Papaver somniferum L. Mohnsaft resp. Opium wurde von Avicenna, Mercurialis, Grevinus und selbst noch in der ersten Hälfte dieses Jahrhunderts als Mittel gegen Schlangenbiss empfohlen, obwohl der wesentlichste seiner Bestandtheile, das Morphium, anstatt der entgegengesetzten fast die nämlichen Wirkungen wie das Schlangengift hervorruft. Auch die verschiedenen Arten von Theriak enthielten als Hauptbestandtheil fast immer Opium, das Meconium der Alten.

P. Argemone L. wird als Argemonia von CeIsus ${ }^{1}$ ) und Apulejus Platonicus ${ }^{2}$ ) gegen Schlangenbiss gerühmt.

Chelidonium majus L. wird von Plinius ${ }^{\circ}$ als Mittel gegen Schlangenbiss erwähnt. Wurzel und Kraut waren früher officinell und wurden namentlich bei Stockungen im Pfortadersystem gebraucht. Die Pflanze enthält ausser anderen Stoffen in ihrer Wurzel die Alkaloide Chelidonin, a-Homochelidonin, $\beta-H o m o c h e l i d o n i n$. Chelerythrin und Protopin.

Sanguinaria canadensis L. Ein Decoct der Wurzel dieser Pflinze wird in den Vereinigten Staaten gegen Schlangenbiss und auch sonst als Emeticum, Expectorans, Diaphoreticum, Purgans und Stimulans angewandt. Die Wurzel ist dort als blood-root oder Puccoon bekannt "). Sie enthält die

1) Celsus, De medicina. V. cap. 27.

$\left.{ }^{2}\right)$ A pulejus Platonicus, De viribus herbarum.

3) Plinius, Hist. nat. XXV. 56.

4) Schöpf, Materia medica americana. 1787. 
Alkaloide Sanguinarin, $\beta$-Homochelidonin, Chelerythrin und Protopin ${ }^{1}$ ).

Argemone mexicana L. wird auf Martinique gegen den Biss der Lanzenschlange gebraucht und hat eine diaphoretische Wirkung ${ }^{2}$ ).

Die Papareraceenalkaloide sind neuerdings von H. Meyer ${ }^{3}$ ) untersucht worden. Danach scheint es, als ob das Protopin, das sich auch im Opium und wahrscheinlich auch in Macleya cordata findet, von allgemeiner Bedeutung für die ganze Familie ist. Es erregt die psychische Sphäre und führt in grösseren Dosen Krümpfe und Tod durch Erstickung oder Erschöpfung herbei. Herz und Gefässnervencentrum werden gelähmt, die Athmung aber wird nicht beeinflusst.

Das Chelidonin liefert bei Oxydation mit Kaliumpermanganat dieselben Producte wie Morphium, so dass man auf eine gewisse Verwandtschaft dieser beiden Alkaloide schliessen kann. Auch seine Wirkung ist eine dem Morphium ähnliche narkotische. Es lähmt das centrale und einen Theil des peripherischen Nervensystems. Die Pulsfrequenz wirl herabgesetzt, der Blutdruck fällt zuerst, steigt damn wieder zur Norm an; bei grossen Dosen sinkt er stetig. Die Herzthätigkeit wird durch Narkose der motorischen Ganglien und durch Erregung der Vagus-Endigungen im Herzen gelähmt.

Das \%-Homochelidonin wirkt fast wie Chelidonin. Es ruft morphiumartige Narkose und Analgesie, absteigende Paralyse, Lähmung der sensiblen Nervenendigungen und der motorischen Herzganglien hervor.

Beim $\beta-H o m o c h e l i d o n i n$ sind, ähnlich wie beim Protopin, die narkotischen Wirkungen schwächer, die krampferregenden stärker. Es wirkt örtlich stark anästhesirend.

1) Ueber die Alkaloide der Wurzel von Sanguinaria s. Ko enig, Inaug.-Diss. Marburg 1890 und Tiet $\%$, Inaug.-Diss. Narburg 1891.

2) Rufz, Enquête. p. 131.

${ }^{3}$ ) H. Meyer, Archiv für experim. Pathologie und Pharmakologie. XXIX. 1892. S. 397. Vgl. auch E. Schmidt, Archiv der Pharmacie. CCXXVIII. 1890. S. 96 . CCXXXI. 1893. S. 136. 
Das Sanguinarin ist ein heftiges Gift, besonders für die nervösen Centralorgane. Es erhöht stark die Reflexerregbarkeit, verursacht in grossen Dosen Kr:̈impfe mit schnellem Uebergang in Lähmung und Speichelfluss. Die Athemfrequenz ist anfangs erhöht und sistirt plötzlich bei letalem Ausgange. Der Blutdruck ist ohne wesentliche Aenderung der Pulsfrequenz erhöht, bei starken Dosen aber herabgesetzt durch Lähmung des Gefässnervencentrums.

Das Chelerythrin endlich bewirkt absteigende motorische Paralyse und Tod durch Athemlähmung. Grosse Dosen lähmen auch die Herzaction und die vasomotorischen Centren. Dem Chelerythrin wird meistens die Schuld an der Giftigkeit des Chelidonium majus zugeschrieben, indessen ist es darin in nur ganz minimalen Mengen enthalten. Die Schärfe der Pflanze beruht viehmehr auf in ihrem gelben Milchsafte befindlichen, vermuthlich harzartigen Stoffen. Das trockene Kraut ist unwirksam und unschädlich.

\section{Cruciferae.}

Die wenigen gegen Schlangenbiss angewandten Pflanzen dieser Familie sind im Wesentlichen folgende:

Sin ap is alba L. Der Senf wurde, mit Essig abgerieben, auf die Bisswunde gelegt ${ }^{1}$ ). Die Samen enthalten ausser anderen Stoffen das Alkaloid Sinapin und das Glycosid $\mathrm{Sin}$ alb in.

Brassica Rapa L. (Rapo der Alten). Die Samen wurden aufgelegt und in Wein getrunken ${ }^{2}$ ).

Lepidium sativum L.

Isatis tinctoria L. (Isatis sativa, Angion, Arufion, Gluta, Glastum) $\left.{ }^{*}\right)$. Die Pflanze enthält Indican.

Raphanus sativus L. ${ }^{4}$ ).

1) Plinius, Hist. nat. XX, 87.

2) Ibid. XX. 9.

$\left.{ }^{3}\right)$ Apulejus Platonicus 1. c.

4) Petrus de Abano, De venenis. 1473. 


\section{Alyssum spinosum L. ${ }^{1}$ ) (s. Echium vulgare).}

Ausser diesen Arten werden von alten Autoren noch einige nicht genauer zu bestimmende Cruciferen erwähnt, wie Nasturtium, Lepidium, Iberis, Thlaspi, Eruca.

\section{Cappuridaceae.}

Capparis spinosa L. wurde nur aus dem Grunde angerwandt, weil die Dornen den Vipernzähnen ähnlich wären ${ }^{2}$ ).

\section{Violaceae.}

Viola ovata Nutt. Ein Infus der Pflanze wurde von Williams empfohlen ${ }^{3}$ ).

\section{Bixineae.}

Von Flacourtia sepiaria Roxb., Courou moelli (Mal.), Sottacla (Tam.), giebt man in Indien innerlich ein Infus der Blätter und Wurzel ${ }^{4}$ ).

\section{Polygalaceae.}

Polygala Senega L. ("rattle-snake root"). Die Senegawurzel führen die Seneka-Indianer in Nordamerika überall, wo sie von einer Schlange gebissen zu werden fürchten, bei sich, streuen, sobald sie gebissen sind, etwas von der gepulverten Wurzel in die Wunde und nehmen auch eine geringe Menge davon ein ${ }^{5}$ ). Der Gebrauch der Pflanze gegen Schlangenbiss wurde im Jahre 1735 durch John Tennant bekannt, der das Geheimniss von den Indianern erfahren hatte ${ }^{6}$ ). Die Wurzel enthält als wirksamen Bestandtheil ein Saponin, welches expectorirende Eigenschaften hat, in grösseren Dosen

1) Schöpf, Reisen.

$\left.{ }^{2}\right)$ Redi, Observationes de vipera. 1729.

3) Williams, Journ. de chim. méd. Nov. 1834.

4) Rhe ede, Hort. Malabar. V. 77.

$\left.{ }^{5}\right) \mathrm{Schöpf} \mathrm{l.c.}$ Vol. II.

$\left.{ }^{6}\right)$ Barton, Vegetable Mat. med. of the United States. 1817/18. 
aber das Herz, das vasomotorische und das Athmungscentrum lähmt. Die darin enthaltene Quillajasäure ist ein Protoplasmagift, indem sie lebendes Protoplasma in todtes verwaindelt und die rothen Blutkörperchen auflöst. Diese Wirkung zeigt sich aber nur bei subcutaner Injection der Säure, innerlich genommen ist sie unwirksam ${ }^{1}$ ). Von geringerer Bedeutung sind:

Polygala purpurea Nutt.,

P. sanguinea L., welche in Nordamerika gegen Schlangenbiss gebraucht werden, und

P. crotalarioides Roxb., die in Vorderindien zu demselben Zwecke angewandt wird ${ }^{2}$ ).

\section{Caryophyllaceae.}

Plinius ${ }^{3}$ ) empfiehlt den Samen der feuerrothen Lychnis in Wein abgerieben zu trinken, womit er vielleicht die südeuropäische Agrostemma coronaria L. meint.

Auch in neuerer Zeit scheinen die Pflanzen dieser Familie uur sehr selten gegen Schlangenbiss angewandt worden zu sein. Die einzige zu ermittelnde Art ist

Polycarpaea spadacea Lam. in Vorderindien ${ }^{4}$ ).

\section{Portulacene.}

Portulaca oleracea L. (Porcillaca, Peplis) wurde im Alterthum gegen die Bisse des Haemorrhus und Prester gegessen und aufgelegt ${ }^{5}$ ).

\section{Hypericineae.}

Das von älteren Autoren empfohlene Hyperikon oder Hyperion ist vielleicht identisch mit Hypericum Coris L.

1) Kobert, Archiv f. experim. Pathol. u. Pharm. XXIII. 1887. S. 232.

2) Madras Quart. Journ. IV. p. 7.

$\left.{ }^{3}\right)$ Plinius, Hist. nat. XXI. 98.

4) Rheede, Hort. Malabar. X. 131.

5) Plinius, Hist. nat. XX. 81 . 
In Brasilien benutzt man von Hypericum laxiusculum St. Hil. ("Alecrim bravo") und H. connatum Lam. ("Orelha de Gato") ein Decoct der adstringirend wirkenden Blätter ${ }^{1}$ ).

\section{Guttiferae.}

Mesua ferrea L., hindostanisch Nagasur. Blüthen, Blätter und Rinde werden in Indien innerlich und äusserlich als Pulver angewandt. Die Wirkung ist eine diaphoretische ${ }^{2}$ ).

\section{Malvaceae.}

Malven wurden bereits im Alterthum zuweilen bei S'chlangenbiss gebraucht. In der Neuzeit wendet man rou Malvaceen an:

Hibiscus Abelmoschus L., Kala-kastoree (Hind.), Katta-kasturi (Mal.), Kathe-kasturi, Kasturi-venday, Vettlei-kustorei (Tam.) in Indien ${ }^{3}$ ) und

Gossypium brasiliense Mact. auf Martinique ${ }^{1}$ ), und zwar hiervon ein Infus der Wurzel, von Hibiscus dagegen die an Pflanzenschleim reichen Samen innerlich und äusserlich.

\section{Lineae.}

Linum usitatissimum L. Leinsamen werden ron Avicenna gegen Schlangenbiss empfohlen.

Erythroxylon anguifugum Mart. („Fruta de Pomba"). Man benutzt hiervon in Brasilien die Rinde der Wurzel ${ }^{5}$ )

Von Hugonia Mystax L., Modera canni (Mal.), A goore (Tam.), gebraucht man in Indien die zerquetschte IVurzel äusserlich und die Wurzelrinde innerlich ${ }^{6}$ ). Die

1) v. Martius, Syst. mat. med. Brasil. p. 116.

2) Madras Quart. Journ. IV. p. 12.

3) Ibid. p. 11.

4) Rufz, Enquête. p. 138.

$\left.{ }^{5}\right)$ v. Martius 1. c. p. 73.

C) Rheede, Hort. Malabar. II. 30. 
Pflanze wirkt diuretisch, diaphoretisch, tonisch und stimulirend.

\section{Malpighiaceae.}

Von Byrsonima crassifolia H. B. Kth. (B. Moureila Loud.) wird in Guyana ein Infus der Rinde gegen Schlangenbiss angewandt ${ }^{1}$ ).

\section{Zygophylleae.}

Tribulus terrestris L. wird von Dioscorides als Mittel gegen Schlangenbiss erwähnt.

\section{Geraniaceae.}

Eine Oxalis war im Alterthum in Gebrauch ${ }^{2}$ ).

Averrhoa Carambola L. wird in $\operatorname{Indien}{ }^{3}$ ), und

Impatiens in mehreren Arten in Nordamerika benutzt ${ }^{1}$ ).

\section{Rutaceae.}

Ruta graveolens L. (Ruta, Peganum) wurde im Alterthum als Mittel gegen Schlangenbiss sehr hoch geschätzt und als solches von Dioscorides, Plinius, Celsus und Anderen empfohlen. Die Raute enthält ausser einem ätherischen Oele in ihren Blättern das Glycosid Rutin.

Der Gebrauch des

Dictamnus albus L. gehörte mehr dem Mittelalter als dem Alterthum an.

Citrus Limonum Risso. Schon Rhazes empfiehlt Citronensamen gegen Schlangenbiss, und noch gegenwärtig scheint der Citronensaft in den verschiedensten Ländern zu demselben Zwecke angewandt zu werden, so auf Martinique innerlich und äusserlich, ebenso wie die Wurzel

1) Rich. Schomburgk, Reisen in Britisch-Guyana, und Laness:all 1. L. S. 371 .

2) Scribon. Largus in Matthioli Commentarii.

$\left.{ }^{3}\right) \mathrm{Burman}$, Thesaur. Zeylanicus. p. 148.

^) Germer, Wöchentlicher Leuchtthurm von Erie. 23. Juli 1869. 
des Baumes gregen den Biss der Lanzenschlange ${ }^{1}$ ), und auch in Paraguas ${ }^{2}$ ). Die Citronen enthalten Citronenöl, Citronensäure und in den Kernen das Glycosid Limonin.

Pilocarpus pinnatus Lam. Die Blätter dieser Pflanze, die Folia Jaborandi ${ }^{3}$ ), in Südamerika und zwar besonders in Brasilien schon lange als Mittel gegen Schlangenbiss bekannt und geschätzt, wurden erst 1874 näher bekannt. Sie enthalten als wirksame Bestandtheile neben einem ätherischen Oele zwei Alkaloide, Pilocarpin und Pilocarpidin ${ }^{4}$ ). Beide bewirken hauptsächlich Termehrung der Speichel- und Schweisssecretion, jedoch das Pilocarpin in weit stärkerem Grade als Pilocarpidin. Auch die Diurese wird gesteigert. Vielleicht ist die Beschleunigung der Giftausscheidung durch die Anregung der Drüsenthätigkeit als Ursache des Gebrauchs heranzuziehen.

Bergera Königii L. (Murraya Königii Spr.), Karibepon, Karreya-pela (Mal.). C'arroova-pillay (Tam.), Karay-paak (Hind.). Rinde und Wurzel werden in Indien gegen Schlangenbiss gebraucht ${ }^{5}$ ). Tielleicht tindet sich darin ebenso wie in den Blüthen von Murraya exotica das Glycosid Murrayin. Die Wirkung ist eine stimulirende und laxirende. Auch legt man die in Milch gekochten Blätter der Pflanze zerquetscht als Umschlag auf die Bissstelle ${ }^{6}$ ).

Ton A gle Marmelos Corr., Madja (Mal.), Módjôh (Jav.). werden auf Java die Blätter, deren Saft laxirend wirkt. als Antidot bei Schlagenbiss angewandt ${ }^{7}$ ).

1) Rufz, Enquête. p. 147, 193.

2) Rengger, Meckel's Arch. f. An. u. Phys. 1829. S. 271.

3) Auch das ähnlich wirkende Piper reticulatum L. führt in Südamerika clen Namen, $\mathrm{J}$ a b or a $\mathrm{n} \mathrm{d}^{\longleftarrow}$.

$\left.{ }^{4}\right)$ E. Harnack, Arch. f. experim. Pathol. u. Pharm. XX. 1886. S. 489 .

5) Roxburgh, Flor: Ind. II. 374.

6) Drury l. c. p. 78 .

7) Bisschop Grevelink, Planten van Nederlandsch-Indie. Amsterdam 1883. p. 481. 


\section{Simarubaceae.}

Von Samadera indica Gaert. gelten in Indien die Blätter als Antidot gegen Schlangenbiss ${ }^{1}$ ). Die Pflanze enthält wahrscheinlich Quas siin.

Simaba Cedron J. F. Planch. Die Samenkörner der Pflanze sollen im Jahre 1828 von Indianern auf den Markt ron ('arthagena in C'olumbien gebracht, und ihre Wirksamkeit an Thieren, die man von Schlangen beissen liess, erprobt worden sein. [Dieser Mittel fand in Folge dessen bald ein solches Ansehen in jener Gegend, dass der Preis für ein einziges Korn uuf s:3 Franken stieg. Herran. der das Mittel prïfte. sah ebenfills nach innerlicher Anwendung von fünt his sechs Körnern als Pulver günstige Erfolge. Nach Dumont dagegen sind die Körner nur, wenn einige stunden vor dem Bisse gnenommen, in Stande die Wirkung des Giftes abzuschwiichen, so dass nur Localerscheinungen auftreten, der Tod aber vermieden wird. Nach dem Bisse genommen sollen sie jedoch erfolglos sein ${ }^{2}$ ). Die Samen enthalten den intensiv bitteren Stoff Cedrin, der viele Analogieen mit Strychnin zeigt und ein starkes Gift ist. Die Früchte enthalten ebenso wie die Samen von Picrolemma Valdivia G. Planch. den Bitterstoff Valdivin, ler noch giftiger ist als Cedrin. Hunde in Dosen ron $0,006 \mathrm{~g}$ in 5 - 4 ; Stunden tödtet und beim Nenschen $7.100 .004 \%$ in einer Viertelstunde emetisch wirkt. liestrepo. der mit beiden Stoffen Versuche anstellte, find dieselben erfolglos bei Hunden und Kaninchen ${ }^{3}$ ).

\section{Burseraceae.}

Amyristiliadensis L. wird in Aegypten bei Schlangenbiss gebraucht ${ }^{4}$ ).

1) R heede, Hort. Malabar. VI. 32.

2) $R$ ufz, Enquête. p. 297.

3) Restrepo, Ftudes du Cédron, du Valdivia et de leurs principes actifs, la cédrine et la valdivine. Thèse, Paris 1881.

4) Ainslie, Mat. med. ind. I. 27. 
Balsamodendron africanum Arn. in Senegambien und

B. Mukal Hook. in Indien liefern ein früher zur Bereitung von Pflastern benutztes Gummiharz, Bdellium, das vom Alterthum bis in die neueste Zeit eine ausgedehnte Verbreitung in der Behandlung des Schlangenbisses gefunden hat.

B. Myrrha Nees liefert das Mrrhenharz, und mehrere Arten von

Boswellia das Olibanum (Weihrauch), welche beide ebenfalls zur Heilung des Schlangenbisses gebraucht wurden.

\section{Celastrineae.}

Von Elaeodendron Roxburghii W. et A. gilt die Wurzel in Indien als ausgezeichnetes Mittel gegen Schlangenbiss. Die mit Wasser geriebene Wurzelrinde soll äusserlich angewandt fast jede Schwellung beseitigen. Die Wirkung ist eine sehr stark adstringirende ${ }^{1}$ ).

\section{Rhamneae.}

Paliurus australis Gaertn. (Zizyphus Paliurus Willd.) wurde nur selten benutzt.

\section{Ampelidaceae.}

Vitis vin ifera L. Der Genuss von Weintrauben wurde im Alterthum auch für heilsam gegen den Schlangenbiss erachtet.

\section{Sapindaceae.}

Sapindus trifoliatus L., Ritha (Hind.), Ponnínkottai (Tam.) in Suidindien. Man benutzt die Pulpa der Frucht, in der zu $11,5^{n} \mathrm{n}$ Saponin enthalten ist. Die reifen Früchte enthalten über $10^{\circ}$, Glucose und etwas Pectin. Der Destillation unterworfen zeigt die Drogue eine Substanz. die der Buttersäure gleicht ${ }^{2}$ ).

1) Drury 1. c. p. 190 .

2) Dymock, Hooper and W arden, Pharmacographia indica. II. $\mathrm{p} .368$. 
Aceraceae.

A c e r N egu n d o L. wird in Nordamerika gegen Schlangenbiss angewandt. Der Saft ist wie auch bei anderen Ahornarten stark zuckerhaltig.

\section{Anacardiaceae.}

Pistacia vera L. Die von Plinius ${ }^{1}$ ) empfohlenen Fruchtierne, die sogenannten Pistacien, enthalten ein süsses, fettes Oel.

\section{Leguminosae.}

Von in frïheren 7eiten benutzten Leguminosen sind zu nennen:

Psoralea bituminosa L. (Triphyllon, Trifolium bituminosum).

Lupinus hirsutus L. und

L. angustifolius L. (Lupini silvestres). Die Lupinen enthalten Alkaloide (Lupinin u. a.).

Cicer arietinum L. (Cicer silvestre).

Glycyrrhiza glabra L. (Liquiritia) enthält in ihrer Wurzel das Glycosid Glycyrrhizin, das purgirend wirkt.

Ferner Arten von Astragalus, Orobus, Medicago, Trifolium.

In der Neuzeit werden folgende Arten gegen Schlangenbiss gebraucht:

Pongamia glabra Vent. in Indien (Saft der Blätter) ).

Erythrina Corallodendron L. auf Martinique ${ }^{3}$ ). Der Baum enthält ein narkotisches Alkaloid.

Mucuna mutisiana D.C. in Neu-Granada ( 0 jo de venado", Hirschauge) und Brasilien ("Mucuna Guaca“) ${ }^{4}$ ). Trifolium lupinella ${ }^{5}$ ).

1) L'linius, Hist. nat. XXIH. 78.

${ }^{2}$ ) Rheede, Hort. Malabar. VI. 6.

3) $\mathrm{Rufz}$, Enquête. p. 117.

4) Saffray l.c.

5) De Rose, Gaz. Méd. 1846. p. 562. 
Cassia occidentalis L., Kasondi, Gajarság, Sarikasondi (Hind.), Ponna-virai, Pera-virai (Tam.),

C. alata L., Veleytie Aghatia (Hind.), Wandukolli, Seemee Aghatie (Tam.) und

C. Sophera L. in Indien. Die Blätter und Wurzeln dieser Pflanzen werden mit schwarzem Pfeffer gegen Schlangenbisse gebraucht. Die von C. Sophera enthalten in den wässrigen Lösungen des alkoholischen Extractes eine harzige Substanz und ein bitteres Princip, das nicht alkaloider Natur ist ${ }^{1}$ ).

Indigofera tinctoria L.,

I. Anil L. und andere Indigoarten werden ebenfalls in Indien bei Schlangenbissen angewandt.

Guilandina Bonducella L., Caesalpinia Bonduc Roxb.,

Arachis hypogaea L. und

Acacia Farnesiana Willd. auf Martinique ${ }^{2}$ ).

A. Seeressa Roxb. (Albizzia Lebbek Benth.), Siris (Hind.), Katturagai (Tam.) in Indien (Rinde) ${ }^{3}$ ).

Uraria picta Desv., Dábrá (Hind.), Sankar-jata (Beng.) soll ein Antidot gegen die Phoorsa-Schlange (Echis carinata) in Indien sein ${ }^{4}$ ).

Von Butea frondosa Roxb., Palás, Dhak (Hind.), Purashu, Muruklkan-maram (Tam.), gebraucht man in Indien die Rinde zusammen mit $\mathrm{Ing}$ wer bei Schlangenbiss. Durch Aether lässt sich aus Butea-Gummi eine geringe Menge Pyrocatechin entfernen ${ }^{5}$ ).

Von B. superba Roxb., Palás-lata (Hind.), Kodimurukkan (Tam.), benutzt man in Indien die Wurzel mit gleichen Mengen der Wurzeln von Nyctanthes und Woodfordia floribunda, den Samen von Cassia Tora und Vernonia anthelminthica, und dem Stengelsaft von Tri-

1) Pharmacographia indica. II. p. 520. - Drury 1. c. p. 119.

$\left.{ }^{2}\right) \mathrm{Rufz}$, Enquête. p. 122, 139. - Lanessan 1. c. p. 427.

3) Madras Quart. Journ. of Med. Sc. IV. p. 14.

$\left.{ }^{4}\right)$ Dymock, Veg. Mat. med. of Western India. p. 181.

$\left.{ }^{5}\right)$ Pharmacographia indica. II. p. 454.

Brenuing, Die Vergiftungen durch Schlangen. 
chosanthes palmata mit Kuhurin zu einer Paste verarbeitet äusserlich, und zugleich Aristolochia indica innerlich ${ }^{1}$ ).

Euchresta Horsfieldii Bennet, Prono Djiwa (Jar.) gilt auf Java als Heilmittel gegen Schlangenbiss ${ }^{2}$ ).

\section{Rosaceae.}

Im Alterthum werden von den Rosaceen angehörigen Pflanzen folgende erwähnt: Agrimonium, Pentaphyllum oder Quinquefolium (eine Art der Gattung Potentilla), Rosa, Rubus oder Eruscus (vielleicht Rubus fruticosus L.).

In der reueren Zeit scheint nur eine Rosacee gegen Schlangenbiss Anwendung gefunden zu haben, nïmlich:

Spiraea trifoliata L. in Nordamerika.

\section{Saxifragaceae.}

Ribes nigrum L., die schwarze Johannisbeere, soll in Nordamerika als Mittel gegen Schlangenbiss gelten.

\section{Combretaceae.}

Calycopteris floribunda Lam. in Indien, Assam etc., hindustanischer Name Kokoranj. Man gebraucht die Wurzel mit der von Croton oblongifolium als Paste gegen den Biss der Phoorsaschlange (Echis carinata) ${ }^{3}$ ).

\section{Myrtaceae.}

Punica Granatum L. Die Wurzeln werden von Avicenna als Mittel gegen Schlangenbiss erwähnt.

\section{Lythrarieae.}

Lythrum Salicaria L. wird von den Alten als Lysimachia ${ }^{4}$ ) bei Schlangenbiss empfohlen.

1) Pharmacographia indica. II. p. 458.

2) Bisschop Grevelink 1. c. p. 70 .

3) Pharmacographia indica. III. p. 15.

4) Plinius, Hist. nat. XXV. 55. 


\section{Cucurbitaceae.}

Im Alterthum bediente man sich von Pflanzen dieser Familie, wie es scheint, nur der Gurke, Cucumis sativus L., und einer Bryonia, wahrscheinlich der Bryonia cretica L., in der Therapie des Schlangenbisses.

Bryonia umbellata Rottl. wird in Indien benutzt ${ }^{1}$ ). Ob die Wurzel dieser Pflanze ebenfalls das in derjenigen von B. alba L. entdeckte Glycosid Bryonin enthält, ist zweifelhaft.

Luffa echinata Roxb.; hindustanische Namen: Kukarlata, Bindál, Ghagar-bel, Deodáil. Der Inhalt der Frucht wird in Indien als Infus gegen Schlangengift gebraucht. In der Frucht ist ein Stoff, der dem Colocynthid in verwandt ist. Er verursachte, einer Katze eingegeben, Erbrechen, blutigen Stuhl, Pupillenerweiterung, Contractionen der Bauchmuskeln, Lähmung der hinteren Extremitäten, darauf Convulsionen derselben, spasmodisches Athmen, und führte schliesslich den Tod des Thieres herbei. Ferner findet sich darin noch ein anderer Stoff "Luffeïn" 2).

Cucumis Colocynthis L. Hiervon werden ebenfalls die Früchte, die Coloquinthen, welche das drastisch wirkende Glcyosid Colocynthin, sowie noch einen anderen Stoff, das Colocynthidin, enthalten, in Indien angewandt ${ }^{3}$ ).

Fevillea cordifolia L. Die Früchte gelten auf Martinique als Antidot gegen Schlangenbiss ${ }^{4}$ ).

Corallocarpus epigaeus Hook., Akasgadda, Chhilihinda, Garaj-phal (Hind.), Akásha-garudan, Gollankovaik-kizhangu (Tam.). Die Wurzel der Pflanze wird in Indien innerlich und äusserlich gebraucht; sie enthält ein dem Bryonin gleichendes bitteres Prinzip ${ }^{5}$ ).

Cayaponia Cabocla Mart. (Purga do Gentio",

1) Lanessan 1. c. p. 596 .

2) Pharmacographia indica. III. p. $81 \mathrm{ff}$.

3) Sonnerat, Voyages. II. 54. (Madras Quart. Journ. IV. p. 14.)

4) Lanessan l. c. p. 480 .

5) Pharmacographia indica. III. p. $90 \mathrm{ff}$. 
"Purga do Caboculo"). Man benutzt in Brasilien ein drastisch wirkendes Infus der Wurzel oder Frucht ${ }^{1}$ ). Der wirksame Bestandtheil soll das Cayaponin sein.

Cucurbita Lagenaria L. wird auf Martinique mit anderen Pflanzen zusammen gegen Schlangenbiss angewandt ${ }^{2}$ ). Die Früchte sind zuckerhaltig.

\section{Umbelliferae.}

Die Familie der Umbelliferen gehört zu denjenigen, von denen im Alterthum und Mittelalter eine grosse Zahl von Pflanzen gegen Schlangenbiss im Gebrauch waren, welche jetzt dagegen für diesen $\mathrm{Z}$ weck fast ausnahmslos obsolet sind. Die Früchte vieler Pflanzen dieser Familie zeichnen sich durch einen reichen Gehalt an ätherischen Oelen aus, manche enthalten Glycoside und campherähnliche Körper. Die Wurzeln vieler Gattungen sind reich an Gummiharzen, Säuren, Bitterstoffen und Farbstoffen. Einzelne Pflanzen enthalten auch Alkaloide.

Die am meisten benutzten Pflanzen sind folgende:

Eryngium campestre L.,

E. marmitimum L. und

E. planum L. Von diesen 3 Arten nahm man die viel Schleim enthaltenden und purgirend wirkenden Wurzeln in Wein. Der alte Name ist Erynge oder Eryngion.

E. campestre wird noch jetzt in Venezuela gebraucht (s. Echium vulgare), ebenso Eryngium aquaticum L. und Sanicula canadensis L. in Nordamerika.

Petroselinum sativum Hoffm. wird von Apulejus Platonicus:") erwähnt. Die Petersilie, deren diuretische Wirkung lange und allgemein bekannt ist, enthält einen Campher und das Glycosid Apiin.

Pimpinella Anisum L. (Anisum creticum) enthält ein diuretisch und als Carminativum wirkendes ätherisches Oel.

1) v. Martius, Syst. mat. med. Brasil. p. 81 .

2) Rufz, Enquête. p. 143.

$\left.{ }^{3}\right)$ A pulejus Platonicus, De viribus herbarum. 
Sium Sisarum L. (Elaphoboscon?).

Ammi majus L. und

A. Visnaya L. sollen nach Plinius ${ }^{1}$ ) mit gleichen Theilen Myrha gegen Bisse der Hornschlangen gegeben werden.

Thapsia Silphium Viv. (Silphion, Laser).

Bupleurum protractum L. (die Samen); die BupleurumArten wurden auch als Perfoliatum bezeichnet.

Foeniculum officinale All.

Seseli Hippomarathrum L. soll nach Petrichus und Micton das beste Mittel gegen Schlangenbiss sein.

Meum athamanticum Jacq.

Athamanta cretensis L. (Daucus). Die Wurzel wurde in Wein genommen.

Levisticum officinale Koch. (Ligusticum).

Selinum Carvifolia L.

Archangelica officinalis Hoffm. (Angelica). Wurzel und Samen sind reich an ätherischem Oele.

Peucedanum officinale L. Plinius empfiehlt den Saft gegen Schlangenbiss zu trinken.

Imperatoria Ostruthium L.

Anethum graveolens L.

Pastinaca sativa L. (Elaphoboscon?).

Daucus Carota L. (Staphylinus, Pastinaca erratica). Wer die Pflanze bei sich trägt, soll von Schlangen nicht gebissen werden, und wer davon gegessen hat, soll unverletzlich $\operatorname{sein}^{2}$ ).

Caucalis orientalis $\mathrm{L}$.

Myrrhis odorata Scop.

Coriandrum sativum L.

Smyrnium perfoliatum L.

Ferula communis L. Die Wurzel wurde mit Wein genommen.

1) Plinius, Hist. nat. XX. 58.

2) Ibid, XX, 15. 
Von Ferula galbaniflua Boiss., F. Opoponax Spr., F. rubricaulis Boiss, F. Schaïr Borszcz. wurden theils die Wurzeln gebraucht, theils der eingetrocknete Milchsaft (Galbanum). Wahrscheinlich gehören auch viele von den im Alterthum als Panaces aufgeführten Pflanzen dieser Gattung an. Petrus de Abano ${ }^{1}$ ) empfiehlt gegen Schlangengift eine Arznei aus As a foetida (die ebenfalls von FerulaArten stammt), alter Butter, Allium und reinem Wein.

Mehrere andere im Alterthum angewandte Pflanzen, wie Heracleum, Bupleuros, Buselinon und andere lassen sich nicht mit Sicherheit bestimmen.

\section{Cornaceae.}

Alangium decapetalum Lam., Akola, Akarkanta (Hind.), Alingie-marum (Tam.), Angolam (Mal.). Die gepulverte Wurzel gilt in Indien als Antidot bei Schlangenbissen. Sie wirkt diuretisch und purgirend ${ }^{2}$ ).

\section{Caprifoliaceae.}

Aus dieser Familie wurden in früheren Zeiten nur angẹwandt:

Sambucus Ebulus L., deren Wurzel z. B. Matthiolus empfiehlt, und

Lonicera Caprifolium L. (Kissanthemos der (Alten) ${ }^{3}$ ).

\section{Rubiaceae.}

Galium Aparine L. Die Samen werden von Plinius ${ }^{4}$ ) empfohlen.

Rubia tinctorum L. (Erythrodanus der Alten). Die Blätter wurden auf die Bisswunde gelegt ${ }^{5}$ ). Matthiolus

\footnotetext{
1) Petrus de Abano 1. c.

2) Drury l. c. 1. 24.

3) Plinius, Hist. nat. XXV. 68.

4) Ibid. XXVII. 15.

5) Ibid. XXIV. 56.
} 
empfiehlt den Saft der Wurzel. Dieselbe enthält ausser Farbstoffen und ancleren Substanzen auch ein Glycosid, die Ruberythrinsäure.

Pentas lanceolata (Forsk.) K. Sch. (P. carnea Bth.) gilt in Arabien als Mittel gegen Schlangenbiss.

Chiococca anguifuga Mart. (Ch. densifolia Mart.), in Brasilien unter dem Namen "raiz preta" oder "raiz de cobra" bekannt. Sie hat in ihrem scharfen, widerlichen Geruche viel Aehnlichkeit mit Senega und Valeriana. Der Kranke muss grosse Mengen des Absudes trinken, und die Umschlïge von den frisch zerquetschten Blättern und Wurzeln werden abwechselnd mit denen von melneren anderen Pflanzen, z. B. der "Lóco" (Plumbago scandens L.), die Blasen zieht, dem "Picio" (Bidens graveolens und leucantha W.), der "Erva de Sa. Anna" (Kuhnia arguta H.) und dem Spilanthes brasiliensis hüufig emeuert. Wemn der Gebrauch der "raiz preta" starke Ausleerungen auf allen Wegen zur Folge hat, so schöpft man Hoffnung auf Genesung; besonders sollen starke Schweisse und Stuhlentleerungen günstige Zeichen sein. Man führt dann mit demselben Mittel olne Unterlass mehrere Tage lang fort, bis der Kranke seine normalen Gesichtszüge wieder erhält ${ }^{1}$ ). Der Negern inoculirte Saft der Pflanze soll dieselben ein ganzes Jahr lang gegen Schlangengift schützen, und reibt man seine Hände damit, so soll man, ohne gebissen zu werden, die Schlangen ergreifen können ${ }^{2}$ ).

Chiococca racemosa L. ("Raiz preta", "Cainca“, "Cainana“, „Puaia“, "Cruzereinha") wirkt wie die vorige diuretisch, diaphoretisch, cathartisch und emetisch. Man gebraucht auch hiervon Extracte, Decocte und das Pulver der IVurzel ${ }^{3}$ ). Das diuretische Prinzip ist die in der Wurzelrinde enthaltene Caïncasäure.

Ophiorrhiza mungos L. (singalesisch Mendi, Nagah-

1) Spix u. v. Martius, Reise in Brasilien. I. S. $305 \mathrm{f}$.

$\left.{ }^{2}\right)$ Spix, Serpent. Brasil. Species novae. p. 67.

3) v. Martius, Syst. mat. med. Brasil. p. 93 . 
walhi, jaranisch Ellar) soll nach Kaempfer ${ }^{1}$ ) u. A. sehr wirksim bei Schlangenbiss sein. Ausser auf Ceylon und Java bedient man sich ihrer auch auf Martinique ${ }^{2}$ ). Man benutzt Decocte von der Rinde, den Blättern und der sehr bitteren Wurzel.

Cephälis Ipecacuanha Rich. ist eine schon in älteren Zeiten hüufig bei Schlangenbiss empfohlene Pflanze. Nach Mead ${ }^{3}$ ) soll sie durch ihre emetische Wirkung die oft nach dem Bisse eintretenden Krämpfe verhuiten. Der wesentliche Bestandtheil der Wurzel ist das Alkaloid Emetin.

Macrocnemum corymbosum R.P. Die sehr adstringirende linde wird in Peru zur Heilung des nach dem Bisse zurückbleibenden Geschwüres gebraucht ${ }^{4}$ ).

Die von $\mathrm{C}$ in chona-Arten stammende Chinarinde, welche, nachdem ihre Bedeutung als Fiebermittel um die Mitte des 17. Jahrhunderts bekannt geworden war, auch bei Schlangenbiss empfohlen wurde, erkannte schon Fontana als nutzlos gegen Schlangengift.

\section{Valerianaceae.}

Valeriana celtica L. ist die von Plinius ${ }^{5}$ ) als Nardum gallicum gegen Schlangenbiss empfohlene Baldrian-Art.

V. officinalis L. wurde unter dem Namen $\mathrm{Phu}$ noch häufiger benutzt als die vorige. Sie enthält in ihrer Wurzel Valerianöl, Valeriansäure und zwei Gerbsäuren.

\section{Compositae.}

Diese weit verbreitete Familie lieferte zu allen Zeiten zahlreiche Pflanzen gegen Schlangenbiss, und zwar im Alterthum und Mittelalter besonders folgende:

1) Ka empfer, Amoenitatum exotic. politico-physico-med. fasciculi V. Lemgo 1712. $4^{0}$.

2) R u f z, Enquête. p. 163

3) M ead, De vipera. 1749.

4) Pöppig, Reisen in Chile und Peru.

5) Plinius, Hist. nat. XXI. 79. 
Inula Helenium L. (Helenium, Inula, Enula). Das Pulver der im Schatten getrockneten Wurzel wurde mit Wein getrunken ${ }^{1}$ ). Dieselbe enthält den sog. A lantcampher (Helenin) und war früher als Expectorans und Diureticum officinell.

I. Britannica L. (Herba Britannica) ${ }^{2}$ ).

Artemisia Abrotanum L. (Abrotonum). Die Blätter der Pflanze enthalten ein ätherisches Oel, einen bitteren Extractivstoff und Gerbstoff. Nan gebrauchte sie innerlich mit Wein und auch äusserlich ${ }^{3}$ ).

A. Absinthium L. enthält das Wermuthöl und den Bitterstoff Absynthiin.

Anthemis nobilis L.

A. tinctoria L.

Matricaria Chamomilla L. Diese und vielleicht noch andere Kamillenarten wurden in der Weise angewandt, dass man Blätter, Blüthen und Wurzeln zu einer Paste mischte ${ }^{1}$ ). Die Kamillen enthalten ein ätherisches Oel und sind noch heute ein allgemein bekanntes Diaphoreticum.

Tragopogon picroides L. (Hieracion). Man nahm die in Essig abgeriebenen Blätter und Stengel ein.

Gnaphalium sanguineum L. (Baccharis).

G. Stoechas L. (Helichrysum, Chrysanthemum).

Carthamus tinctorius L. (Sideritis).

C. lanatus L. (Cnicus, Atractylis).

Cnicus benedictus Gaertn., das Cardobenedictenkraut, wurde besonders im Mittelalter viel bei Bronchialkatarrhen, Hydrops, chronischer Dyspepsie und auch bei Schlangenbiss gebraucht. Es enthält den Bitterstoff Cnicin.

Arctium Lappa L. (Persolata, Personata, Arkios, Prosopis).

Santolina Chamaecyparissus L.

1) Plinius, Hist. nat. XX. 19; XXI. 91.

2) Ibid. XXV. 55.

3) Ibid. XXI. 92.

4) Ibid. XXII, 26. 
Cichorium Intybus L. Die Blüthen enthalten ein Gloycosid.

C. Endivia L.

Auch eine Lactuca wird verschiedentlich erwïhnt, jedoch ist die Art nicht sicher zu ermitteln; ebenso verhält es sich mit den alten Namen Lactucella, Sonchus, Condrilla, Carlina, Carduus und anderen.

Scorzonera hispanica L. soll ihren Namen von einer in Catalonien lebenden Schlange "escorç" haben, gegen deren Biss Wurzel und Krant der Pflanze angewandt wurde ${ }^{1}$ ).

Doronicum Pardalianches L. (Scorpio, Aconiton, Thelyphonon). Von der Pflanze gebraucht man noch jetzt in Indien die Wurzel gegen Schlangenbiss ${ }^{2}$ ).

Mikania Guaco H. B. Kth., in Brasilien unter dem Namen "vejuco de huaco" bekannt, ist diejenige Pflanze, welche ron allen die grösste Beriihmtheit als Nittel gegen Schlangengift erlangt hat. Was den Namen der Pflanze betrifft, so soll "Guaco" oder "Huaco" den Schrei eines falkenartigen Vogels bezeichnen, welcher von Schlangen leben und sich durch Gebrauch dieser Pflanze von den Bissen, die er im Kampfe mit den Schlangen erhalten hat, heilen soll. Uebrigens führen ausser dieser noch verschiedene andere Arten der Gattung Mikania und sogar auch anderer Gattungen, wie Aristolochia, wie wir weiter unten sehen werden, den Namen "Guaco". Mikania tuaco nennt man auch zum Unterschiede von anderen Guaco-Arten "Guaco de Guatemala". Sie wurde zuerst durch Mutis bekannt, dem im Jahre 1788 ein Indianer das Geheimniss entdeckt hatte"). Man gebraucht sie in fast ganz Sülamerika, besonders in Chile und Peru. thre Anwendung daselbst ist sehr einfach: man tropft den ausgepressten Saft in die etwas erweiterte Wunde, bedeckt die umliegenden Theile wiederholt mit den zerquetschten

1) Monardes, De lapide Bezaar et herba Scorzonera. p. 7. (In Carolus Clusius, Fxoticorum libri X. 1605.)

$\left.{ }^{2}\right)$ Pharmacographia indica. III. p. 292.

3) Otto, Casper's Wochenschr. 1835. Nr. 11. 
Blättern und lïsst den Saft auch innerlich nehmen. Man rühmt auch die aus dem Guaco mit Zuckerbrauntwein bereitete Tinctur als ein sicheres und von den Reisenden leicht mitzuführendes Arzneimittel. In Guayaquil formt man aus der frisch zerquetschten Pflanze kleine Kuchen, die, an der Sonne getrocknet, lange ihre Wirksamkeit behalten.

Die Wirkungen des Guaco treten zwar nicht bei Allen gleich schnell und entscheidend ein, indessen soll in den meisten Fällen schon nach ?4stündigem Gebrauche des Mittels, alogesehen von einem zurückbleibenden kleinen Geschwüre, Heilung eintreten. In manchen Orten sind seit Menschengedenken durch Gebrauch des Guaco nur einige Kinder an Schlangenbiss gestorben. Nur gegen eine Schlangenart, den Urrucu-Machacayu, dessen Biss in einer Stunde tödtet, soll der Guaco unwirksam sein. Auch in ganz Columbien schätzt man denselben als untrügliches Heilmittel. In einem Orte sollen, wie Pöppig berichtet, innerhalb elf Jahren von 220 gebissenen Einwohmern ausser 8 alle durch Behandlung mit Guaco, Limonensaft und Salz geheilt worden sein. In einem anderen Orte wurden in 14 Jahren mehr als 200 Personen mit Ausnahme eines Mädchens, dem man keine Hittel gegeben hatte, durch Guaco gerettet. Eine giftige Schlange, der man den Saft eingoss, soll in Betäubung verfallen und später trotz mancher Bisse nicht mehr im Stande gewesen sein, einen kleinen Hund zu tödten, da ihr Gift unwirksam geworden war. In Columbien soll ein Bischof von Sa. Martha sogar alle Indianer einer Schutzimpfung mit Guacosaft unterworfen haben, und zwar mit solchem Erfolge, dass dieselben jede Furcht vor Schlangen verloren. Wenn auch in diesen Berichten ohne Zweifel viele Uebertreibungen sind, so scheint doch nach den Beobachtungen Pöppig's die Wirksamkeit des Guaco eine recht grosse zu sein. Nach Otto nehmen auch die Indianer selbst an sich die Impfung vor, indem sie sechs kleine Einschnitte in die Haut machen, nämlich zwei in die Hände, zwei in die Füsse und einen in jede Seite der Brust, und in alle diese Wunden den Guaco-Saft bringen; zuror 
trinken sie jedoch zwei Löffel davon und wiederholen diese Dosis nachher alle Monate 5-6 Tage nach einander, weil sonst die Impfung ihre Schutzkraft verlieren soll.

Auch in Mexiko ist der Guaco seit uralten Zeiten als Mittel gegen Schlangenbiss bekannt und wird daselbst als Decoct oder als Tinctura Huaco alkoholica oder Tinctura Huaco aetherea angewandt; die letztere ist von sehr starker Wirkung und wird nur zu 5-6 Tropfen gegeben ${ }^{1}$ ). Man stellte auch Untersuchungen über die Wirkung des Guacoextractes auf Thiere an und fand, dass dasselbe besonders auf das Nervensrstem wirlit"). Die Versuchsthiere zeigten nach Alssorption der Substanz zunächst eine Periode der Erregung, begleitet ron gastrointestinalen Störungen (Nausea, Erbrechen, Diarrhïe), sodann fallen sie in Sommolenz; hei starker Dosis folgt darauf vollständige motorische Lähmung und Tod. Die Respiration ist beschleunigt, die Inspirationen sind weniger tief, die Herzschläge erfolgen langsamer, die Arterienspannung sinkt. Im Urin findet sich oft Eiweiss. Die Temperatur steigt zuerst etwas und sinkt darauf um 3-4 . Man kann das Guacoextract äusserlich als Analgeticum, sowie ein $2^{\circ} / n$-Decoct der Pflanze bei Ekzem und auch als Emetico-catharticum benutzen. Es gelang bisher noch nicht, ein Alkaloid oder ein Glycosid aus der Pflanze darzustellen. Fauré ${ }^{3}$ ) erhielt durch Extraction der Blätter mit Aether das Guacin, das aber kein reiner Körper sein soll ${ }^{4}$ ) und in Dosen ron $0,06 \mathrm{~g}$ Erbrechen, Pulsbeschleunigung, Schweiss und Absonderung stark harnsïurehaltigen Urins bewirkt. Neuere Autoren ${ }^{5}$ ) sprechen übrigens dem Guaco jeden Nutzen bei Schlangenbiss ab.

Andere gegen Schlangenbiss empfohlene Mikania-Arten sind noch:

$\left.{ }^{1}\right)$ Chabert, Du Huaco et ses virtus médicinales. Paris 1853.

$\left.{ }^{2}\right)$ Butte, Sémaine médicale. 1889. p. 328.

3) Fauré, Journ. de Pharm. (2) XXII. 291.

4) v. Pettenk ofer, Ueber Mikania Guaco. München 1844.

5) Guibourt, Journ. de Pharm. et de Chimie. 1867. 
Mikania opifera Mart., "Erva di cobra". Man legt in Brasilien auf die scarificirte Wunde zerquetschte Blätter und giebt innerlich von Zeit zu Zeit einige Löffel des ausgepressten Saftes $\left.{ }^{1}\right)$. Sie soll die Kirisis besonders durch Urinabsonderung herbeiführen.

M. Huttoni Willd. wird in Mexilio gebraucht (,Guaco de Veracruz").

M. saturejaefolia Willd. (Nathites saturejaefolia D.C.), um Montevideo einheimisch, soll die gleichen Heilkräfte besitzen wie Mikania Guaco.

Von Eupatorium Ayapana Vent., Ayapána (Hind.), Ayapáni (Tam.), Daon Prasman, Daon Panahaw (Mal., Jav.) wird in Indien und anf den Sundainseln der frische Saft innerlich und äusserlich bei Schlangenbiss angewandt ${ }^{2}$ ). Ebenso legt man in Brasilien auf die scarificirte Wunde eine öfter zu wechselnde Menge zerquetschter Blätter und lässt zugleich so lange, bis man den Kranken frei von allen Symptomen, besonders der schrecklichen Angst, sieht, von Zeit zu Zeit einige Löffel des ausgepressten Saftes einnehmen ${ }^{\circ}$ ). Die Pflanze enthält Fett, ätherisches Oel, einen Bitterstoff und Spuren von Zucker ${ }^{4}$ ). Sie wirkt stimulirend, tonisch und diaphoretisch ${ }^{5}$ ).

E. macrophyllum L. wird in Südamerika ${ }^{6}$ ) und

E. perfoliatum L. in Nordamerika ${ }^{7}$ ) gegen Schlangenbiss benutzt.

Von weniger wichtigen, den Compositen angehörigen Pflanzen sind in Amerika, besonders in den Vereinigten Staaten und in Brasilien, folgende in Gebrauch:

Aster montanus Nutt.

1) Spix u. v. Martius, Reise in Brasilien. I. S. 279. Note 2.

2) Pharmographia indica. III. p. 245 und Madras Quart. Journ. IV. 1862. p. 7.

3) Spix u. v. Martius 1. c. I. S. 279. Note 1.

4) Waflart, Journ. de Pharm. Jan. 1829.

5) Drury l. c. p. 203.

$\left.{ }^{6}\right)$ Guibourt 1. c. 1867 . p. 83.

$\left.{ }^{7}\right)$ Germer 1. c. 
Erigeron canadensis L. und andere Arten dieser Gattung ${ }^{1}$ ).

Solidago canadensis L. ("Klapperschlangenkraut") ${ }^{1}$ ).

Liatris spicata Willd. (Gay feather", "Button snake root").

L. dubia (?) ("rattle-snake root"),

L. squarrosa Willd.) ( "Pinetta di prairia",

L. scariosa Willd. Jrattle snakes master").

Von diesen vier Pflanzen legt man in den Vereinigten Staaten die zerquetschten Knollen auf die Bisswunde, während man innerlich eine Abkochung davon in Milch nimmt ${ }^{2}$ ). Die Wirkung ist eine diuretische. Brainard sah bei seinen Thierrersuchen kinen Erfolg von der Anwendung dieser Pflanzen.

Prenanthes alba L. ${ }^{1}$ ) in Nordamerika.

P. Serpentaria Pursh. ${ }^{2}$ ).

Lactuca virosa L. ${ }^{3}$ ). Der Milchsaft der Pflanze, das Lactucarium, enthält einen Bitterstoff, Lactucin, und wirkt ähnlich dem Opium narkotisch.

Bidens graveolens Mart. und

B. leucantha W. sind in Brasilien als "Picío" bekannt. Man macht von den frisch zerquetschten Blättern und Wurzeln Umschläge ${ }^{4}$ ).

Hieracium venosum L. ${ }^{5}$ ) in Nordamerika.

Echinacia purpurea Moench.

(E. serotina D.C.)

E. angustifolia D.C. in Nordamerika.

Milleria Contrayerba L.

Spilanthes brasiliensis Spr. ${ }^{4}$ ) in Bra-

S. ciliata H. B. Kth. ("Guaco de Santa Fé") (silien.

Kuhnia arguta H.B. ${ }^{1}$ )

1) Schöpf l. c.

2) Barton, Vegetable materia medica of the United States. 1817/18. Vol. II. p. 225. - Germer l. c.

$\left.{ }^{3}\right)$ Spix, Serpentum Brasil. Species novae. 1824. p. 64.

$\left.{ }^{4}\right)$ Spix u. v. Martius 1. c. I. S. 286. Note 49.

i) Schöpfl.c. 
Eclipta alba Hassk. ("Louise Beberie") in Surinam ${ }^{1}$ ). (Siehe Solanum mammosum.)

In Indien gebraucht man:

Artemisia vulgaris L., Nagdoun, Mastáru (Hind.), Máchipattiri (Tam.), Tiru-nitripachcha (Mal.), und zwar das Kraut der Pflanze $\left.{ }^{2}\right)$; ferner

A. maritima L., Kirmálá (Hind.). Die Blüthenköpfe enthalten das bekannte Santonin und werden mehr als Wurmmittel als gegen Schlangenbiss angewandt ${ }^{2}$ ). Das Oel der Samen wirkt auch diuretisch und purgirend.

Serratula amara L., Girmot der Javaner, ist auf Ceylon und an der Westküste von Ostindien in Gebrauch ${ }^{3}$ ).

Inula squarrosa L. wird von $\mathrm{O}$ modei ${ }^{4}$ ) erwähnt.

Vernonia anthelmintica Willd., Caatsiragum (Tam.), Catta-seragam (Mal.), Buckche (Hind.). Die Samen bilden einen Bestandtheil eines gegen Schlangenbiss gebrauchten Pulvers in Indien und wirken wurmtreibend und diuretisch ${ }^{5}$.

\section{Ericaceae.}

Erica arborea L. wurde nur selten angewandt.

Pirola maculata L. und P. rotundifolia L. ${ }^{6}$ ) werden in Nordamerika benutzt.

\section{Plumbaginaceae.}

Plumbago scandens L., in Brasilien unter dem Namen "Loco" bekannt. Die frisch zerquetschten Blätter und Wurzeln werden daselbst als Umschläge äusserlich angewandt. Die Pflanze hat die Eigenschaft, Blasen zu ziehen ${ }^{7}$ ).

1) Martin, Bericht über eine Reise nach Niederländisch-Westindien. I. S. $29 \mathrm{ft}$.

$\left.{ }^{2}\right)$ Pharmacographia indica. III. p. 284 u, 288.

3) Horsfield, Account of the Medical Plants of Java. 1816.

4) Omodei, Annali universali di medicina. Vol. LXXXII. April 1837. p. 5.
5) Drury l.c. p. 441 .
$\left.{ }^{6}\right)$ Barton, Transact. Am. Phil. Soc. Vol. III. p. 103.
?) Spix u. v. Martius 1. c. I. p. 305 f, 
Statice Limonium L. (Leimonion, Limonium) wird u. a. von Plinius ${ }^{1}$ ) empfohlen.

\section{Primulaceae.}

Anagallis arvensis L., in Europa, Westasien und Inlien. Hindustanische Namen: Jonkmari, Jainghani. Die Pflanze wurde schon im Alterthum unter dem Namen Corchorus $^{2}$ ) und wird noch jetzt in Indien ${ }^{3}$ ) bei Schlangenbiss gegeben. Nach Malapert (1857) enthält die Pflanze einen dem Saponin sehr ähnlichen Stoff. Aus dem trockenen Traute stellte man eine gèringe Menge eines flüchtigen, eigenthümlich und stark riechenden und sauer schmeckenden Oeles dar. Ein paar Tropfen davon verursachten Kopfschmerzen und mehrere Stunden andauernde Uebelkeit.

Cyclamen persicum Mill., in Griechenland, Persien etc., wird ebenfalls schon von Plinius ${ }^{4}$ ) empfohlen. Die Pflanze enthält ebenfalls einen dem Saponin ähnlichen Stoff, das Cyclamin. Es hat einen bitteren, scharfen Geschmack, bildet mit Wasser eine seifige Mischung und wird, wenn mit Säuren gekocht, in Glucose und in eine harzige Substanz verwandelt, die man Cyclamiretin nannte. Vergiftete Fische sterben asphylitisch. Das Cyclamin erregt im Magen Brennen, Uebelkeit, Erbrechen, sowie Speichelfluss, wenn es in die Gefïsse gelangt.

\section{Ebenaceae.}

Von Diospyros Kaki L. f. wird im nördlichen Japan der stark gerbsäurehaltige Saft der unreifen Früchte bei Schlangenbiss äusserlich angewandt ${ }^{5}$ ).

1) Plinius, Hist. nat. XXV. 61.

2) Ibid. XXI. 106 .

3) Pharmacographia indica. IV. 345.

4) Plinius, Hist. nat. XXV. 67.

5) Mittheilungen der deutschen Gesellschaft für Natur- u. Völkerkunde Ostasiens. I. Heft 9. S. 6. 1876. 


\section{Oleacecie.}

Olea europaea L. Das aus dem Fruchtfleische des Olivenbaumes gewonnene Olivenöl wurde zuerst im Jahre 1707 von einem englischen Bauer als Mittel gegen Schlangenbiss empfohlen und erlangte als solches bald einen solchen Ruf, dass die Pariser Akademie Hunauld und Geoffroy mit der Prüfung des Mittels beauftragte. Diese führte zu dem Resultate, dass das Olivenöl kiein Specificum gegen Schlangenbiss sei; aber, obgleich Mïnner wie Mead und Fontana auf Grund ihrer Versuche dasselbe ebenfalls für nutzlos erklärten, so hat es doch bis in die neueste Zeit hinein eine ausgedehnte innere und äusssere Anwendung gefunden, und noch 1850 behauptete $\mathrm{D}$ u s o u r d ${ }^{1}$ ), dass das lauwarme Olivenöl das beste Mittel gegen Vipernbiss sei. Einreibungen des Oeles um die Wunde bewirken allerdings häufig ein schnelles Erweichen der Geschwulst; dagegen wirkt dasselbe bei innerlichem Gebrauch, bei dẹm es esslöffelweise gereicht werden soll, in sehr hohen Dosen höchstens als Brechmittel und Catharticum, aber sicher nicht specifisch. Auch Weir Mitchell sah keinen Erfolg von der Anwendung des Olivenöles bei seinen Versuchsthieren.

Fraxinus excelsior L. Der Saft vom Eschenlaub wurde gegen den Kreuzotterbiss von Mercurialis und Montin empfohlen. Man stellte aus Eschenblättern einen purgirend wirkenden Stoff Fraxinit dar, der aber vielleicht nichts weiter als Mannit war.

Von Nyctanthes Sambac L. (Jasminum Sambac Ait.) und Jasminum pubescens Willd. benutzt man in Indien die Wurzel gegen Schlangenbiss ${ }^{2}$ ).

\section{Salvadoraceae.}

Salvadora oleoides Dene., Pilu, Jhál (Hind.), Kalarva, Kárkol, Ughai-puttai (Tam.). Die Samen wur-

1) Dusourd, Bull. de Thérap. Mai 1850.

$\left.{ }^{2}\right)$ Rheede, Hort. Malabar. VI. 89. 95.

Brenning, Die Vergiftungen durch Schlangen. 
den in mehreren Fiillen von Schlangenbiss in Indien mit gutem Erfolge gegeben ${ }^{1}$ ). Sie enthalten ein weisses Fett und ein in Aether und Amylalkohol lösliches Alkaloid.

Von S. persica L., Piloo-kurjal (Hind.), Ooghaimarum (Tam.) werden ebentialls die purgirend wirkenden Samen innerlich angewandt ${ }^{2}$ ).

\section{Apocynaceas.}

Von Apocyneen werden als Mittel gegen Schlangenbiss von den alten Autoren empfohlen:

Vinca major L. (ägyptische Clematis, Daphnoides, Polygonoides):i).

Nerium Oleander L. (Rhododendros der Alten ${ }^{4}$ ). Die frischen Oleanderblätter enthalten neben Oleandrin und Pseudocurarin ein Glycosid Neriin, das alle Eigenschaften des Digitalë̈ns zeigt und wahrscheinlich mit diesem identisch ist. In trockenen Blättern fand man ausserdem die dem Digitaliresin entsprechenden Derivate des Oleandrins und Neriins, ferner einen stickstofffreien Stoff Nerianthin, der Digitalinreaction giebt und beim Kochen mit verdünnten Süuren Glycose und ein krystallinisches, dieselbe Reaction gebendos Spaltungsproduct Nerianthogenin liefert ${ }^{5}$ ). Das Oleandrin ist ein Herzgift, das zu (0,25 mg systolischen Herzstillstand beim Frosche bedingt. Neriin wirkt wie Digitaleïn, dagegen bringt Nerianthin keinen systolischen Herzstillstand hervor.

N. odorum Ait., Kaner (Hind.), Alari (Tam., Mal.) wird in Indien gegen Schlangenbiss angewandt. Aus der Rinde lassen sich zwei ebenfalls als Herzgifte wirkende Bitterstoffe, Neriodorin und Neriodoreïn extrahiren ${ }^{6}$ ). Vielleicht sind dieselben identisch mit Oleandrin und Neriin.

$\left.{ }^{1}\right)$ Bomb. Med. and Phys. Trans., New Ser. III. p. 80.

2) Madras Quart. Journ. IV. 13.

3) Plinius, Hist. nat. XXIV. 90.

4) Ibid. XXIV. 53.

5) Schmiedeberg, Archiv für experimentelle Pathologie und Pharmokologie, XVI. 1882. S. 151.

4) Greenisch, Pharm. Journ. Transact. (3) XI. p. 873. 
N. tomentosum Roxb. (Wrightia tomentosa R. et S.), Velam-pala (Mal.). Die Rinde der Wurzel wird in Indien innerlich gegen Schlangengitt gegeben.

Ophioxylon serpentinum L. (Rauwolfia serpentina Benth.) wird in Indien und auf Java gegen Schlangenbiss benutzt. Die einheimischen Namen sind: Chandraka, Chandrapushpa (Sanskr.), Chota - chand, Moonlet (Hind.), (Yhivan-amelpodi (Mal.), Puli-pandak (Jav.). Den Gebrauch der Pflanze gegen Schlangenbiss soll man angeblich, wie auch den des Guaco, von Thieren kennen gelernt haben, und noch 1831 erzählt $\mathrm{Duncan}{ }^{1}$ ), der in Ostindien einen Kampf eines Ichneumons mit einer Brillenschlange mit angesehen haben will, dass jenes, als es von der Schlange gebissen war, zuerst in heftiger Aufregung herumlief, in verschiedene Büsche und Blätter biss, endlich aber Ophioxylon serpentinum fand und, nachdem es einige Blätter davon verzehrt hatte, wieder auf die Schlange zulief, sie tödtete und gesund blieb. Man giebt den Gebissenen innerlich eine Abkochung besonders der jungen, intensiv bitter schmeckenden Wurzeln und applicirt ausserdem dieselben gepulvert auf die Wunde und auf die Augen ${ }^{2}$ ). Ebenso trüufelt man den ausgepressten Saft in die Augen. Der wirksame Bestandtheil der Wurzel ist ein Alkaloid"). Das beste Erkennungsmittel für die OphioxylonWurzel ist die mikrochemische Reaction mit Salpetersäure. Befeuchtet man ein Wurzelscheibchen mit dieser Süure, dann färbt sich der Kindentheil dunkel kirschroth. Bei älteren Wurzeln fürbt sich der Holztheil und die Korkschicht gar nicht; bei jungen Wurzeln ist auch noch stellenweise im Holztheile ein wenig Alkaloid abgesetzt. Man kann durch diese Reaction nicht nur die Localisation des Alkaloides in der OphioxylonWurzel erkennen, sondern auch die Wurzel selbst von anderen

1) Archiv der Pharmacie. XXXVII. 1831. S. 369.

2) Pharmacographia indica. IV. 414.

3) M. Gresh off, Mededeelingen uit s'Lands Plantentuin. VII. p. 51. Batavia 1890 . 
ämlichen. oft zur Verfülschung der ersteren angewandten Wurzeln unterscheiden, so von Calotropis gigantea, Cocculus umbellatus und von der falschen Pandak-Wurzel, die von Plumbago rosea L. abstammt.

Uebrigens liefern ausser Ophioxylon serpentinum L. auch andere Arten, mämlich O. trifoliatum Gaertn., O. majus und (O. obversum das berühmte javanische Heilmittel Pulil'andak. Die Wurzel gehört zu den ersten Heilmitteln, die ron Indien nach Europa kamen. Man findet sie in älteren Werken ausier als Ophioxylon auch als Radix Mungos (liadix Serpentum) anfgeführt. unter welchem Namen auch die Wurzeln der Rubiacee Ophiorriza Mungos L. verkauft wurden.

Thevetia Ahovai L. und

Th. neriifolia Juss. (Cerbera Thevetia L.) werden in Brasilien in der Weise angewandt, dass man den Milchsaft onder die zerquetschten Blätter und Samen auf die Bisswunde applicirt ${ }^{1}$ ). Letztere enthalten das Glycosid Theretin, das sehr stark toxisch wirkt und bei Hunden Speichelfuss, Erbrechen, flüssige Stühle. Zittrm u. a. Symptome hervorruft:

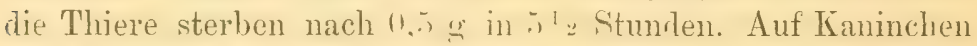
und Frösche wirlit es als Herzgift: der Herzstillstand erfolgt in der Systole. Die örtliche Wirkung ist eine reizende. Beim Kochen mit verdünnten Süuren spaltet sich das Thevetin in Glycose und Theveresin, welches letztere ebenfalls stark niftig ist und Steifigkeit der Glieder, Insensibilität sowie Her'zstillstand verursacht.

\section{Asclepiadaceae.}

Vincetoxicum of ficinale L., die Schwalbenwurz, wird nu1 selten als Mittel gegen Schlangenbiss erwïhnt. Sie enthält einen glycosidischen Stott, Asclepiadin. der emetisch, diaphoretisch und purgirend wirkt.

1) v. Martius 1. c. p. 90 . 
Asclepias Dioscoridis Fraas. (Asklepias, Dracontium der Alten). Man gehrauchte die Wurzeln offenbar nur ihrer Gestalt wegen, denn Apulejus Platonicus sagt von der Pflanze: radix ima caput dracontis habet.

A. gigantea Ait. (Calotropis gigantea R. Br.), A k, Madar (Hind.), Y e r kum (Tam.), Yerica (Mal.), Waduri (Jav.) bildet mit ihrem Safte einen Bestandtheil der schon früher genannten Tanjore-Pillen. Auch wentet man die purgirend wirkende Wurzel der wilden Baumwolle äusserlich an ${ }^{1}$ ).

Daemia extensa R. Br., Utrum (Hind.), Vela paruti (Tam.), Telli navi, ist ehenfalls in den Tanjore-Pillen enthalten $\left.{ }^{2}\right)$.

Ferner benutzt man noch folgende Asclepiadeen in Indien gegen Schlangenbiss ${ }^{3}$ ):

Tylophora asthmatica Wight., Unta-mool (Hind.), Kurinja (Tam.).

Hoya pendula Wight. (Nansjira-patsja).

Ceropegia Candelabrum L. (Watta-kaka codi).

Gymnema silvestre R. Br., Mera-singi (Hind.), Sirukurinja (Tam.). Die Hindus legen die gepulverte Wurzel auf den gebissenen Theil und geben eine Ablochung derselben innerlich ${ }^{4}$. In Tunis gebraucht man die Blïtter der Pflanze äusserlich gegen Schlangenbiss. Wurzel und Blätter haben die Eigenthümlichkeit, dass sie, wenn man sie kaut, für längere Zeit den süssen Geschmack, in geringem Naasse auch den bitteren, aufheben. Das wirksame Prinzip ist die Gymnesinsäure. Die Blätter enthalten ausserdem Weinsäure, Glycose und einen Alkaloidreaction gebenden bitteren Stoff ${ }^{5}$ ).

1) Madras Quart. Journ. IV. p. 3.

2) Ibid. IV. p. 1 .

3) Ibid. IV. p. 3-4.

4) Pharmacogr. indica. IV. 450. - Madras Quart. Journ. IV. p. 2.

$\left.{ }^{5}\right)$ Suchannek, Therap. Monatshefte. VIII. 1894. S. 403. 


\section{Loganiaceat.}

Die (rattung Strychnos ${ }^{1}$ ) liefert ilen grössten Theil des frïher so berühmten Lignum colubrinum, welches einen hohen Rang unter den Alexipharmacis einnahm. Ws wird zu(rst ron Garcia al, Horto erwähnt"). Derselbe führt drei Arten von Ceylon an; die eine war wohl die Wurzel von ()phioxylum serpentinum L., die beiden anderen Producte von Strychmos colubrina L. und Strychnos ligustrina Blume.

Strychnos colubrina L. wird von den Eingeborenen Indiens von allen Schlangenhölzem am meisten geschützt. Die einheimischen Namen sind: Koochila-luta (Beng.), Mahapenala (Sing:), Widoroo-pait, Vidoo-pait (Jav.). Es ist das "Pìo de Cobra“ der Portugiesen. Man giebt das Holz der Wurzel äusserlich und innerlich. Die Pflanze enthält ebenso wie alle folgenden Arten von Strychnos die beiden Alkaloide Strychnin und Brucin.

S. ligustrina Blume, auf dem Malayischen Archipel. ist das alte Lignum colubrinum von Timor. Einheimische Namen: Caju-ular, Caju-nassi, Caju-bidara-lant.

S. potatorum L. Einheimische indische Namen: Nirmulee, Nir-mal-i (Beng. u. Hind.), Téttan-kotei (Tam.). Die Samen sollen ein gutes Antidot bilden.

S. Ignatii Bergius (Ignatia amara L.) auf den Philippinen und in Cochinchina. Es werten hiervon ebenfalls die Samen, die bekannten Ignatiusbohnen, gegen Schlangenbiss gebraucht. Der hindustanische Namen der Pflanze ist Pepeitha. Die Samen enthalten die Alkaloide Strychnin und Brucin.

Als Schlangenholz werden auch folgende Arten in Indien verkauft ${ }^{3}$ ) :

1) E. J. Waring, Antidotes to Snake-Bites. Madras Quart. Journ. of med. se. III. 1861. p. $336 \mathrm{ff}$.

$\left.{ }^{2}\right)$ Garcia ab Horto, Historia Aromatum etc. 1579. p. 161. J. A. Darellius, Lignum colubrinum. Dissertatio sub praes. Caroli Linné. Upsalae 1749.

3) Pharmacographia indica. IV. 503. 
S. Rheedii Clarke. Modira-caniram (Mal.), Kuchilalata (Hind.).

S. Beddomei Clarke.

S. laurina Wall.

S. cinnamomifolia Thwaites.

S. Gautheriana Pierr. (S. Malakkensis Benth.), „Hoang nan" oder "Huang nan", wird in Tonkin gegen Schlangenbiss gebraucht ${ }^{1}$ ).

Die grösste Bedeutung aber von allen Strychnosarten hat als Antidot gegen Schlangenbiss

S. nux vomica L., die bekannte Brechnuss. Sie wird besonders in Indien, Birma und auf Ceylon unter folgenden Namen gebraucht: Koochla, Kagphill (Hind.), Koochila (Beng.), Yetti (Tam.). Auch die Araber sollen sie als Antidot kennen. Nach Rheede sollen 1-2 Samen täglich, zwei Jahre lang genommen, den Körper gegen Cobra-Gift schützen. Wie schon oben erwähnt, ist das aus den Samen dieser Pflanze bereitete Strychnin in neuester Zeit von A. Müller in Australien mit grossem Erfolge gegen die dortigen Giftschlangen angewandt worden.

\section{Gentianacene.}

Gentiana lutea L. Vom gelben Enzian wurden die Blätter und besonders die Wurzel zu allen Zeiten als wirksam gegen Schlangengift gerühmt. Dieselbe enthält ausser anderen Stoffen Gentiansäure und einen glycosidischen Bitterstoft Gentiopikrin.

Erythraea Centaurium Pers. wird ebenfalls häufig von älteren Autoren erwähnt.

Menyanthes indica Thunb. wird in Indien angewandt ${ }^{2}$ ).

\section{Polemoniacede.}

Polemonium coeruleum L. (Polemonia, Philetaeris der Alten) wird von Plinius ${ }^{3}$ ) empfohlen.

$\left.{ }^{1}\right)$ Kobert, Jahresh. d. Pharmakoth. f. 1884. S. 36.

2) Rheede, Hort. Malabar. XI. 56.

3) Plinius, Hist. nat. XXV. 55. 


\section{Hydrophyllaceae.}

Hydrophyllum canadense L. wird in Nordamerika bei Schlangenbiss benutzt ${ }^{1}$ ).

\section{Boragineae.}

Heliotropium villosum Desf.(Heliotropium, Helionscorpion, Solago major) ${ }^{2}$ ). Die Pflanze enthält ein Alkaloid, das Heliotropin, das zu 0,025 g subcutan applicirt Katzen unter Sommolenz, der zuweilen Zittern, Unruhe und Erbrechen voraufgeht, tödtet.

Cynoglossum officinale L. und

C. pictum Ait. (Cynoglossa, Lingua canina ${ }^{5}$ ). Aus el'sterem ist ebenfalls ein zu $0,1 \mathrm{~g}$ auf Frösche paralysirend wirkendes Alkaloid dargestellt worden.

C. virginicum L. in den Vereinigten Staaten.

Echium rubrum L. (Anchusa, Onochiles, Rhexia, Arcebium). Man gebrauchte Wurzel und Blätter innerlich ${ }^{1}$ ).

E. vulgare L. (Pseudoanchusa, Echis, Echion, Doris). Man nahm gegen Schlangenbiss einen Trank von den Blättern oder Samen ${ }^{5}$ ). Die Bewohner von Valencia in Tenezuela nelimen, wenn sie von einer Giftschlange gebissen sind, neun Tage lang Morgens und Abends etwa $1,25 \mathrm{~g}$ von einem Pulver ein, das aus gleichen Theilen von Echium vulgare, Eryngium campestre, Nepeta marifolia und Alyssum spinosum besteht ${ }^{6}$ ).

Das frische Kiraut von Echium vulgare enthält ein Alkaloid, das bei Fröschen zu 0,025 g Irregularität der Athmung und Muskelrigidität, zu $0,1 \mathrm{~g}$ tetanischen Krampf und mehrtägigen Rigor der Muskeln erzeugt.

1) Schöpf 1. c.

${ }^{2}$ ) Plinius, Hist. nat. XXII. 29. - Apulejus Platonicus, De viribus herbarum.

3) Plinius, Hist. nat. XXV. 41.

4) Ibid. XXII. 25.

5) Ibid. XXII. 24; XXV. 58.

c) 1 imm in l. (c. 
Anchusa tinctoria L. (Alkibiadion, Alkibidion). Blätter und Wurzeln wurden innerlich und äusserlich angewandt ${ }^{1}$ ). Ausser dem Alkannaroth soll die Wurzel noch eine giftige Base enthalten.

Trichodesma indicum Lehm., Chota-kulpee (Berfo.), Jhingi, Jhingino (Hind.), ist in Vorderindien berühmt als Mittel gegen Schlangenbiss "). Die Wirkung ist eine diuretische.

Tiaridium indicum Lehm., Hatee-shooro (Beng.), Tayl-kodukhoo (Tam.), Benapatsja (Mal.), wird auf Jamaica, mit Ricinusöl gekocht, üusserlich gebraucht. Die Pflanze wirlt adstringirend und soll nach Martius mit sicherem Erfolge Entzündungen mildern ${ }^{3}$ ).

\section{Convolvulaceae.}

Convolvulus Cantabrica L. wurde im Alterthum häufig bei Schlangenbiss gebraucht ${ }^{4}$ ).

C. purpureus L. (Ipomoea purpurea Roth.) in Nordamerika $^{5}$ ).

Ipomoea bona nox L. ${ }^{6}$ ).

I. campanulata L. ${ }^{7}$ ).

I. grandiflora Roxb. (Calonyetion grandiflorum Choisy) ${ }^{8}$ ) in Ostindien.

\section{Solanaceae.}

Mandragora officinalis Mill. (M. officinarum L.), der bekannte Alraun, wurde im Alterthum auch gegen Schlangenbiss angewandt.

1) Plinius, Hist. nat. XXVII. 22.

2) Madras Quart. Journ. IV. p. 10. - Pharmacographia indica. IV. 523. - Spry's Modern India. Vol. I.

3) Drury 1. c. p. 426 .

4) Celsus, De medicina. V. cap. 27. - Plinius, Hist. nat. $\mathrm{XXV} .55$.

$\left.{ }^{5}\right)$ Schöpf l. c.

6) Pharmacographia indica. IV. 540.

$\left.{ }^{7}\right)$ Rheede, Hort. Malabar. XI. 115.

$\left.{ }^{8}\right)$ Ainslie, Mat. med. ind. II. 355. 
Von Physalis somnifera L. (Halicacabum, Callium) legte man die mit Oel abgeriebene Wurzel auf. Wenn man die Wurzel den Schlangen nähert, so schlafen sie, wie man glaubte, ein und verlieren ihre giftigen Eigenschaften ${ }^{1}$ ). Die Pflanze, welche den Bitterstoff Physalin enthält, hat eine diuretische Wirkung.

Von Hyoscyamus niger L., H. albus L. u. a. nahm man die zerstossenen Blätter mit Wein innerlich *). Die Pflanzen enthalten die sehr siftigen Alkaloide Hyoscyamin und Hyoscin.

Nic otiana T'a bac um $L$. und andere Nicotianaarten werden noch in der neuesten Zeit in den verschiedensten Ländern als ein gutes Mittel gegen Schlangenbiss gerühmt. Man gebraucht vom Tabak zu diesem Zwecke theils die frische Pflanze, besonder's den Saft, immerlich und äusserlich, theils Decocte, Infuse, Tincturen etc. In Japan rieb man früher die Bisswunde mit Tabakssaft ein, den auch die Neger auf Martinique in derselben Weise verwenden; er wirkt vermöge seines hohen Nicotingehaltes reizend, vielleicht sogar caustisch.

Von anderen Nicotianaarten gebraucht man

N. Langsdorffii Weinm. in Brasilien ${ }^{3}$ ).

Solanum incanum R. Pav. Aus den Blättern macht man in Peru zusammen mit denen des Tabaks einen warmen Brei und verbindet damit die Bisswunde ${ }^{4}$ ).

S. mammosum L. (matrozendruif"). Die Wurzeln und Blïtter dieser Pflanze werden in Niederländisch-Westindien zusammen mit denen von Eclipta alba ("Louise Beberie“) und der Prairiebohne gegen Schlangenbiss gebraucht; dazu fügt man noch die verkohlten Köpfe giftiger Schlangen. Man erhïlt so eine an Roggenbrot erinnernde Masse, welche die Leute stet: hei sich führen und gegen hohe Preise verkaufen. Dieselbe wird aber weder eingeimpft noch als Präservativ-

I) Plinius, Hist. nat. XXI. 105.

$\left.{ }^{2}\right)$ Ibid. XXV. 58.

$\left.{ }^{3}\right)$ v. Martius l. c. p. 120.

4) Pöppig, Reise in Chile und Peru. II. S. $268 \mathrm{ff}$. 
mittel genommen, sondern nur dem bervits Gebissenen eingegeben. Zu diesem Zwecke muss sie in Schnaps ("dram") oder dergleichen gelöst sein, ebenso wird sie in aufgelösten Zustande auf die Wunde gelegt. Indessen kann auch das trockene Präparat einfach gekaut und dann auf die Bissstelle gebracht werden; der Schnaps ist also unwesentlich ${ }^{1}$ ).

S. mammosum enthält ebenso wie die Kartoffel und andere Solanumarten das Glykosidalkaloid Solanin, welches besonders central wirkt und in erster Linie die motorischen und das Athmungscentrum lähmt, also durch Ersticliung tödtet. Ausserdem wirkt die Pflanze diuretisch.

Franciscea uniflora Pohl (Brunfelsia Hopeana Benth.) ist in Brasilien unter dem Namen "Manacác" als Mittel gegen Schlangenbiss bekannt. Die ganze Pflanze, besonders die Wurzel, wirkt diaphoretisch, diuretisch und purgirend ${ }^{2}$ ). Wurzel und Blätter enthalten ein Alkaloid.

Capsicum baccatum L. und C. frutescens L., Mollaghai (Tam.), Capoo mologoo (Mal.), Lunka mirch (Hind.), werden in Nordamerika und in Indien angewandt. In Indien nimmt man den Saft der Blätter innerlich oder reibt denselben in eine auf dem Scheitel des Kopfes gemachte Incision ein ${ }^{3}$ ). Das wirksame Princip des spanischen Pfeffers, die flüchtige Base Capsäicin, scheint nur eine local irritirende Wirkung zu haben.

\section{Scrophulariaceae.}

Verbascum Blattaria L. (Blattaria),

V. Thapsus L.

V. sinuatum L.

V. plicatum Sibth.

(Verbascum, Phlomos,

Phlomis),

V. limnense Fraas (Phlomis, Lychnitis) sind die im Alterthum gebrauchten Pflanzen dieser Familie ${ }^{1}$ ).

1) K. Martin, Bericht über eine Reise nach Niederländisch-Westindien. I. 1888. S. $29 \mathrm{ff}$.

${ }^{2}$ ) . Martius 1. c. p. 67 .

3) Madras Quart. Journ. IV. p. 12.

๑) Plinius, Hist. nat. XXV. 60. 73. 74. 


\section{$-\quad 140$}

Digitalis Sesanum (?) wird auf Martinique gegen Schlangenbiss benutzt ${ }^{1}$ ).

Herpestes colubrina H. B. Kth., in Chile und Peru, soll noch wirksamer bei Schlangenbiss sein als der berühmte: Guaco ${ }^{2}$ ).

Scrophularia marilandica L. in Nordamerika.

\section{Bignoniaceae.}

Von Bignonia chelonoides L. gilt in Indien die Rinde, von B. unguis cati L. gelten auf Martinique die Wurzel und Blätter als Mittel gegen Schlangenbiss ${ }^{3}$ ).

\section{Acanthaceae.}

Acanthus ilicifolius L. (Dilivaria ilicifolia Juss.), Kiolee-molee-cheddie (Tam.), Hurkut, Hárkúchliánta (Hind.), Paina-schulli (Mal.) wird in Indien äusserlich angewandt. Die Blätter enthalten ein Alkaloid ${ }^{4}$ ).

Rhinacanthus communis Nees., Palak-juhi (Hind.), Nága-malli (Tam.), Puzhuk-kolli, Pushpa-kedal (Mal.). Die Wurzel wird in Indien gegen Schlangenbiss gebraucht" ${ }^{5}$. Sie enthält Rhinocanthin, eine harrige, chinonähnliche Substanz.

Barleria cristata L. (Surp-jeeba). Man benutzt in Indien die Samen ${ }^{6}$ ).

Peristrophe bicalyculata Nees., Nhasa-bhaga (Beng.). Die junge Pflanze wird in Indien imnerlich und äusserlich angewandt ${ }^{7}$ ).

1) Rufz, Enquête. p. 161.

2) Pöppig, Reise in Chile und Peru.

3) Rheede, Hort. Malabar. VI. 48. - Lanessan J. c. p. 471.

1) Yharmacographia indica. V. 42.

5) Roxburgh, Flor. ind. I. 121.

i) Madras Quart. Journ. IV. p. 4.

†) Ibicl. IV. I, 5. 


\section{$-141$ \\ Verbenaceae.}

Verbena officinalis L. (Verbenaca, Hierabotane, Verminacia) ist eine im Alterthum häufig gegen Schlangenbiss empfohlene Pflanze ${ }^{1}$ ).

Von V. virgata R. P. gebraucht man in Brasilien innerlich und äusserlich ein Infus ${ }^{2}$ ).

Von Vitex agnus castus L. (Vitex, Lygos, Agnos) gab man im Alterthum die Samen und Blätter mit Wein ein $\left.{ }^{3}\right)$. Die Samen sollen einen alkaloidischen Stoff Viticin enthalten.

- Von V. altissima Roxb. gebraucht man in Indien die Blätter ${ }^{4}$ ).

Von Aegiphila salutaris Kth. ("Contracolevra“) benutzt man in Südamerika ein Decoct der Blätter ${ }^{5}$ ).

Clerodendron infortunatum L. Die Blätter sind aut Java gegen Schlangenbiss in Gebrauch ${ }^{6}$ ).

Zapania nodiflora L., Bhookokra (Hind.), Baleya eetheecannee (Mal.). Der Saft wird in Indien benutzt ${ }^{7}$ ).

\section{Labiatae.}

Die an Arzneipflanzen und Küchengewächsen so reiche Familie der Labiaten lieferte im Alterthume eine grosse Menge von gegen Schlangenbiss gebrauchten Pflanzen, rielleicht sogar die meisten von allen Familien. Offenbar spielte das Vorkommen von ätherischen Oelen in rerselben bei ihrer Anwendung eine bedeutende Rolle.

Abgesehen von einigen Gewächsen, deren Gattung und Art sich jetzt nicht. mehr mit Sicherheit bestimmen lassen,

1) Plinius, Hist. nat. XXV. 59. - Apulejus Platonicus, De viribus herbarum.

$\left.{ }^{2}\right)$ L enz, Schlangenkunde.

3) Plinius, Hist. nat. XXIV. 38.

4) Rhe ede, Hort. Malabar. V. 3 .

5) Saffray 1. c.

6) Bisschop Grevelink l. c. p. 689 .

7) Rheede, Hort. Malabar. X. 93. 
werden von den alten Autoren besonders folgende Arten gegen Schlangenbiss empfohlen:

Mentha piperita L. (Mentha sativa).

M. silvestris L. (Mentastrum).

M. Pulegium L. (Pulegium).

Salvia officinalis L. (Salvia, Sphakos, Elelisphalios: mit letzteren beiden Namen sind vielleicht auch Salvia pomifera L., Salvia calycina L. u. a. gemeint).

S. Horminum L. (Orminon, Corruda). Von dieser Pflanze wurde der gekochte Saft benutzt.

Origanum vulgare L. (Origanum viride).

O. heracleoticum L. (Cunila gallinacea).

O. smyrnaeum L. (Dictamnus). Auch die oft erwiilmte cunila bubila ist eine, jedoch nicht genau zu bestimmende Origanum-Art.

Thymus Serpyllum L.

T. Tragoriganum L. ist vielleicht das alte Tragoriganon.

Satureja hortensis L.

S. Juliana L. ist zum Theil ebenfalls das alte Tragoriganum.

Calamintha Clinopodium Benth.

Hyssopus officinalis L.

Nepeta Cataria L.

N. italica Willd.

Dracocephalum Moldavicum L. (Melissa).

Betonica Alopecurus L. (Herba Vettonicae, Syderitis, Serratula); vielleicht ist auch Sideritis syriaca $L$. gemeint.

Marrubium vulgare L. (Prasion).

Ajuga Ira L. (Abiga, Chamaepitys).

Teucrium Scorodonia L. (Scordotis).

T. Scordium L. (Scordion).

T. Chamaedrys L., auch T. lucidum L., T. flavum L. (Chamaedrys, Chamaedrops, Teucria, Teucrion, Trixago). 
T. Polium L.

Ocimum basilicum L. (Basilica, Ocymum).

Rosmarinus officinalis L. (Rosmarinum, Ros maris, Libanotis).

In neuerer Zeit werden von den Labiaten folgende Arten gegen Schlangenbiss angewandt:

Collinsonia canadensis L. und

Cunila Mariana L. in Nordamerika. Von letzterer Pflanze gebraucht man den ausgepressten Saft mit Milch äusserlich; sie wurde zuerst von Schöpf ${ }^{1}$ ) empfohlen.

Ocimum basilicum L. in Nordamerika und Cochinchina $^{2}$ ).

O. gratissimum L. und

O. minimum L. ebenfalls in Cochinchina, und zwar die Samenkörner.

Mikromeria marifolia Benth. (Nepeta marifolia Cav.) in Venezuela (s. Echium vulgare).

Pogostemon parviflorus Benth. Die Wurzel wird in Indien innerlich und ausserlich, besnnders beim Biss der Phorsa-Schlange (Echis carinata), angewandt ${ }^{3}$ ). Die Pflanze enthält ein Alkaloid Pogostemonin, ferner Trimethylamin, harzige Stoffe und einen flüchtigen Körper.

Leucas cephalotes Spr., Goma, Madha-pati (Hind.), Tumba (Mal.),

L. aspera Spr. (Phlomis aspera Willd.), Halkusa, Chota halkusa (Hind.),

L. linifolia Spr. und

L. zeylanica $\mathrm{R}$. Br. werden in Indien meistens in der Weise benutzt, dass man den Saft der zerquetschten Blätter in die Nase einzieht ${ }^{4}$ ). Die zuletzt genannte Art enthält ein flüchtiges Alkaloid.

1) Schoepf, Mat. med. americana. 1787.

2) Lanessan 1. c. p. 768.

3) Pharmacographia indica. V. 95.

4) Ibid. V. $122 \mathrm{ff}$. 


\section{Plantaginede.}

Plantago maritima L. (Herba Plantago) wird von Apulejus Platonicus und

P. Serpentina Lam. von Matthiolus empfohlen.

\section{Amarantaceae.}

Achyranthes aspera L., Chirchirà, Chikrà (Hind.), Na-yurioi (Tam.). Katalíti (Mal.). Die Samen der adstringirende und diuretische Eigenschaften besitzenden Pflanze grelten in Indien als Heilmittel gegen Schlangenbiss ${ }^{1}$ ).

\section{Chenopodiaceae.}

Beta vulgaris L. Die Runkelrübe oder Mangoltwurzel wurde im Alterthum und Mittelalter häufig angewandt; sie enthält Betaïn.

\section{Phytolaccaceae.}

Phytolacea decandra L. wird in Nordamerika gebraucht: die Samen enthalten Phytolaccin, die Beeren Phytolaccinsäure.

\section{Polygonaceae.}

Rheum Rhaponticum L., Rl. Rhabarbarum L. u. a. Rhabarberarten wurden in früheren Zeiten auch gegen Schlangenbiss empfohlen.

Polygonum Bistorta L. wurde wegen der schlangenförmigen Gestalt der Wurzel gebraucht.

\section{Aristolochiaceae.}

Die Arten dieser Familie ") haben ron allen gegen Schlangenbis: angewandten Pflanzen neben Micania Guaco den grössten liuhm erlangt. Namentlich sind es einzelne Arten der Gattung

1) Drury l. e. p. 11.

$\left.{ }^{2}\right)$ L. Planchon, Les Aristoloches. Montp. 1891. - E. J. W ayin 2 1. 1. 
Aristolochia, welche in allen Keitaltern und in alleu Lündern als die besten Mittel gegen Schlangengift empfohlen wurden, so schon von Theophrastus, Dioscorides, Plinius, Apulejus Platonicus, Avicenna, später von Petrus de Abano, Grevinus, Charas und vielen Anderen. Manche glaubten sogar, es genüge schon, sich die Hände mit einer Aristolochia zu reiben, um Vipern einzuschläfern und unschädlich zu machen oder sie zu verscheuchen. Im Alterthum und Mittelalter gebrauchte man folgende Arten:

Aristolochia rotunda L.; diese galt für die wirksamste und bildete einen wichtigen Bestandtheil mancher Sorten Theriak, von Skorpionen-Oelen und anderen Medicamenten.

A. longa L.

A. Clematitis L.

A. Pistolochia L. wurde zuerst von Plinius unterschieden, während die anderen Arten bereits lange vor ihm bekannt waren. Man gebrauchte die Wurzel unter dem Namen radix Aristolochiae tenuis oder radix Polyrrhizae s. Pistolochiae.

Die Neuzeit ersetzte die erwähnten 4 Arten, welche jetzt als Mittel gegen Schlangenbiss nirgends mehr im Gebrauch zu sein scheinen, durch folgende:

Aristolochia Serpentaria L. (Serpentaria virginiana). Diese Pflanze ist die ehemals so berühmte Virginische Schlangenwurzel, welche als Virginian snake-root oder snake-weed zuerst um die Mitte des 17. Jahrhunderts von Thomas Johnson erwähnt wurde. Sie findet sich besonders in den südlichen Vereinigten Staaten, wo man sie in der Weise gebraucht, dass man den Saft der frischen Wurzel oder der gekauten Pflanze einnimmt und die zerquetschten Blätter auf die Wunde legt. Die Pflanze soll ein ausgezeichnetes Diaphoreticum sein und auch stimulirend, antiseptisch, diuretisch und purgirend wirken.

A. reticulata Nutt, die Serpentaria von Texas oder falsche Virginische Schlangenwurzel, wird in den Vereinigten Staaten ebenso wie die vorige Art angewandt.

Breuning, Die Vergiftungen durch Schlangen. 
A. macroura Gomez, in Brasilien, der Heimat der Pflanze, Jarinha senamnt. Man benutzt Wurzel und Stengel.

A. trilobata L. (Raiz de Milhomens, Urubu-ca) wird in Brasilien, Guyana und auf den Antillen, besonders auf Martinique, sehr geschätzt. Sie ist ein gutes Diaphoreticum und vielleicht die wirksamste von allen Aristolochien ${ }^{1}$ ). Man gebraucht die Wurzel als Pulver oder Infus innerlich oder äusserlich.

A. glandulosa Kickx soll nach d'Almeida in Brasilien unter dem Namen "Angelico" gegen Schlangenbiss angewandt werden.

A. ovalifolia Duch. (Flor de Guaco) in Mexiko.

A. maxima L. (Guaco, Vejuco-Carare, Capitan) in Centralamerika und Columbien.

A. fragrantissima Ruiz (Bejugo de la Estrella, Contrayerba de Bejugo, Pehuamo, Guaco, Guaco de terra caliente) in Peru, Ecuador, Centralamerika. Man legt die frische Rinde auf die Bisswunde.

A. cynanchifolia Mart. in Peru.

A. anguicida L. (Guaco von Columbien, Mort aux serpents, Manarou, Yabacani, Contra capitan, Snake poison) auf den Antillen und der benachbarten amerikanischen Küste ron Mexiko bis Brasilien, besonders in Columbien. Diese Pflanze, auf deren Bedeutung in der Therapie des Schlangenbisses schon ihre Namen hinweisen, ist eine der am meisten gerühmten Arten. Wenn man einige Tropfen ihres Saftes einer Schlange in den Mund bringt, so soll sie betïubt werden. Dieser Thatsache sollen sich die Gaukler bei ihren Productionen mit Giftschlangen bedienen, um letztere auf diese Weise unschädlich zu machen. Einige behaupten, die Schlange sterbe sogar unter Zuckungen, wenn man die Wurzel der Pflanze kaut und ihr einige Tropfen des Speichels heibringt; ebenso soll sie sterben, wenn sie in die ihr vor-

1) Th. Peckolt, Ueber brasilianische Volksheilmittel. Arch. der Pharm. LXXXII. 93. 
gehaltene Wurzel beisst. Auch soll es schon genügen, sich Hände und Füsse mit der Pflanze zu reiben, um die Schlange ohne Gefahr ergreifen zu können. Ist man gebissen, so legt man die Pflanze auf die frische Wunde und nimmt ein Decoct davon innerlich.

A. tenera Pohl (Matos) in Columbien. Nach der Sage soll sich ein kleines Süugethier, genannt „Matos", durch Essen der Wurzel vom Schlangenbisse heilen.

A. cymbifera Mart. (Jarra, Papo de Perù) in Brasilien. Man gebraucht das Pulver, den Saft oder ein Infus oder Decoct von den Blätteru. Bei Thieren treten folgende Intoxicationserscheinungen nach Eingeben der Pflanze auf: zuerst Erregung, Erbrechen und Diarrhöe, damn Somnolenz, Schwäche und absolute motorische Paralyse, schliesslich Stillstand der Respiration vor dem des Herzens ${ }^{1}$ ).

A. brasiliensis Mart. (Vejugo, Mil-homens) in Brasilien (der Name "Vejugo" bedeutet weiter nichts als "Liane").

A. ringens Vahl. (Vejugo carare, Mil-homens, Racine (lu Soleil) auf den Antillen, in Columbien, Venezuela und Brasilien. Man benutzt die Stengel und Wurzel als Pulver oder Decoct und auch den frischen Saft. Die Wurzel hat einen äusserst penetranten, widerlichen, rauteähnlichen Geruch und einen stark bitteren, aromatischen Geschmack; sie soll in ihren Wirkungen fast ganz der Aristolochia Serpentaria L. gleichen.

A. cordifolia Nutis (Contracapitana de Monpox, Flor de Alcatras de Monpox) in Columbien (Wurzel).

A. odoratissima L. (Tacopatle, Tacopaste, Tlacopatli, Raiz para el flato, Contrayerva, Birthwort) auf den Antillen, in Mexiko, Central- und Südamerika (Wurzel und Samen).

A. sempervirens L, hat in Arabien einen grossen Ruf.

1) Butte, Recherches expérimentales sur l'action physiologique et thérapeutique de l'extrait aqueux du Guaco (Aristol. cymbifera). Journ. des nouveaux remèdes. 1889. p. 460. 
Eine 40 Tage lang gebrauchte Abkochung der Wurzel soll gegen die schädlichen Zufälle des Schlangenbisses schützen ${ }^{1}$ ). Man legt auch die gekauten Blätter als Kataplasma auf dieWunde.

A. Turbacensis Bonpl. (Capitana de Corazon) in Mexiko (Decoct der Wurzel).

A. galeata Mart.,

A. rumicifolia Mart.,

A. theriaca Mart. und

A. antihysterica Mart. in Brasilien ${ }^{2}$ ).

A. indica L. in Ostindien, Arabien, Australien, auf Java, Timor, den Philippinen etc. Sie ist bekannt unter den Namen Isharmul, Isarmel, Isharamoula, Isarmul-jorabel (Hind. und Bengal.), Perumarundoo, Peroum-Aroundou, Is churamuli, Ichura-muliver (Tam.), A karmulia, Ishwari, Sunauda (Sanskr.), Wallas (Jav.), Akarpoe-loeron (Mal.).

Die ehemaligen portugiesischen Ansiedler an der Westküste scheinen zuerst ihren Gebrauch ron den Eingeborenen gelernt zu haben und nannten sie "raiz de cobra". Einige Forscher ${ }^{3}$ ) rühmen ihre Wirksamkeit bei Schlangenbiss, andere fanden sie dagegen unwirksam "). Nach einem Hindustanischen Sprichworte soll die Pflanze sogar die Schlangen fernhalten (dasselbe behauptet Plinius von der A. pistolochia). Lowther ${ }^{5}$ ) berichtet zwei Fälle, wo eine schon fast für todt gehaltene junge Frau und ein bereits comatöses Kind durch innere und äussere Anwendung der Blätter dieser Pflanze gerettet wurden. Aeusserlich gebraucht man letztere in der Weise, dass man Stirn und Glieder mit den Blättern reibt und dieselben zugleich in die Nase steckt. Auch berlient man sich der getrockneten Wurzel, oder einer Ablochung der ganzen Pflanze, oder der in Wasser zerstossenen Wurzel.

1) Forskah 1, Flora aegyptiaco-arabica. p. 156.

$\left.{ }^{2}\right)$ v. Martius 1. c. p. 107.

$\left.{ }^{3}\right)$ Rheede, Hort. Malabar. VIII. p. 18-25. - Burman, Thes. Zeylan. p. 33.

4) Russell, Indian serpents. I. p. 86 .

s) Madras Quart. Journ. V. p. 138, 742. 
A. bracteata Retz., Cattrabungla (Sanskr.), Keeramár (Hind.), Addin-náppále (Tam.) in Ostindien, Persien, Arabien etc. Sie wird in Mysore zusammen mit Nux vomicaRinde gegeben. Auch in Abessynien wird sie als Mittel gegen vergiftete Wunden gebraucht.

Es ist sehr wilhrscheinlich, dass ausser diesen angeführten Arten noch andere, besonders in Südamerika, gegen Schlangenbiss angewandt werden.

Die Wirkung der Aristolochien ist, wie schon bei einzelnen Arten angegeben wurde, im Allgemeinen eine stimulirende, diuretische, diaphoretische und antiseptische. Es ist möglich, dass der scharfe frische Saft, wenn örtlich angewandt, auch auf das Gift selbst eine im gewissen Grade caustische oder sonst irgend eine Wirkung ausübt.

Orfila ${ }^{1}$ ) fand, dass Thiere durch grössere Mengen der Wurzel von Aristolochia Clematitis oder deren wässrigem Extracte nach eimigen Tagen unter allgemeinen Lühmungserscheinungen zu Grunde gingen. Die Section ergab leichte Entzündungserscheinungen der Magenwand. Bei Pferden sah man nach Eingaben grösserer Mengen eine Art Trunkenheit, unsicheren Gang, allgemeine Trägheit, Somnolenz, Coma, Krämpf, Mydriasis auftreten; nach Besserung dieser Symptome blieb noch längere Zeit Verstopfung und starke Diurese zurück.

Frühere Untersucher fanden in den Aristolochien einen Bitterstoff, gelben Farbstoff, Oele und Harze. Pohl2), der die Samen von Aristolochia Clematitis und die Wurzeln von A. longa und rotunda verarbeitete, fand als giftigen Bestandtheil das Aristolochin. Kaninchen starben daran in wenigen Tagen infolge einer sehr heftigen acuten Nephritis an Urämie; die Diurese war anfangs vermehrt, wahrscheinlich durch Reizung der secernirenden Nierenelemente, später wurde der Harn spärlicher und bluthaltig. Es traten ferner Parese der hinteren Extremitäten, Pendelberregungen des Kopfes, selten

1) Orfila, Toxicologie. II. S. 471. 1854.

2) Pohl, Ueber Aristolochin. Arch. f. experim. Pathol. u. Pharmacol. XXIX. 3. 4. 1891. S. 282. 
Trismus ein. Die Athmung wurde beschwerlich, der Herzschlag aussetzend, die Cornealreflexe schwanden. Dosen von 0,02 g pro Kílo erwiesen sich als tödtlich. Ein Kaninchen abortirte. Bei der. Section zeigte sich eine ansgebreitete Nekrose der epithelialen Nierenelemente. Die Glomeruli waren intact.

Bei Hunden traten nach subcutaner Application des Aristolochins Würgbewegungen, Erbrechen, dünfluissige Stuhlentleerungen. Schwïche, stockende Respiration und Tod unter Coma und Respirationslähmung auf. Albuminurie fehlte; dagegen zeigte sich eine deutliche Herabsetzung des Blutdruckes. Die Herzaction war nicht nennenswert verändert. Bei den Sectionen ergaben sich Hyperämien, Blutungen und hämorrhagische Infiltrationen besonders in Darme.

Wahrscheinlich bewirkt das Aristolochin eine Gefässdilatation im Darmgebiete, welche die allmïhlich bis zum tödtlichen Grade fortschreitende Blutdrucksenkung, sowie die starke hämorrhagische Infarcirung der Darmschleimhaut zur Folge hat. Das Aristolochin ist nach Pohl eins der heftigsten bisher belsannten Nierengifte. Aehnlich dem Aristolochin, doch weit schwächer, wirkt das Aloin ${ }^{1}$ ).

Man benutzte übrigens die Aristolochien besonders wegen ihrer diaphoretischen und diuretischen Eigenschaften ausser gegen Schlangenbiss auch gegen zahllose andere Krankheiten.

Von sonstigen zur Familie der Aristolochiaceen gehörigen Pflanzen werden noch folgende gegen Schlangenbiss empfohlen:

Bragantia Wallichii R. Br. (Apamia siliquosa Lamarck, malaiisch Alpam, Alpama und Pahiora). Der Saft der Blïtter wird mit Acorus calamus in Indien als Antidot gegen Schlangengift äusserlich gebraucht, ebenso die zerriebene Wurzel mit Limonensaft als Schnupfmittel gegen Cobra-Biss. Die Wurzel wird auch innerlich in Milch gegeben und als Kataplasma aufgelegt. Nach einem malabarischen Sprichwort verlässt das Gift den Körper, sobald "alpam" in ihn eintritt.

1) Murset, Arch. f. experim. Pathol. u. Pharmacol. XIX. S. 310. 
In Nordamerika benutzt man

Asarum virginicum L. und

A. canadense L., auch canadische Serpentaria genannt und mit Aristolochia Serpentaria zusammen gegeben. Die Wurzel dieser Pflanze wirkt brechenerregend und purgirend und regt vielleicht, wie die ron Asarum e u ropa e u m L., die Gefässthätigkeit an. (Asarum europaeum. enthält den Haselwurzcampher Asarin.)

\section{Piperaceae.}

Piper nigrum L.,

P. reticulatum L. (Jaborandi in Brasilien),

P. procumbens Desc. (?),

P. nodulosum Link,

P. unguiculatum R. P. (Nhandi, Nhandu, Pimenta dos Indios) werden in Amerika, besonders in Brasilien, viel bei Schlangenbiss angewandt. Der schwarze Pfeffer wurde auch in Europa früher häufig zu demselben Zwecke empfohlen, so schon von Celsus ${ }^{1}$ ). Man gebraucht den Pfeffer in Amerika theils innerlich, theils legt man die zerquetschten Wurzeln auf die Bisswunde. Die Wurzel ron P. reticulatum soll ein kräftiges Sialagogum sein ${ }^{2}$ ), P. nodulosum und P. unguiculatum dagegen diuretisch wirken ${ }^{3}$ ). Von P. procumbens gilt der Stengel auf Martinique als ein sicheres Heilmittel ${ }^{4}$ ).

\section{Lauraceae.}

Laurus nobilis L. Man machte bei Schlangenbiss Umschläge mit den Blättern und der Rinde des Lorbeerbaumes und trank die Beeren in Wein ${ }^{5}$ ). A ricenna empfiehlt auch das Lorbeeröl.

1) Celsus, De medicina. V. Cap. 27.

2) Spix u. v. Martius, Reise in Brasilien. I. S. $279 \mathrm{ft}$.

$\left.{ }^{3}\right)$ v. Martius, Syst. mat. med. Brasil. p. 99.

4) Lanessan 1. c. p. 433 .

5) Plinius, Hist. nat. XXIII. 80. 
Auch das von L. officinalis L. (Sassafras officinarum Nees) stammende Sassafrasöl gilt als Gegenmittel, besonders gegen den Biss von Trigonocephalus.

Cinnamomum zeylanicum Nees und andere Zimmtarten wurden ebenfalls früher angewandt ${ }^{1}$ ).

\section{Loranthaceae.}

Von Loranthus americanus Jacq. gilt der Saft der Rinde und der Früchte auf Martinique als Antidot ${ }^{2}$ ).

\section{Euphorbiacede.}

Euphorbia officinarum L. Plinius ${ }^{3}$ ) empfiehlt den Saft der Euphorbia als ein ausgezeichnetes Gegengift gegen Schlangenbiss und rïth, auf dem Scheitel des Kopfes einen Einschnitt zu machen und dort das Mittel einzuführen, ebenso Dioscorides.

E. neriifolia L. (E. Ligularia Roxb.), Schadidacalli, Katak-kalli, Daun-susu-sudu (Mal.), Shadraykullie (Tam.), Manasí-sij, Munsa-sij (Beng.) ist der indischen Schlangengottheit Manasá (Munsa) geweiht. Die Eingeborenen von Indien gebrauchen die Wurzel mit schwarzem Pfeffer innerlich und äusserlich. An jedem Dienstag und Donnerstag der Monate Juli und August bringen sie den Baum zugleich mit Gaben von Reis, Milch und Zucker der Gottheit dar und beten zu ihr um Befreiung von den Schlangenbissen ${ }^{4}$ ).

E. Antiquorum L., Elak-kalli (Mal.), Ilaik-kalli (Tam.), Sehund, Thokar (Hind.) wird in Vorderindien in derselben Weise angewandt wie die vorige ${ }^{5}$ ).

E. thymifolia L., Sittra paládi (Tam.), Chhoti dudhi, Nigíchúni (Hind.). Der ausgepresste Saft oder

1) Celsus 1. c.

2) Lanessan 1. c. p. 462 .

3) Plinius, Hist. nat. XXV. 38.

4) Madras Quart. Journ. III. 1861. - Drury 1. c. p. 205.

s) Pharmacographia indica. V. 253. 
die gepulverte Pflanze wird in Indien mit Wein innerlich genommen und auch äusserlich auf den gebissenen Theil applicirt. Das ätherische Extract der Pflanze entlält ein Alkaloid.

E. Guyoniana Boiss. et Reut. wird in Algier gegen Schlangenbiss benutzt. Tissaire ${ }^{1}$ ) empfiehlt den frischen Milchsaft der Pflanze zu 8-10 Tropfen in Wasser zu nehmen, nach einer Stunde nochmals 5 Tropfen und nach 2-3 Stunden weitere 5 Tropfen zu nehmen; in den Zwischenrüumen verordnet er Stimulantien und Diaphoretica mit etwas Ammoniumacetat, eventuell noch zwei weitere Dosen von 5 Tropfen in Pausen von $31 / 2$ bis 4 Stunden. Wenn keine frischen Pflanzen da sind, so soll man ein Decoct der trockenen anwenden.

E. pilulifera L. (E. hirta L., E. capitata Lam.) ist auf Martinique und anderen Antillen als Malnommée bekannt. Die auf die Wunde gelegte gekaute Pflanze soll den Schmerz lindern, das Gift neutralisiren und die Bisswunde heilen. Etwas von der gepulverten Pflanze innerlich genommen soll das Herz stärken und die durch das Schlangengift verloren gegangenen Kräfte wieder herstellen. Auch in Brasilien wird die Pflanze bei Schlangenbiss angewandt ${ }^{2}$ ).

E. prostrata Ait. wird in Nordamerika gegen Schlangenbiss gebraucht.

Der Milchsaft der Euphorbien wirkt äusserlich angewandt als Reizmittel, innerlich genommen aber als Catharticum.

Croton oblongifolius Roxb., Arjuna (Hind.), Kote, Putol (Mal.) in Indien. Die Pflanze enthält einen alkaloidischen Stoff ${ }^{3}$ ).

C. Tiglium L., Jumalghota (Hind.), Cadel-avanacu, Neervaula, Pantjahar (Mal.), Nervalum (Tam.), AdalAdal (Javan.), wird ebenfalls in Indien benutzt. Man legt ein Pulver der getrockneten Blätter auf die Bisswunde ${ }^{4}$ ).

1) Annuaire de thérapeutique. 1859. p. 263. - Tissaire, Etudes sur la vipère cornue (bicorne) de l'Algérie du Sud. Alger 1858.

$\left.{ }^{2}\right)$ Rufz, Enquête. - Bisschop Grevelink 1. c. p. 426.

${ }^{3}$ ) Pharmacographia indica. V. 286.

4) Rheede, Hort. Malabar. II. 62. 
Croton Tiglium ist auch ein Bestandtheil der Tanjore-Pillen. Der wirksame Bestandtheil der Pflanze ist das Crotonöl, welches :iusserlich hautreizend, innerlich dagegen stark drastisch wirkt.

C.antisyphiliticus Mart. (Erva mular, Curraleira, Pé de perdis, Alcanfora). Die Blätter werden in Brasilien theils äusserlich als Foment auf die Bissstelle applicirt, theils in Form eines Infuses imnerlich gegeben. Die Wirkung soll eine diaphoretische, diuretische und excitirende $\operatorname{sein}^{1}$ ).

Antidesma Alexiteria L. und

A. Bunius Spr., Amtee (Hind.), Nolei-tali (Tam.), Nuli-tali (Mal.), Hoenie (Jav.) werden in Indien und auf Java gegen Schlangenbiss gebraucht und wirken diaphoretisch ${ }^{2}$ ).

Rottlera tinctoria Rosb. (Mallotus philippinensis Müil.), Kamal (Hind.), Capilapodi (Tam.), Ponnagam (Mal.). Blätter und Früchte werden in Indien angewendet ${ }^{3}$ ). Der wirksame Stoff ist wahrscheinlich das Rottlerin.

Jatropha opifera Mart. (Adenoropium opiferum) in Brasilien (Herva de lagarto) ${ }^{4}$ ).

\section{Urticacene.}

Schon Plinius erwähnt eine Urtica, deren Samen die von einer Schlange Gebissenen mit Schilukiötenbrühe trinken sollen ${ }^{5}$ ), und noch jetzt soll von den nordamerikanischen Indianern eine Nessel bei Schlaugenbiss angewandt werden ${ }^{6}$ ). Die Nesselarten enthalten in ihren Drüsenhaaren vielleicht

1) v. Martius 1. c. p. 85 .

$\left.{ }^{2}\right)$ Madras Quart. Journ. IV. p. 12. - Bisschop Grevelink 1. c. p. 427 .

$\left.{ }^{3}\right)$ Rh e ede, Hort. Malabar. V. 42.

$\left.{ }^{4}\right)$ L e op. J. W e iss, Beiträge zur Kenntniss der südbrasilianischen Provinz Paraná. Curityba 1886. S. 21.

$\left.{ }^{5}\right)$ Plinius, Hist. nat. XXII. 15.

$\left.{ }^{6}\right)$ Germer 1.c. 
neben noch anderen wirksamen Stoften freie Ameisensäure, welche die hautröthende Wirkung dieser Pflanzen verursacht. Auch Ficus Sycomorus L. (Blätter), Morus alba L. und M. nigra L. (Saft) wurden zuweilen gegen Schlangenbiss angewandt.

Dorstenia brasiliensis Lam. (Contrayerva, Caiapiá) wird in Brasilien benutzt und soll in frischem Zustande noch kräftiger wirken als die berühmte Serpentaria, ihre heilsamen Eigenschaften jedoch schneller verlieren ${ }^{1}$ ).

D. tubicina R. P. gilt in Chile und Peru als Nittel gegen Schlangenbiss ${ }^{2}$ ).

D. Contrayerva L. (Mano de sapo, Krötenhand) ist in Mexiko, Central- und Südamerika in Gebrauch. Die Curadores de culebras in Mexiko impfen den Saft der Pflanze zum Schutze gegen Schlangenbiss ein und geben dann dem Geimpften die Wurzel in einer starken Dosis Branntwein innerlich. Die Pflanze bewirkt Sinken der Körpertemperatur und der Pulsfrequenz, sowie Erbrechen ${ }^{3}$ ); ausserdem soll sie diuretisch, diaphoretisch und excitirend wirken. Wässrige Aufgüsse und Abkochungen sind unwirksam. Alkoholische oder wässrig-alkoholische lassen die excitirende Wirkung auf Herz, Gehirn und Rückenmark hervortreten.

Girardina palmata Gandich., in Indien.

\section{Plantanaceae.}

Platanus orientalis L. wurde im Alterthum und Mittelalter, und

Pl. occidentalis L. wird noch jetzt in Nordamerika von den Eingeborenen benutzt ${ }^{4}$ ). Die Knospen der ersteren enthalten Asparagin und Allantoin.

1) Spix u. v. Martius, Reise in Brasilien. I. S. 279 ff.

2) Pöppig, Reise in Chile und Peru.

3) Jacolot, Arch. de méd. navale. 1867. VII. p. 390.

4) Germer 1. c. 


\section{Juglandede.}

Juglans alba L. und

J. nigra L. werden in Nordamerika gegen Schlangenbiss gebraucht.

\section{Cupulifercie.}

Quercus Robur L. und Q. sessiliflora Sm. Man nahm theils die Eicheln innerlich, theils legte man die in Milch abgekochte Rinde auf die Bissstelle ${ }^{1}$ ).

Q. nigra L. gilt in Nordamerika als Mittel gegen Schlangenbiss.

\section{Zingiberaceae.}

Curcuma aromatica Salisb., Jangli-haldi, Banlıaldi (Hind.), Kashturi-manjal (Tam.) wird in Südindien gebraucht ${ }^{2}$ ). Die Wurzel hat tonische Wirkungen.

Amomum Grana paradisi L. (Guianapfeffer) und

Maranta arundinacea $L$. werden auf Martinique mit mehreren anderen Pflanzen zusammen, wie Erythrina ciralodendron, Aristolochia triloba und einer Anagallis, gegen den Biss der Lanzenschlange angewandt. Der Guianapfeffer bildet überhaupt den wesentlichsten Bestandtheil der meisten auf jener Insel von den Negern gebrauchten, in der Regel aus vielen Pflanzen und anderen Dingen zusammengesetzten Heilmittel gegen Schlangenbiss"). Die Maranta wird übrigens auch in Indien benutzt.

\section{Musaceae.}

Musa paradisiaca $L$. und

M. sapientium L. Der Saft der Bananenwurzel wird ebenfalls auf Martinique innerlich und äusserlich angewandt ${ }^{4}$ ).

1) Plinius, Hist. nat. XXIV. 3.

$\left.{ }^{2}\right)$ Pharmacographia indica. VI. 396.

3) Rufz, Enquête. p. 117 ff.

4) Ibid. p. 166 . 


\section{Irideae.}

Von Gladiolus segetum Gawl. (Hyacinthus) gab man im Alterthum den Gebissenen die Samen zusammen mit Abrotonum ein ${ }^{1}$ ).

Iris florentina L. und I. germanica L. (Iris rufa) wurde mit saurem Wein getrunken ${ }^{2}$ ).

Von Pardanthus chinensis Ker. (Belemcanda punctata Mönch.) werden in Indien die Blätter bei Cobrabiss gegeben ${ }^{3}$ ).

\section{Amaryllideae.}

Hypoxis erecta L. gilt in Nordamerika als Mittel gegen Schlangenbiss.

Von Agave virginica Lam. legen die Mexikaner die gekaute Wurzel auf die Bissstelle und gebrauchen dieselbe zugleich innerlich ${ }^{4}$ ). Die Wirkung ist wahrscheinlich eine diuretische.

Von A. mexicana Lam. bereitet man in Mexiko einen Branntwein ("mescal"), den man dem Gebissenen bis zur Trunkenheit eingiebt, während man zugleich die Wunde mit einem Pflaster aus dem Saft der Pflanze und schwarzem Pfeffer verbindet ${ }^{5}$ ).

Ton Polianthus tuberosa L. (Margueritas) gebraucht man in Peru theils innerlich einen Aufguss, theils legt man die durchschnittene Wurzel auf die Bisswunde ${ }^{6}$ ).

Crinum asiaticum L., Belutta pola-tali (Mal.), Veshi Moonghee (Tam.) ist ein Bestandtheil der TanjorePillen und soll emetische Eigenschaften haben. Man legt

1) Plinius, Hist. nat. XXI. 97.

2) Ibid. XXI. 83.

$\left.{ }^{3}\right)$ Rheede, Hort. Malabar. XI. 74.

4) Croft, Chemical News. XLVI. p. 165. 1882.

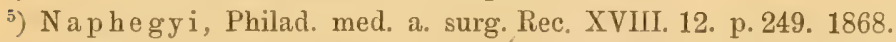

6) Pöppig, Reise in Chile u. Peru. II. S. 230 ff. - v. Tschudi, Peru. S. 433. 
auch einen Theil der gekauten Wurzel auf die Bisswunde und nimmt den anderen innerlich ${ }^{1}$ ).

\section{Liliaceae.}

Im Alterthum waren folgende Allium-Arten beliebte Mittel gegen Schlangenbiss:

Allium sativum L., der Knoblauch. Derselbe soll schon durch seinen Geruch die Schlangen vertreiben (noch jetzt bestreicht man in Indien hüufig Thüren und Fenster danit, um die Schlangen fernzuhalten), und aufgelegt oder gegessen den Biss aller Thiere heilen. Ganz besonders sollte er gegen die Schlange Hämorrhois wirksam sein, wenn man den Wein, in welchem man ihn zu sich genommen hat, durch Erbrechen wieder von sich gab ${ }^{2}$ ).

A. Cepa L., die Zwiebel, sollte ebenso wirken und wurde ebenfalls innerlich und äusserlich bei Schlangenbiss angewandt. Russell stellte jedoch fest, dass die Schlangen heineswegs eine besondere Abneigung gegen Knoblauch und Zwiebeln zeigen.

A. Porrum L., Porree.

A. Schoenoprasum L., Schnittlauch, und A. carinatum L. wurden in ähnlicher Weise gebraucht.

Ton Asphodelus ramosus L. benutzte man die Samen, Stengel und Knollen ${ }^{3}$ ).

Von Scilla maritima L. wurden die in Essig gekochten Zwiebeln aufgelegt.

Anthericum graecum L. (Lloyda graeca Salisb., Phalangitis, Phalangion, Leucanthe mum, Leucantha) wurde in Form ron Kataplasmen und Abkochungsn angervandt; man benutzte daron die Blätter, Blüthen und Samen ${ }^{*}$ ).

Lilium Martagon L. (Hemerocallis) u. a. Lilienarten galten auch als Mittel gegen Schlangenbiss.

1) Lanessan l. c. p. 784 .

$\left.{ }^{2}\right)$ Plinius, Hist. nat. XX. 28.

3) Ibid. XXII. 32.

4) Ibid. XXVII. 98. 
Gloriosa superba L., Kalihári, Languli (Hind.), Kalaipai-kizhangu, Caateejan (Tam.) wird in Madras als Specificum gegen Schlangenbiss gebraucht ${ }^{1}$ ). Warden fand in der Wurzel einen Gerbstoff und einen dem Scillain der Meerzwiebeln verwandten bitteren, giftigen Stoff, "Superbin". Eine Frau, die eine Quantität der gepulverten Wurzel einnahm, bekam nach einer halben Stunde heftiges Erbrechen, Krämpfe, Verdrehungen des Körpers, verbunden mit furchtbaren Schmerzen, und starb nach vier Stunden. Die Section ergab Congestion im Gehirn und seinen Häuten mit Blutextravasaten, sowie Congestionen in Lungen, Leber, Nieren und Entzündung der Magenschleimhaut.

Asparagus officinalis L., der Spargel, gilt in Persien als Antidot gegen Schlangenbiss; man nennt ihn daselbst Márchubeh oder Márgiyeh, d. h. Schlangenkraut $\left.{ }^{2}\right)$. Der Spargel enthält als wirksamsten Bestandtheil das Asparagin.

Uvularia perfoliata L.,

U. grandiflora Smith und

Veratrum luteum L. werden in Nordamerika bei Schlangenbiss benutzt; die letztere Pflanze enthält wahrscheinlich ähnliche giftige Alkaloide wie $V$. album und V. viride.

\section{Commelinaceae.}

Aneilema tuberosum Ham. Die Knollen werden von den Eingeborenen in Ostindien als Antidot gegen Schlangenbiss gebraucht ${ }^{3}$ ).

\section{Palmaceae.}

Kunthia montana H. B. soll in Neugranada wegen ihres zuckerhaltigen Stammes gegen Schlangenbiss angewandt werden ${ }^{4}$ ).

1) Pharmacographia indica. VI. $480 \mathrm{ff}$.

2) Ibid. VI. 486.

3) Drury 1. c. p. 42 .

4) Lenz, Schlangenkunde. 


\section{Typhacear.}

Von Sparganium ramosum L. wurde in Alterthum die Wurzel gebraucht ${ }^{1}$ ).

\section{Aroideae.}

Ton den in Alterthum bei Schlangenbiss benutzten ArumArten ist ausser Arum maculatum L., A. italicum Mill. und A. Dioscoridis Sibth. vor Allem

Arum Dracunculus L. (Dracunculus vulgaris Schott) zu erwähnen, auf dessen Bedeutung als Mittel gegen Schlangenbiss schon die alten Namen Dracontium, Dracunculus, Viperina hinweisen. Namen und Gebrauch der Pflanze sind wohl zurückzuführen auf die schlangenartigen Flecke ihrer Wurzel. Der Saft der letzteren hat scharfe, ätzende Eigenschaften.

A. Colocasia L. (Tayove) wird in Cayenne benutzt.

Caladium helleborinum Vent. in Chile und Peru.

Quebitea guianensis Aubl. und

Dracontium dubium Kth. in Britisch-Guyana.

D. polyphyllum L. (Jiraraca) in Brasilien und auf Martinique ${ }^{2}$. Die Pflanze wirkt stark stimulirend, die Wurzel purgirend.

Arisaema Pythonium Blume (Erva de Santa Maria) in Brasilien ${ }^{3}$ ).

Typhonium orixense Schott, Ghekul (Hind.), und

Scindapsus pertusus Sweet. in Ostindien. Der Saft der letzteren Pflanze wird mit schwarzem Pfeffer beim Biss der Daboia immerlich gegeben und mit dem Saft der Wurzeln von Croton oblongifolius und von der Frucht von Momordica Charantia auch auf den gebissenen Theil gelegtt).

1) Plinius, Hist. nat. XXV. 63.

$\left.{ }^{2}\right)$ Lanessan l. c. p. 486.

$\left.{ }^{3}\right)$ v. Maxtius 1. c. p. 95,96 .

4) Pharmacographia indica. VI. 544. - Madras Quart. Journ. IV. p. 12. 


\section{- $161-$ \\ Cyperaceae.}

Von Cyperus longus L. und C. rotundus L. galt die Wurzel bei den Alten als Mittel gegen Schlangenbiss ${ }^{1}$ ).

\section{Gramineae.}

Von Panicum miliaceum L. und von. der Gerste wurden Mehlumschläge um die Bissstelle gemacht ${ }^{2}$ ).

Ob die als Schoenus oder Juncus odoratus ${ }^{3}$ ) bezeichnete Pflanze Andropogon laniger Desf. ist oder $\mathrm{Cy}$ perus rotundus L. erscheint zweifelhaft.

Saccharum officinarum L. Der Saft des Zuckerrohres steht bei den Eingeborenen von Amerika, besonders von Brasilien, in hohem Ansehen als Antidot gegen Schlangengift und wird von denselben innerlich und äusserlich angewandt. Grössere Gaben davon sollen purgirend wirken, während ihm bei äusserer Anwendung eine blutstillende Wirkung zukommen soll ${ }^{4}$ ).

\section{Coniferae.}

Taxus baccata L. war im Alterthum sehr berühmt als Mittel gegen Schlangenbiss, und der Kaiser Claudius soll sogar in einem Edicte den Saft der Eibe für das wirksamste von allen bei Schlangenbiss angewandten Heilmitteln erklärt haben ${ }^{5}$ ). Sie enthält ein narkotisch wirkendes Alkaloid Taxin.

Von Juniperus communis L., dem Wachlolder, wird ron Dioscorides der Saft gegen Schlangenbiss empfohlen. Auch sollen Räucherungen mit Wachholderlaub die Schlangen vertreiben, ein Glauben, der sich bis auf die Neuzeit erhalten hat. Die diuretisch wirkenden Beeren wurden ebenfalls gebraucht.

1) Plinius, Hist. nat. XXI. 70.

$\left.{ }^{2}\right)$ Ibid. XXII. 62.

$\left.{ }^{3}\right)$ Seribonius Largus, De compositionibus medicamentorum. Cap. 167.

4) Rufz, Enquête. p. 162.

5) Mercurialis, De venenis.

Brenning, Die Vergiftungen durch Schlangen. 
Cupressus sempervirens L. wird auch von älteren Autoren erwähnt; ebenso das besonders aus Kiefern und Fichten gewonnene Kienöl.

Henzel in Südafrika behauptet aus dem Safte der sogenannten schwarzen Edeltanne ein unfehlbares Mittel hergestellt $\mathrm{zu}$ haben, durch welches von 500 von giftigen Schlangeu gebissenen Negern 487 rom sicheren Torle gerettet seien ${ }^{1}$ ).

\section{Cryptogamen.}

Salvinia natans All. (Lenticula) wird von Paulus Aegineta, ein Adianton (Kallitrichon, Polytrichon) und ein Agaricus (vielleicht Boletus igniarius) von Plinius ${ }^{2}$ ) erwähnt.

Osmunda virginica(?).

Adianthum pedatum L. und

Hypnum crista castrensis L. werden in Nordameriki gegen Schlangenbiss angewandt ${ }^{3}$ ).

Ausser den ggenannten Pflanzen werden noch eine Anzahl anderer angewandt, deren wissenschaftliche Namen sich nicht haben ermitteln lassen. So gebraucht man bei Cantagallo in Brasilien eine ammoniakalische Tinctur, welche der Apotheker Peckolt aus einer von den Eingeborenen gegen Schlangenbiss benutaten unbekannten Pflanze der Urwälder bereitet unr unter dem Namen "Polygonaton“ in den Handel gebracht hat. Dieser Tinctur wird ein Schröptkopf alus vulcanisirtem Kautschuk beigegeben, um ihn nach Unterbindung des Gliedes sogleich auf the durch einige Einschnitte erweiterte Wunde zu setzen. Die Tinctur wird je nach der Intensität der Erscheinungen in kürzeren oder längeren Zwischenräumen tropfenweise eingenommen. Dieses Mittel hat in der Umgegend von (antagallo in mehr als 70 Fällen den ausgezeichnetsten El-

1) Globus. Nr. 61. S. 61. 1892.

2) Plinius, Hist. nat. XXII. 30 u. XXV. 50.

3) Schöpf, Reisen. 
folg gehabt. Selbst wenn es sehr spät zur Anwendung kam, die Vergittungssymptome den bedrohlichsten Charaliter angenonmen hatten, und das so gefährliche Blutbrechen eingetreten war, führte es noch einen günstigen Ausgang der Krankheit herbei. Die grösste Zahl von Schlangenbissen in dieser Gegend rührt von der Jararacá her ${ }^{1}$ ).

In Columbien, Venezuela und anderen südamerikanischen Staaten ist unter dem Namen Curarina de Juan Salas Nieto ein allgemein beliebtes Volksmittel verbreitet, das als Specificum gegen Bisse von Giftschlangen, Skorpionen und tollen Hunden, sowie gegen Sumpt- und gelbes Fieber, gegen Durchfall und Menstruationsbeschwerden gilt. Lis stellt eine bräunlichgelbe, etwas trübe Flüssigkeit dar, welche wahrscheinlich ein mit Rum hergestellter Pflanzenauszug ist. Die ïbliche Dosis ist 1 Theelöffel bis 2 Esslöffel ${ }^{2}$ ).

Un noch einige andere nur unter den einheimischen Namen bekannte Pflanzen zu erwähnen, so gebraucht man in Guatemala gegen Schlangenbiss eine Pflanze "Algalia"3), in Mexiko äusserlich eine Abkochung der narkotisch wirkenden „mala mujer" (ytlohomakil), die für so giftig gilt, dass die Indianer nicht unter ihrem Schatten zu schlafen wagen ${ }^{4}$ ), in Surinam eine "sabanaboontje"5), in Südafrika eine "Herrenbohne", in Südamerika eine "Astrilobata" und "Maporite chequita" ${ }^{6}$, auf Martinique eine "Nhandiroba" (..Noix de Serpent") etc. Von unbekannten indischen Pflanzen führt Waring ${ }^{7}$ ) eine ganze Reihe auf, nämlich: Amelpodi. Ben-moenja, Belutta-amelpodi, Maravara tsjembo, Kussowndje, Kokid, Uck, Naglee, Toore, Nangale Wal, Kird, Gogaree.

1) v. 'Tschudi, Reisen durch Südamerika. III. S. $160 \mathrm{ff}$.

2) Pharmac: Centralhalle. N. F. XV. Nr. 39. 27. Sept. 1884. S. อ51.

3) Gazetta de Guatemala. 29. Nov. 1799.

4) Naphegyi l. c.

5) Nartin a. a. 0 .

6) Hancoek, Arch. d. Pharm. XXXVII. 1831. p. 65.

7) Madras Quart. Journ. IV. p. $14 \mathrm{f}$. 
Es ist nicht zu bezweifeln. dass von den Eingeborenen der verschiedenen, besonders tropischer Gebiete, gegen Schlangenbiss noch andere Pflanzen gebraucht werden, deren Kenntniss sich bisher den Nachforschungen der Reisenden entzogen hat.

Ein geheimes Mittel gegen Schlangenbiss will auch ein gewisser $\operatorname{ran}$ Tol, ein Mischling, in Surinam entdeckt haben ${ }^{1}$ ). Derselbe ritzt den Leuten die Haut an beiden Händen oberhallb des Gelenkes durch drei an der linken und zwei an der rechten Seite gemachte leichte Einschnitte auf, in welche er sein Pulver einreibt, das nach seiner Angabe aus zu Kohle verbrannten, nur ihm allein bekannten heilkrïftigen Kräutern bestehen soll. Darauf muss der Betreffende eine kleine Menge des Pulvers mit Branntwein gemengt zu sich nehmen. Diese Procedur wird jührlich wiederholt und dient zur Prophylaxe. Auch nach dem Bisse behauptet van Tol durch seine Methode heilen zu können. Salkowski fand in einer von Joest nach Berlin gebrachten Probe des Pulvers Eisen, Kalk, Magnesia, Kali, Spuren von Natron, Kohlensäure, Phosphorsäture und etwas Sand; giftige Metallverbindungen fehlen darin. Es ist nach diesem Befund möglich, dass das Mittel nichts weiter ist als eine durch sand verunreinigte Kohle. Versuche an Kaninchen und Meerschweinchen, die mit dem Mittel in der rorgeschriebenen Weise behandelt waren, zeigten die Werthlosigkeit desselben gegen Schlangenbiss. Die damit geimpften Thiere starben durch den Biss der Klapperschlange und der Puffotter ebenso wie nicht geimpfte.

Aehnlich mag es sich mit anderen melr oder minder zusammengesetzten Heilmitteln gegren Schlangenbiss verhalten. Diese alle hier anzuführen unterlasse ich, weil die Bestandtheile zum Theil unbekannt sind. Sind sie aber bekannt, so vermag man nicht den wirksimen Antheil eines solchen Gemisches zu bezeichnen. Von der Mannigfaltigkeit solcher Compositionen griebt die Mittheilung von $\mathrm{Rufz} \mathrm{z}^{*}$ ) eine Vorstellung,

1) W. Joest, Ueber ein angebliches Mittel gegen Schlangengift aus Surinam. Globus. Nr. 59. S. 358. 1891. Nr.61. S.61. 1892.

2) Rufz, Enquête. p. 132. 
wonach die ganze Flora der Antillen in den auf Martinique gebrauchten zusammengesetzten Arzneien vorkommen soll.

Auch im Alterthum hatte man das Bestreben, möglichst viele Stoffe, besonders Pflanzen, zu einem Heilmittel zu vereinigen, das dann als Universalmittel gegen alle möglichen Krankheiten, besonders auch gegen Vergiftungen angewandt wurde. Einen Hauptbestandtheil solcher Mittel bildeten vielfach, wie schon oben erwähnt, Theile von Vipern. Derartige zusammengesetzte Mittel wurden auch gegen Schlangenbisse empfohlen, z. B. von Avicenna der Theriak Alfuruk, die Latwerge des Hurmus, die des Aristomachus, von Galen die Theriaca Andromachi ex viperis ${ }^{1}$ ), das Antidotum Zopyrium ${ }^{2}$ ), das Antidotum Antipatri ${ }^{3}$ ) und das des Democrates ${ }^{4}$ ). Galen berichtet auch, dass man absichtlich Thiere von Vipern beissen liess und ihnen dann Theriak gab, um sich von der Güte des Mittels $\mathrm{zu}$ überzeugen.

\section{Impfung mit Schlangengift.}

Es bleibt noch eine Methode zu besprechen übrig, welche angesichts der günstigen Resultate, die man in der neueren Zeit mit der Einimpfung von Krankheitsgiften, z. B. bei Pocken, Hundswuth, Diphtheritis, erzielt hat, vielleicht eine grössere Zukunft hat als alle bisher besprochenen Mittel, nämlich die Impfung mit Schlangengift zum Schutze gegen die Vergiftung durch Schlangenbiss. 'Zwar war schon im Alterthum, wie bereits in dem Kapitel über thierische Antidota hervorgehoben wurde, das Bestreben vorhanden, sich durch Genuss von Viperntheilen, besonders von Vipernküpfen, gegen Schlangenbiss zu sichern, indessen ist die berwusste Anwendung

1) Galen, De Antidotis. Liber I. Cap. 6-7.

$\left.{ }^{2}\right)$ Ibid. liber II. Cap. 8.

3) Ibid. Cap. 10.

4) Ibid. Cap. 15. 
der Impfung doch erst der neueren Zeit vorbehalten gewesen. Es ist auffallend, dass wir dieses Mittel bei den Eingeborenen der verschiedensten Länder bereits zu einer Zeit in Gebrauch finclen, in welcher bei uns selbst die Pockenimpfung noch völlig unbekannt war. Freilich die Art und Weise, wie diese Impfung von manchen Eingeborenen vorgenommen wird, macht es zweifelhaft, ob dieselbe immer den Geimpften den gewünschten Schutz gegen die schädlichen Folgen eines etwaigen Bisses verleiht - jedenfalls hegen die so Behandelten eine feste Zuversicht zu der Schutzkraft dieses Mittels, und nach den Berichten von Reisenden zu urtheilen, müsste dieselbe in der That im Allgemeinen eine ziemlich sichere sein.

Ich erinnere hier noch einmal an die Schlangenbeschwörer. welche sich aller Wahrscheinlichkeit nach wenigstens in manchen Lïndern theilweise durch Impfung mit Schlangengift immun gegen die Bisse der Giftschlangen gemacht haben. In Südamerika, besonders in Brasilien, ist seit alten Zeiten der Glaube weit verbreitet, dass man sich gegen Schlangenbisse schützen könne, wenn man sich den Rücken mit dem Giftzahne einer Schlange kreuz und quer zerkratzen lasse. In ahnlicher Weise macht man in Französisch-Guyana mit dem Zahne einer Giftschlange drei ca. $3 \mathrm{~cm}$ lange Einschnitte auf dem Fussrücken und lässt die Wunden eine Minute lang bluten. Sodann werden dieselben mit einem schwärzlichen Pulver behandelt, das aus Leber und Galle des Thieres besteht, welche an der Sonne getrocknet und mit den Giftdrüsen zusammen zerrieben sind; das Blut hört danach auf zu rinnen. Der Indianer, der die Operation vornimmt, kaut darauf Baumblätter mit diesem Pulver und bringt soviel Speichel, wie er produciren kann, auf die Wunde. Damit ist die Impfung beendet. Die dadurch angeblich erlangte Immunitiit soll nach dem Glauben der Eingeborenen sogar in mehreren Generationen erblich sein. Ein französischer Reisender. welcher einer solchen Impfung beizuwohnen Gelegenheit hatte, liess dieselbe auch an sich selbst rollziehen und behauptet, seitdem $7 \mathrm{Mal}$ von verschiedenen, theilweise sehr 
gefährlichen Giftschlangen gebissen worden zu sein, olne auch nur einen Fieberanfall davongetragen zu haben ${ }^{1}$ ).

Da bei der beschriebenen Operation mit der zerriebenen Giftdrüse unzweifelhaft auch etwas von dem darin enthaltenen Gifte in das Blut gelangen kann, so scheint es sich hier in der That um eine wirkliche Impfung mit Schlangengift $z u$ handeln. An dem zum Ritzen der Haut gebrauchten Giftzahne dürfte sich wohl in den meisten Fällen kein Gift mehr befinden, es sei denn, dass er einer frisch getödteten Schlange entnommen und nicht schon früher zur Impfung benutzt wurde.

Recht interessant ist auch das in manchen Gegenden Mexikos geübte Verfahren, Menschen gegen Schlangenbiss immun zu machen ${ }^{2}$ ). Hier spielen aber wieder durch abergrläubische Vorstellungen beeinflusste äusserliche Formalitäten eine Hauptrolle. Zunächst darf die Impfung nur an einem Freitage vorgenommen werden. Vor derselben muss der Betreffende zur Vorbereitung 5-15 Knollen von der "Mano de sapo" genannten Pflanze (Dorstenia Contrayerva L.) essen, und zwar nur in ungerader Zahl (also 5, 7, 9. 15), je nach der Toleranz des Individuums. Am besten sollen die Pflanzen sein, welche am ersten Freitag des Monates März gepflückt sind. Auch im getrockneten Zustande sind sie noch geeignet zur Vorbereitung der Impfung. Die physiologische Wirkung der Pflanze besteht darin, dass die Circulation des Blutes etwas verlangsamt wird, und ein Kältegefühl, oft auch Uebelkeit und Erbrechen eintritt. Gegen letzteres muss man nach Möglichkeit ankämpfen, deun wenn die genossenen Wurzeln wieder ausgebrochen werden, soll es gefährlich sein, sich der Impfung zu unterwerfen.

Zur Impfung selbst, die noch an demselben Tage von einem "Curador de culebras" vorgenommen wird, wird ein grosser Giftzahn von den giftigsten Schlangen benutzt. Diese müssen an einem Freitag getödtet sein, und die Zähne noch

1) Archives d'anthropologie criminelle. Janv. 1892.

2) J a colot, Arch. de méd. navale. 1867. p. 390. 
an demselben Tage herausgenommen sein. Ein und derselbe Zahn kann mehrere Jahre lang zu Impfungen dienen. Zunächst wird mit dem Zahne auf dem linken Fussrücken die Haut in Form eines Viereckes geritzt, so dass es etwas blutet; man muss sich dabei hüten, eine Vene zu verletzen. Sodann kommen das rechte Handgelenk, der rechte Fussriicken, das linke Handgelenk, der linke Schenkel, der rechte Arm, der rechte Schenkel, der linke Arm, die Mitte des Brustbeins, der Nacken, die Stirn an die Reihe, so dass im Ganzen elf Inorulationen gemacht werden; den Schluss bildet endlich eine sinnbildliche Incision auf der Zunge. Vor der Impfung muss der Betreffende viel Branntwein trinken, während derselben darf er weder rauchen noch Tabak kauen, weil das Gift sonst durch den Speichel entwischen könnte.

Mindestens sieben solcher Impfungen sind nöthig, um einen Menschen sicher gegen Schlangenbiss zu schützen und ihm die Fähigkeit zu verleihen, Bisswunden auszusaugen; denn nur Geimpfte sollen im Stande sein, dies ohne Gefahr zu thun. In jedem Falle aber soll der Aussaugende seinen Mund mit Tabak gefüllt haben, da sonst die Zähne ausfallen und sogar der Tol eintreten kamn. Der Gebissene dagegen soll nach dem Aussaugen Ḱnollen von der "Mano de sapo" essen und auch davon Cataplasmen machen. Manche lassen sich bis 15. Mal impfen (stets ist auch hier eine ungerade Zahl vorgeschrieben), sollen dann aber so von Schlangengift gesättigt sein, dass sie zuweilen wahnsinnig werden. In der Regel sind sonst während der Impfzeit nur unerhebliche Störungen, wie Kopfschmerz, geringe Erregung etc. vorhanden, aber bei Vollmond soll die Geimpften eine furchtbare Wuth ergreifen, der speichel soll ihnen in Strömen aus dem Munde fliessen, sie sollen das Bedürfniss haben zu beissen, und, um nicht Menschen $z u$ beissen, in die Wälder fliehen und in die Bäume beissen, welche in Folge dessen absterben. Der Biss eines solchen Geimpften soll für Menschen eben so gefährlich sein wie der Biss einer Giftschlange.

Dass in diesem Berichte über die Wirkung der Impfung 
etwas Wahrheit mit viel Aberglauben, Mysticismus und Uebertreibungen verbrämt ist, wird ohne Weiteres klar. Wenn man bedenkt, dass ein Giftzahn mehrere Jahre lang zu den Impfungen gebraucht wird, während welcher Zeit sicher jede Spur von Gift von seiner die Haut verletzenden Spitze verschwunden sein müsste, so ist es doch sehr fraglich, ob man diesem ganzen Verfahren überhaupt noch einen Werth zuschreiben darf und es nicht vielmehr als eine bewusste Täuschung von Impfenden und eine Suggestivtäuschung der Geimpften bezeichnen soll.

In Afrika tragen die Eingeborenen von Namaqua, Damara, Kalahari, sowie die Buschmänner stets getrocknete Giftdrüsen bei sich, machen, falls sie gebissen sind, an der betreffenden Stelle kleine Einschnitte und legen Stückchen des getrockneten Inhaltes der Drüsen hinein. Zuvor legen sie eine Ligatur um das gebissene Glied und saugen die Wunde aus. Auch suchen sie die Schlange zu tödten, schneiden die Giftdrüse heraus und trinken den Inhalt derselben aus. Manche verwenden übrigens statt der getrockneten Giftdrüse in derselben Weise den getrockneten Körper einer giftigen Eidechse "t'nobo". Bolton, der sich zwei Jahre lang in jenen Gegenden aufhielt, will sich durch wiederholte Beobachtungen an den Einwohnern und an europäischen Reisenden von der vollkommen sicheren Wirkung dieser Heilmethode überzeugt haben. So sah er z. B. einen Eingeborenen, der "Gifttrinker" und Schlangenfänger war, seine Hand in einen Behälter mit giftigen Schlangen stecken und, trotzdem er ernstlich gebissen wurde, doch völlig gesund bleiben. Die einzige Folge des Bisses soll eine leichte örtliche Entzündung sein ${ }^{1}$ ).

Es handelt sich also hier um eine wirkliche Inoculation des Schlangengiftes, die aber im Gegensatze zu den bisher mitgetheilten Beobachtungen nicht als Präventivmittel vor dem Bisse, sondern erst nach geschehenem Bisse angewandt wird. $\mathrm{Zu}$ der bereits durch diesen in den Körper hinein-

1) Lancet. 7. Jan. 1886. p. 92. 
gelangten Giftmenge wird also auf demselben Wege noch eine neue, wemn auch nur geringe Quantitït gefügt, wodurch doch die Wirkung des Giftes der landläufigen Auffassung nach eher verstärkt als abgeschwächt werden müsste. Auf welche Weise hier der angebliche Erfolg der Impfung zu erklären ist, dürfte vorlïufig deductiv schwer zu ermitteln sein. Möglicherweise spielt dabei die gleichzeitige innere Anwendung des Schlangengiftes eine Rolle. Es ist nämlich denkbar, dass bei grenügender Menge von saurem Magensafte eine Modification des Giftstoffes zu Stande kommt, welche die Fähigkeit hat, die Herzthätigkeit und zugleich die Ausscheidung durch Haut und Nieren stark anzuregen; wenigstens soll den innerlich genommenen Schlangengift eine die Herzaction sehr beschleunigende Wirkung zukommen ${ }^{1}$ ). Dieser Meinung widerspricht jedoch die Beobachtung, dass Magensaft die Wirkung des Giftes nicht zerstört, sondern bei Thieren noch um das Doppelte verstärkt *).

Vor einiger Zeit suchte man von zoologischer Seite die medicinischen Kreise Deutschlands für die innere Anwendung des Schlangengiftes gegen Schlangenbiss zu gewinnen ${ }^{3}$ ). Der Empfehlende hatte in Aegypten nach jedem Bisse ein paar Tropten Schlangengift, das er stets in einem Fläschchen bei sich trug, innerlich genommen und war stets von allen schweren Erscheinungen frei geblieben. Als er einstmals bei einer Demonstration in Alexandrien von einer sehr giftigen Schlange gebissen worden war, und sich alsbald Angstgefühl, starke Schwellung der Hand und Ohnmacht eingestellt hatte, so dass ihn Alle für verloren hielten, wurden ihm ein paar Tropfen von seinem Schlangengift in Cognac eingeflösst. Schon nach kurzer Zeit folgte ein colossaler Schweissausbruch, das Bewusstsein kehrte allmälig wieder, und nach einer Stunde konnte er sich bereits auf die Strasse begeben.

$\mathrm{Ob}$ in diesem Falle wirklich dem Schlangengifte oder

$\left.{ }^{1}\right)$ Ziem, Allg. Med. Central-Zeitg. XCIV. 1886. p. 1597.

2) Gautier, Bull. de l'Acad. de méd. 2. sér. X. 1881. p. 950.

3) Ziem 1. c. 
nicht vielmehr dem gleichzeitig verabreichten Coguac der Erfolg zuzuschreiben ist, erscheint mindestens sehr zweifelhaft.

Auch in Schlesien soll ein Schuhflicker, der wegen zahlreicher glücklicher Curen bei Kreuzotterbissen berühmt war, seine Erfolge der Anwendung von gefangenen Thieren abgenommenem Schlangengifte verdankt haben.

In manchen Gegenden Afrikas soll man sogar kleine Kinder von weniger gefährlichen Giftschlangen beissen lassen, um sie gegen den Biss grösserer zu schützen.

Wissenschaftliche Untersuchungen über Immunisirung von Menschen gegen Schlangenbiss durch Schlangengift selbst scheinen bisher noch nicht angestellt worden zu sein. Dagegen liegen eine Reihe von Beobachtungen vor, welche zeigen, dass es bei Thieren möglich ist, wenn auch keine absolute, so doch eine relative Immunität gegen Schlangengift hervorzubringen, und zwar in der Weise, dass successive Giftinoculationen den Thieren grössere Widerstandsfähigkeit gegen stärkere Giftdosen ertheilen, besonders wenn letztere an demselben Punkte applicirt werden wie die ersteren ${ }^{1}$ ).

Nach den neuesten in Frankreich angestellten Untersuchungen ${ }^{2}$ ) erwiesen sich folgende Methoden als geeignet zur Immunisirung von Thieren gegen Schlangengift:

1. Man gewöhnt die Thiere an progressiv wachsende Dosen verdünnten Schlangengiftes. Zuerst injicirt man dem Thiere die Hälfte der tödtlichen Giftdosis, also z. B. einem Kaninchen von $2 \mathrm{~kg}$ Gewicht $0,25 \mathrm{mg}$ Cobra-Gift; nach 12-15 Tagen verabfolgt man ihm dieselbe Dosis noch einmal, nach 6 Tagen bereits die doppelte Dosis von

1) M. K a u $\mathrm{mann}$, Du venin de la vipère. Paris 1889.

2) M. Kaufmann, Compt. rend. de la soc. de biologie. 9. sér. VI. 1894. p. 113. - A. Calmette, Annales de l'institut Pasteur. 1892. p. 160. 1894. p. 275; Compt. rend. de la soc. de biologie. 9. sér. VI. 1894. p. 120. 10. sér. 1894. p. 204; Compt. rend. de l'Acad. des sciences. CXVIII. 1894. p. 720, 1004. - C. Phisalix et G. Bertrand, Compt. rend. de l'Acad. des sciences. CXVIII. 1894. p. 288, 356; Arch. de physiol. 5. sér. VI. 3. 1894. p. 567, 611; Conıpt. rend. de la soc. de biol. 9. sér. VI. 1894. p. 111, 124. 
$0,5 \mathrm{mg}$, nach weiteren 6 Tagen $0,75 \mathrm{mg}$, schliesslich $1 \mathrm{mg}$. Von da an kanu man jedesmal die Menge des injicirten Giftes um $1 \mathrm{mg}$ steigern, und in 2 Monaten verträgt das Thier bereits $6 \mathrm{mg}$, also eine sonst 12 fach tödtliche Dosis.

2. Injectionen von Chlorkalklösung oder anderen, das Schlangengift abschwächenden Substanzen einige Zeit nach den Giftinoculationen. Hierdurch wird ein Thier nach 2 Wochen gregen die tödtliche Dosis von $0,5 \mathrm{mg}$ Schlangengift immun. Van darf jedoch das betreffende Mittel nicht zu früh nach der Giftinoculation einspritzen.

3. Man inoculirt ten Thieren alle 5 Tage ein Gemisch von $2 \mathrm{mg}$ Cobra-Gift mit einer Lösung von Chlorkalk oder Natriumhypochlorid in einer Concentration von $1: 60$, wovon man bei jeder folgenden Einspritzung eine immer geringere Menge zum Gifte hinzufügt. Nach Verlauf eines Monats ist eine Immunität gegen '2 $\mathrm{mg}$ reinen Giftes vorhanden, welche man noch dadurch steigern kann, dass man alle 8-10 Tage jedesmal um 1-2 mg steigende Giftinjectionen macht. Es soll sogar genügen, Kaninchen 4-5 Tage lang jedesmal 6-8 ccm einer Chlorkalklösung $(1: 60)$ subcutan zu injiciren, um sie gegen eine zweifach tödtliche Giftmenge zu immunisiren.

4. Injectionen von durch Erhitzen abgeschwächtem Schlangengifte. Wenn man Viperngift eine Viertelstunde $\operatorname{lang}$ bei 75" erhitzt, so tödtet es nicht mehr; erhitzt man es 15 -20 Minuten lang bei $100^{\circ}$, so bringt es überhaupt keine Vergiftungserscheinungen mehr hervor.

Fünf Minuten langes Erhitzen auf $80^{\circ}$ soll ebenfalls das Gift abschwächen, und zwar in der Weise, dass die Localwirkungen desselben ganz aufgehoben werden, während die Allgemeinwirkungen nur gemildert werden. Impft man nun ein derartig abgeschwächtes Gift Meerschweinchen ein, so sollen dieselben schon nach 2 Tagen gegen eine tödtliche Dosis des ursprünglichen Giftes immun sein.

5. Injection von Blut oder Blutserum von durch Schlangengift immunisirten Thieren. Dasselbe wirkt 
antitoxisch und vermag andere Thiere nicht nur gegen gleiches Schlangengift, sondern auch gegen andere Arten immun zu machen, so dass also z. B. das Serum von gegen Viperngift immunen Thieren auch gegen Cobra-Gift präventiv und therapeutisch angewandt werden kann.

Auch das Serum von mit Chlorkalk behandelten Thieren soll in derselben Weise antitoxisch wirkeu. Die mit antitoxischem Serum immunisirten Thiere behalten ihre Immunität ziemlich lange. Dieselbe tritt übrigens nicht sofort nach der Inoculation, sondern erst nach einiger Zeit (24 bis 48 Stunden) ein und wird nicht direct durch den Impfstoff hervorgebracht, sondern ist eine Folge der Reaction des Organismus, indem der Giftstoff im Blute angeblich die Bildung einer antitoxischen Substanz hervorruft, welche physiologisch die Wirkungen des Giftes neutralisirt und welche von einer chemischen Wirkung des Impfstoffes auf einen der Blutbestandtheile herzurühren scheint. Was die Menge des nöthigen Impfstoffes betrifft, so sollen $0,3 \mathrm{mg}$ Vaccine gegen die gleiche Menge Schlangengift schützen können.

Man vollzieht die Impfung mit Serum in der Weise, dass man $1-1^{1 / 2}$ Stunden nach der Giftinoculation und dem Auftreten der ersten Vergiftungserscheinungen $i-8$ ccm Serum intraperitoneal und subcutan injicirt. Selbst mit einem schwachen Impfserum kann man hierdurch nicht nur die Thiere heilen, sondern auch gegen weitere Giftinoculationen immun machen.

Die antitoxischen Eigenschaften des Serums verschwinden, wenn man letzteres auf $60-70^{\circ}$ erhitzt, indem durch die Hitze das Antitoxin alterirt wird.

Uebrigens kam man auch theilweise das Serum von Giftschlangen selhst zur Impfung benutzen. Wenn man z. B. eine nicht tödtliche Dosis von frischem Serum von Naja haje einem Thiere einimpft, so verträgt das letztere nach 4 Tagen eine tödtliche Dosis dieses Giftes.

Mit Cobra-Serum scheint sich jedoch eine ähnliche Immunität nicht erzielen $\mathrm{zu}$ lassen.

Dagegen scheint das Blut von Varanus Bengalensis, 
der gregen den Biss der Brillenschlange unemptindlich sein soll, bei Thieren die Wirkung des Schlangengiftes, wenn es zugleich mit diesem injicirt wird, abzuschwächen, d. h. die Thiere lebten längere Zeit als nach der Injection des Giftes allein ${ }^{1}$ ).

Neuerdings hat man auch die Entdeckung gemacht, dass sogar das Serum ron gegen Tetanus oder Hundswuth immun gemachten 'Thieren im Stande ist, andere Thiere gegen wachfolgende V'ergiftung durch Cobra-Gift zu schützen, und dass gegen Wuth geimpfte Kaninchen eine 4-5fach tödtliche Dosis von schlangengift ertragen können. Und was noch wunderbarer ist, das Serum von Kaninchen, welche gegen Abrin. den wirksamen Bestandtheil der Jequirity-Bohnen. immunisirt sind, macht andere Thiere resistenter gegen Schlangengift, und umgekehrt macht das Serum von gegen Schlangengift immunen Thieren andere resistenter gegen Abrin *).

Es wäre voreilig, wollte man, vorausgesetzt, dass diese Mittheilungen als sichere Thatsachen angesehen werden können. ron diesen bei Thieren günstigen Resultaten der Impfung mit Schlangengitt sofort auf eine gleich günstige Wirkung derselben bei Menschen schliessen. Indessen die Beobachtungen bei den wilden Völkerschaften und die wissenschaftlichen Untersuchungen der neuesten Zeit über die Schutzkraft der Impfung bei verschiedenen anderen Krankheiten, namentlich die jetzigen Erfolge der Serumtherapie bei der Diphtheritis, machen es doch sehr wahrscheinlich, dass es schliesslich gelingen wird. auch die Menschen nicht nur nach erfolgten Bissen von Giftschlangen sicher zu heilen, sondern sie auch gegen Schlingengift zu immunisiren, was für ,jene Länder, in denen die Giftschlangen die furchtbarste Plage bilden, selbstrerständlich von der allergrössten Bedeutung sein würde.

Solange dieses Ziel aber noch nicht erreicht ist, muss min sich eben dumit begnügen, abgesehen von der möglichst frihzeitigen Anwendung geeigneter Heilmittel, von denen

i) Kanthack, Journ. of Physiol. XIII. 3. 4. 1892. p. 272.

2) R.onx, Ann. de l'inst. Pasteur. 1894. Nr. 10. p. 722. 
die mechanischen, besonders Ligatur, Ausschneiden, Aussaugen und Aetzen der Wunde, vorläufig immer noch die sichersten sind, die Bisse so viel als möglich überhaupt zu verhindern. Dazu ist zunächst die grösste Vorsicht an Orten, wo sich Giftschlangen aufhalten, erforderlich, wie Tragen einer festen, für die Giftzähne undurchdringlichen Fussbekleidung u. dgl. Sodann müssen die Giftschlangen überall energisch verfolgt und getödtet werden, und womöglich von Staats wegen Prämien dafür ausgesetzt werden, wie es schon in manchen Lïndern, so in Britisch-Indien und auch bei uns, der Fall ist. Auch soll man alle solche Thiere, welche als Schlangenfeinde bekannt sind, wie Igel, Iltis, Wiesel, Dachs, Bussard, Storch, Eichelhäher, schonen. Auch die Schweine sollen die Schlangen durch Aufwühlen ihrer Höhlen vertreiben. Zum Fernhalten der Giftschlangen von den Wohnungen emptiehlt Fayrer, die Wände mit Carbolsäure oder mit Kohlentheer zu bestreichen, da die Schlangen den grïssten Widerwillen gegen den Phenolgeruch besitzen; auch durch Knoblauch sucht man in Indien, wie schon oben erwähnt, die Schlangen fernzuhalten.

Es empfiehlt sich auch in Ländern, welche an Giftschlangen reich sind, besondere Versuchsstationen für Schlangengift einzurichten. So existirt bereits in Calcutta neben einem Schlangenhause ein Laboratorium behufs genauer Untersuchungen über die pathologischen Folgen von Schlangenbissen. Es sollen in diesem Institute auch alle diejenigen Mittel auf ihre Wirksamkeit und Leistungsfähigkeit untersucht werden, welche man bisher gegen Schlangenbisse empfohlen hat.

Möge sich diese Einrichtung nicht nur für Ostindien. sondern für alle an der Giftschlangenplage leidenden Lünder als eine erfolg- und segensreiche erweisen. 


$$
{ }^{0} * v_{3}
$$






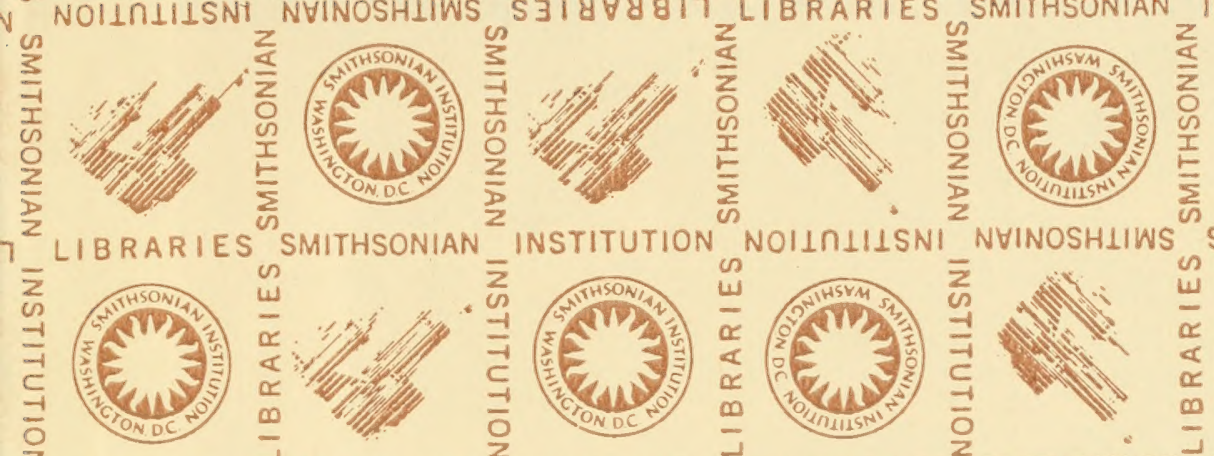

NOIINIIISNI NVINOSHIIWS
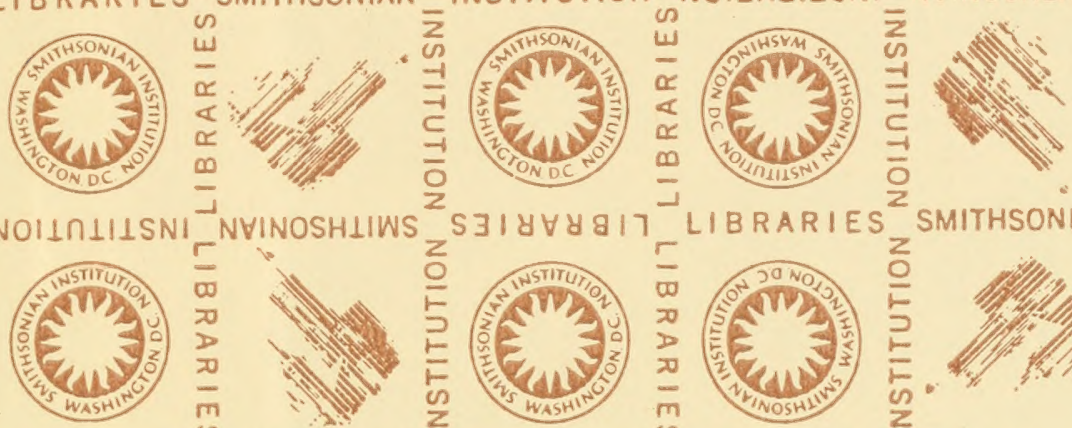

$n$
$\alpha$
$\alpha$
$\alpha$
$\alpha$

SMITHSONIAN

LIBRARIES

SMITHSONIAN
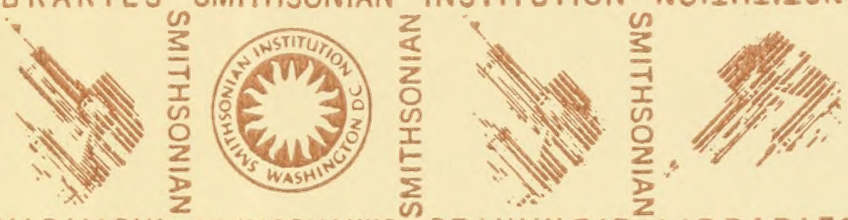

를
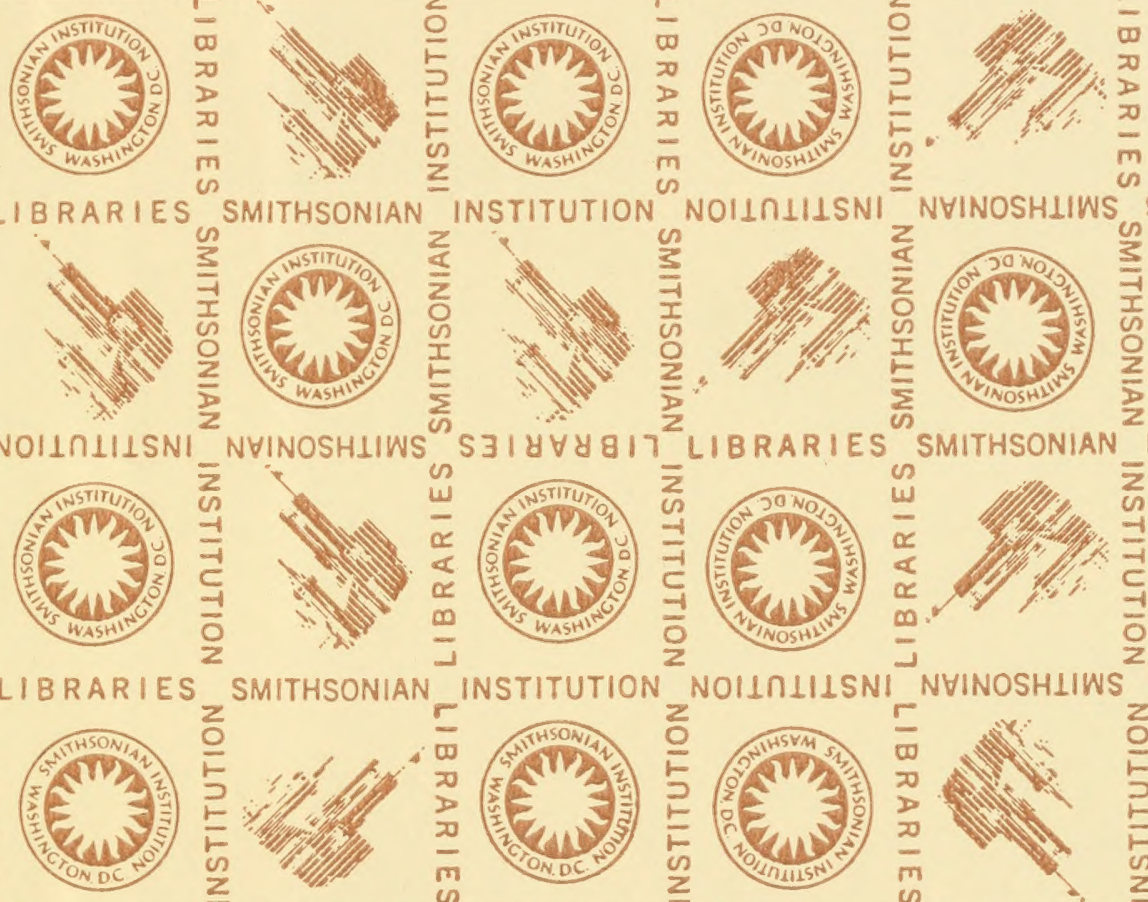

NVINOSHIIWS
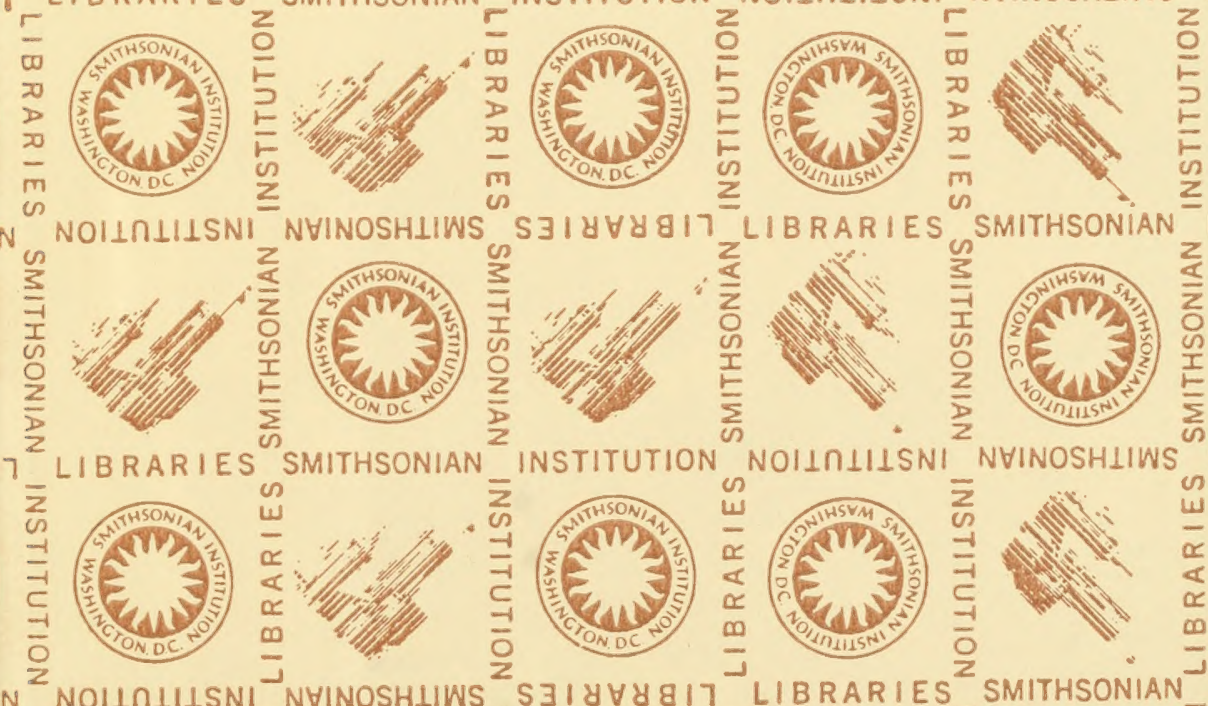

$z$
$\frac{1}{z}$
0
0
$I$
$\frac{I}{n}$

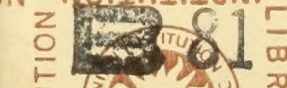

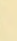
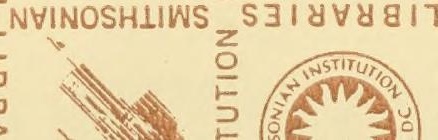

LIBRARIES

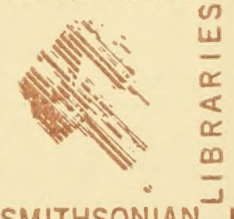


